WML01 2/13/2007 3:47 PM Page 27

I Wittgenstein 


\title{
1 A Recently Discovered Manuscript
}

\author{
Edited by Johannes Climacus
}

The document before you is by a member of a fanatical sect of heretical Ludwig scholars. Through a twist of fate it has fallen into my hands. I hesitate to make it public, since its circulation may do more harm than good. What speaks against publication is that it has the power to corrupt young minds. I do not take a light view of the dangers it poses in this regard. What speaks in favor of publication is the fact that these people must be stopped. Through their pamphlets and brochures they continue to attract more converts everyday. The importance of this document lies in the fact that it brings to light some of the more esoteric doctrines of the sect, revealing the vulnerable theological underbelly of their creed. It also speaks of quarrelling within the infidel camp. There are even suggestions that the author fears that he himself may be excommunicated by an up-and-coming generation of zealots. He pleads here for a mild interpretation of their creed. (Oblivious to the stench of his own blasphemies, he even imagines entering into dialogue with mainstream Ludwig scholars!) My main aim in making this text generally available is that more learned men than I may make a study of it. A sound theological thrashing of the author's own (according to him, mild!) version of the creed is devoutly to be wished. But my fondest hope is that, in the hands of one of our finer Ludwig scholars, it might become a weapon that can be turned against the infidel camp. I have a Trojan horse maneuver in mind here. A cunningly crafted pseudonymous publication, addressing some of the niceties of their more peculiar doctrines, under the pretence of attempting to heal the looming schism in their sect, ought to be able to bust it wide open.

One particularly confusing feature of the document is that the author occasionally adopts a heavily ironical tone, actually going so far as to refer to himself as an infidel, etc., though without apparently the least appreciation of the fact that the heavier he allows his irony to become, the closer he comes finally to speaking the truth. This makes for some confusing reading. The irony is apparently directed at reputable Ludwig scholars. Alas, the fellow has no sense of the poor impression all this must make on any person of sound theological principles.

I have lightly edited the document and corrected some of its grosser infelicities of grammar and spelling, but have resisted any temptation to improve on the author's barbaric mode of expressing himself. The one great editorial liberty I have taken is to insert a brief abstract of each section of the paper at its beginning, in which I briefly indicate the contents of each of the numbered subsections that follow. The merely curious or theologically squeamish might wish to peruse these first. These abstracts should be of assistance to those who prefer to read selectively in heretical tracts or have weak stomachs for blasphemy. I must confess that I have found it somewhat distasteful to allow my prose thus to mingle so closely with that of the infidel. I have placed my initials in square brackets after each abstract in order to indicate that the preceding words 
are mine, rather than his, though it is hard to imagine that anyone would ever confuse us. The titles of the sections (which immediately precede my abstracts) and the titles of the subsections (that follow my abstracts) are all his, not mine, and often show a great lack of taste. The quotation from Freud immediately below seems to have been chosen by the author himself to introduce the document. I have no idea what it is doing there. But I have allowed it to stand in case it has a significance that escapes me.

Now comes something strange. After the quotation from Freud, there is a second quotation, also apparently intended to introduce the manuscript. It is attributed to someone who has exactly the same name as I. (Incidentally, no works by this author seem to be listed in the catalogues of any of our libraries or for sale in any of our bookstores.) As you might imagine, I felt a small temptation simply to omit the quotation or at least just the name that follows it, especially since neither sheds any light on anything. But, as I have nothing to hide, I have let the passage stand. If all the rest is nonsense, shouldn't the epigraph be as well? Johannes Climacus, Assistant Professor, Department of Ludwig Studies, University of Skjolden 


\title{
Mild Mono-Wittgensteinianism
}

\author{
James Conant
}

We may now express the issue before us in the shortest possible way by means of the following formula: ... two moments in which a new religious order is founded, the first one overturned by the second and yet reemerging victorious, and two founders, who are both called by the same name, ... and whose personalities we have to separate from each other.

-Sigmund Freud ${ }^{1}$

From the fact that irony is present it does not follow that earnestness is excluded. Only an assistant professor would assume otherwise.

-Johannes Climacus ${ }^{2}$

\section{To Cora}

This essay represents an effort to advance the debate between those who advocate resolute readings of Wittgenstein and those who deplore them. It seeks to do so by, on the one hand, attempting to correct certain misunderstandings of such readings (explaining, in effect, why they amount to caricatures) while, on the other, seeking to discourage advocates of such readings from accepting the terms of the debate as defined by the critics (thereby, in effect, embracing the caricature and seeking to defend it). The twin qualifications ("mild" and "mono-") that figure in the title jointly seek to introduce a sort of equilibrium into our reading of Wittgenstein that has hitherto proven elusive to commentary on his work. The difficulty has two sides that must be balanced against each other, without permitting either to assume an undue share of the burden. The first half of the difficulty is to do full justice to the profound discontinuity in Wittgenstein's thinking without neglecting (as those whom I will call "standard readers" do) the extent to which it is folded within a fundamental continuity in his philosophy. The second half of the difficulty is to do full justice to the profound continuity in his thinking without minimizing (as those whom I call "severe mono-Wittgensteinians" do) the extent to which it is folded within a fundamental 
discontinuity in his philosophy. The aim of this paper will be twofold: (1) to argue that a full acknowledgment of the moment of continuity requires a reasonably heterodox degree of mono-Wittgensteinianism, and (2) that an equally full acknowledgment of the complementary moment of discontinuity requires that the degree of this heterodoxy remain reasonably mild.

\section{Infidel Wittgensteinianism}

[The infidel scholar begins by (1) confessing his membership in the heretical sect, (2) attempting in the most pathetic way to reunite himself with the Church, and (3) discovering that the reconciliation will not hold as long as he persists in his blasphemous practice of defacing copies of the authorized edition of The Life and Works of Saint Ludwig.-J. C.]

\section{The Heresy}

Cora Diamond and I, along with others, ${ }^{3}$ have sought to advance and defend an interpretative framework for understanding Wittgenstein's Tractatus that has come to be known as "the resolute reading of the Tractatus." ${ }^{4}$ In this essay, I want to isolate and consider one particular strand of criticism of this reading. The problem with this reading, it is sometimes alleged, ${ }^{5}$ is that it commits one to the view that there is only one Wittgenstein (whereas every educated person, of course, knows that there are two Wittgensteins). ${ }^{6}$ Thus it has come to pass (in the predominantly polytheistic world of contemporary Wittgenstein scholarship) that resolute readers of the Tractatus are taken to espouse the heresy of (what one might call) monoWittgensteinianism. One might lend an Islamic flavor to this credo by summing up its central tenet as follows: "There is no Wittgenstein but Wittgenstein, and his name is Wittgenstein!"

Now, whatever one's attitude toward the corresponding tenet of a genuinely monotheistic creed, one can be forgiven for thinking that this particular sentence (about the man named Wittgenstein) ought to be interpretable as saying something far too innocuous to occasion a scholarly jihad. What alternatives are there to affirming it? What is poly-Wittgensteinianism? Well, presumably, it is the view that there are at least two Wittgensteins: "Early" and "Later" being the names of the two most famous members of the family. Yet, when one is talking about people named Wittgenstein, no one believes Early and Later to bear the sort of relation to one another that William and Henry do (when talking about Jameses) let alone Irving and Isaiah (when talking about Berlins). So what does either side of the squabble (concerning how many Wittgensteins there are) believe that the other would want to deny? How 
ought one to go about adjudicating disputes between infidel mono-Wittgensteinians and orthodox poly-Wittgensteinians?

\section{Premature Ecumenicalism}

One might profess to find any dispute of this general form misguided on the ground that the following two sorts of claim regarding the work of a given philosopher are perfectly reconcilable:

(1) Every important line the philosopher in question ever wrote over the course of his lifetime bears the highly individual marks of his particular philosophical personality: his entire body of work is recognizably the product of a single author and thus marked by numerous points of continuity-in this sense his work forms a unity.

(2) The philosophical views of the individual in question and the manner in which they are expressed developed very substantially over the course of his lifetime: so substantially, indeed, that it behooves a commentator to distinguish between different significant periods in his thought—in this sense, his work does not form a unity.

(1) and (2) are perfectly compatible because there are two different understandings in play of the sense in which it can be said of a philosopher's work that it "forms a unity." Affirming that his work does so in the first sense does not preclude one from denying that it does so in the second. More to the point, if the dispute at issue concerns Wittgenstein's development in particular, one might well be inclined to affirm each of the following specifications of the foregoing pair:

$\left(1^{\prime}\right)$ All of the writings currently published under the name of Wittgenstein are the product of a single, highly distinctive philosophical mind, and recognizably so: there are countless discernible points of continuity in philosophical concern, sensibility, aim, style, topic, and mode of authorship across the full range of the corpus.

(2') The thought of this philosopher underwent substantial development across the years of his productivity-in particular, at least one such moment of substantial development can be traced to the period beginning sometime not too long after his return to active philosophical work in 1929; and one can quite properly speak of this moment as marking a significant break in his thought.

It should be equally clear that ( $\left.1^{\prime}\right)$ and ( $\left.2^{\prime}\right)$ express perfectly compatible thoughts. This opens up the heady prospect that one might go ecumenical and subscribe to both (the 
mono- and poly-) variants of Wittgensteinianism all at once. ${ }^{7}$ Or, if that seems too wishy-washy, perhaps go Trinitarian: there is a single being who exists as three indissoluble persons-Early, Later, and Wittgenstein.

\section{The Life and Works of Saint Ludwig}

But let us not be so hasty. When it comes to the very special case of Wittgenstein, many are apt to feel that a conjunction of commonsensical observations such as ( $\left.1^{\prime}\right)$ and $\left(2^{\prime}\right)$ above, if allowed to stand without further qualification, fails in an important respect to do full justice to what they take themselves to know about the intellectual trajectory of this singular figure in the history of philosophy. For the special character of Wittgenstein's achievement is generally thought to lie precisely in the following fact: Wittgenstein's thought did not merely develop, as another philosopher's might, rather he accomplished the feat of establishing two disjoint schools of philosophic thought in a single human lifetime. Here, for example, is how Wolfgang Stegmüller summarizes the feat in question: "Wittgenstein's position in the history of philosophy is ... remarkable: first of all, because he developed two distinct philosophies, of which the second cannot in any way be properly characterized as a continuation of the first." ${ }^{8}$ Others will want to insist that the relation between these phases in Wittgenstein's thought is not to be characterized merely as one of radical disjunction, but rather as one of radical contradiction, his later philosophy being devoted to nothing less than the complete overturning of his early philosophy. Here, for example, is how Anthony Quinton summarizes the point of significant intellectual contact between the early and the later philosophy: "Although Wittgenstein came to reject most of the particular doctrines of the Tractatus, the fact that he spent so much of his time in the Investigations in refuting them, shows that even if the answers in the earlier book were wrong the questions that they were given to were not."

Thus, on a streamlined and Promethean telling of it, a rough outline of the tale of Wittgenstein's intellectual trajectory goes like this: Wittgenstein's unique achievement lies in his having, at a remarkably young age, successfully formulated a conception of philosophy sufficiently compelling to transform the entire way in which philosophy was (and, to this very day, still is) conducted by some of its practitioners, and then, after the philosophical equivalent of a decade of wandering in the desert, having seen the light, and in a complete about-face, throughout his later years, tirelessly devoting himself to the task of converting (and, to this very day, from beyond the grave, still converting) practitioners of the subject to the task of undoing that very conception of philosophy. So when the charge is leveled at resolute readers by their critics that they hold the mistaken view that there is only one Wittgenstein (whereas every educated 
person knows that there are at least two), it is not some anodyne monoWittgensteinian creed that such readers are taken by their critics to espouse, but rather a genuinely heretical one-heretical precisely because it seeks to challenge even the basic outline of the foregoing canonical version of The Life and Works of Saint Ludwig and its account of wherein the uniqueness of his philosophical accomplishment and its pleasingness to all who behold it is supposed to lie.

\section{An Alleged Failure to Acknowledge Ludwig's Recantation}

[The infidel scholar here undertakes (1) to clarify the grave charge that has been entered against him and all members of his sect by leading authorities of the Church (and he finds a pretext for mentioning Saint Bertrand and Saint Rudolf), (2) to lament that the first phase of the dialogue between the infidels and the Church stalled, thereby causing what he seems to imagine is some great schism, (3) to initiate a second phase of dialogue, and (4) to comment on his fear that finer theological minds than his will be able to show that his doctrine entails an outright denial of the Miracle of the Recantation.-J. C.]

\section{The Charge}

This essay will not attempt anything like a nailing of The Ninety-Five Theses of Any Resolute Reading to the church door, let alone a summary of the ongoing dispute between resolute readers and their critics over how to read the works of Ludwig. ${ }^{10}$ I will say a few words about what makes a reading resolute in the next section of the paper. All that matters for this section is the charge against resolute readers already before us: namely, their willful interference in the telling of the canonical tale. The tale presupposes, among other things, that the fundamental aims of Wittgenstein's philosophy suffer little significant misunderstanding in the course of their reception by the unwashed masses, both among those who were converted to his early conception of philosophy and among those converted to his later conception. Whereas resolute readers are obliged to hold, first and foremost, that the aim of Wittgenstein's early philosophy has not been widely understood let alone received. This feature of what is under dispute in exchanges between resolute readers and their critics has remained (in so far as anything ever has in this debate) reasonably clear, accordingly figuring as the central bone of contention. ${ }^{11}$ What has not been equally clear (and what I hope to make clearer in what follows) is that it is equally open to resolute readers further to hold, secondly, that it is this very misunderstanding of the aim of Wittgenstein's early philosophy that has helped to bring about a correlative misunderstanding of the aim of his later philosophy. This has an immediate bearing on the original dispute for the following reason: many of their critics look to evidence in Wittgenstein's later 
writings to bolster their case against the approach that resolute readers take to the early work. This is fair play, of course, if the proper interpretation of the evidence and its bearing on the debate is reasonably clear. If, however, putative refutations of resolute readings proceed in part by looking to passages in Wittgenstein's later writings (that are adduced as evidence against those readings), with the critics in question (in their understanding of the bearing of the relevant passages) simply presupposing their preferred understanding of the later philosophy (reading it in ways that it is open to resolute interpreters to contend rests upon a misunderstanding related to the original one under contention), then such a procedure of refutation runs a serious risk of begging the original question. ${ }^{12}$

It is true that if any version of a resolute approach to reading Wittgenstein were allowed to form a standing part of an introductory philosophical curriculum, then it would interfere with the narration of various episodes in other canonical tales (e.g., from the life of Saint Bertrand or that of Saint Rudolf) as these are typically recounted in the currently popular potted history of the development of early analytic philosophy. But the claim that some piece of potted history might be false is itself hardly a ground for philosophical scandal. Interesting work in the history of philosophy often takes the form of unsettling potted narratives. The charge leveled against resolute readers at issue here (to which this essay seeks to respond) only partly rests on this (comparatively shallow) sort of ground of dissatisfaction. Formulated in the broadest of terms, the charge at issue is therefore most helpfully understood as coming in two separate parts: (i) resolute readings of the Tractatus leave us with an account of Wittgenstein's early work that is heretical, in that it flies in the face of what we all already (supposedly) know to be the case about at least the basic outline of Wittgenstein' philosophical development, and moreover (ii) such readers of Wittgenstein's early work leave themselves in the position of having no satisfactory story of their own to tell about the shape of Wittgenstein's overall philosophical development.

It is worth separating out the charges in this way for two reasons. First, resolute readers are more than happy to plead guilty to the first of these charges (the charge of heresy); it is the second of these charges (the charge of being unable to square the Tractatus with the Investigations) that they ought to deny (and it is to one aspect of this charge that I will primarily seek to respond here). Second, the sense (on the part of at least some of their critics) of there being something scandalously inadequate about the approach to the interpretation of Wittgenstein's work that they take is not merely a function of their refusal to toe a party line. It can be traced at least in part to a prevalent sense that the reading of the Tractatus with which they thus saddle themselves is such as to leave no room for any plausible alternative story about 
Wittgenstein's development-that is, a story in which Wittgenstein's own vehement later criticisms of his earlier thought can be accorded an appropriate gravity.

\section{The First Phase}

Resolute readers tend, at this point, not to be able to resist going on the offensive, urging that any reader of Wittgenstein ought to be uncomfortable with the following sort of account of the relation between Wittgenstein's early and later thought (to which the quotation from Quinton above gives characteristic expression):

The Tractatus and the Investigations are both trying to answer the same philosophical questions, but in each case in which early Wittgenstein aimed to show that the answer to a given philosophical question was $p$, later Wittgenstein aims to refute his earlier self and show instead that the answer to the question is really not $p$.

Let's call this "the doctrinal schema." It is not that resolute and standard readers disagree about which doctrines are to be plugged in for $p$ above (in a proper reconstruction of Wittgenstein's own understanding of the character of his philosophical development). It is rather that resolute readers hold that any schema of this form must yield a distorted account of Wittgenstein's philosophical aims early and late. ${ }^{13}$ There are in fact many reasons to be uncomfortable with an account of this form, but perhaps the most textually ready-to-hand one, they will urge, lies in the various characterizations that Wittgenstein, early and late, supplies of his own philosophical procedures. To cite just one instance, already in the Tractatus, Wittgenstein announces his interest in pursuing an approach to philosophical questions in which the answers to the questions, we are told, are to be seen in the vanishing of the questions themselves. ${ }^{14}$ And, in the Philosophical Investigations, Wittgenstein says things that are not dissimilar. ${ }^{15}$ So resolute readers will want to ask: if the Tractatus and the Investigations both aspire to bring about a situation in which many of the same philosophical questions are caused to vanish, then in what sense can it be right to say (as not only Quinton does, but many others do): "Although Wittgenstein came to reject most of the particular doctrines of the Tractatus, the fact that he spent so much of his time in the Investigations in refuting them, shows that even if the answers . . were wrong the questions... were not." One might have thought that, whatever the differences between Early and Later, there is at least this much agreement between them: it is the questions themselves that stand under indictment (and not merely any particular set of answers that we are inclined to give to them). If this is right, then the doctrinal schema would appear to be poorly suited to its purpose. 
The critics of resolute readings tend to respond at this point by saying, in effect: ah, yes, but we must distinguish between (Early's conception of) "vanishing" (which is best placed in scare quotes) and (Later's conception of) vanishing. Early only sought to make the questions "vanish" in the limited sense that he wished to show that there could be no stable linguistic formulations of the questions to which we seek answers in philosophy. The really important philosophical questions (about, say, the nature of, and relation between, language, thought, and reality) do not stand under indictment here, but merely the possibility of their successful formulation in language. To say that Early "sought to make the questions vanish" is therefore not to claim that he did not supply answers to them. On the contrary, it is only to claim that he sought to show that the particular answers he favored were (like the questions themselves) such as to be incapable of satisfactory expression in linguistic form, but were, for all that, qua answers to those questions, quite correct. Whereas, so this response continues, Later was concerned to show that those very same answers (that Early had sought to impart and defend) had to be made really to vanish (now in a much less forgiving sense of the term) because he saw that they were (even qua unsayable answers to the questions) not in the least correct. ${ }^{16}$

\section{The Second Phase}

In previous exchanges between resolute readers and their critics, the debate has tended to get hung up at just this point-that is, over questions about what ought to count as a satisfactory reading of the overall text of the Tractatus, taken on its own termswith resolute readers, for example, challenging the coherence of the aforementioned distinction between "vanishing" and vanishing, as well as the exegetical adequacy of ascribing the former of these two varieties of "vanishing" to the Tractatus. ${ }^{17}$ I propose in this essay, to the extent that this is possible, simply to leap over this first stage in the ongoing debate (prior, in the minds of many, no doubt, to any satisfactory clarification of its terms). That is, I propose simply to postpone for the time being any further discussion of the many criticisms to which a resolute approach to the Tractatus considered strictly as a reading of the text might appear to be vulnerable, in order to give some indication of what a further possible stage in the dispute between resolute readers and their critics might look like (if it ever were to be reached by less unnatural means) - a stage at which attention could now shift, without prejudging the outcome, to the question of how best to conceive the relation between Wittgenstein's earlier and later thought.

The leap I hope to perform in this essay is, however, not one straight into the midst of this further stage of the dispute, but rather only up to its threshold. For, already at 
this point, the dispute is faced with a source of unproductive gridlock. A central aim of this essay is the limited one of attempting to remove this initial obstacle to this second stage of the dispute. This, in turn, requires, first of all, that we gain a better purchase on the aforementioned reason why it has seemed so evident to some scholars that there is something scandalously inadequate about the sort of approach that resolute readers take to the interpretation of Wittgenstein's work. Why is it that such an approach seems "to leave no room" for a story about Wittgenstein's development that accords his later criticisms of his earlier thought a sufficient weight? In order to pursue this question, we must clarify how we are to understand the second half of the charge stated above.

In the above formulation, it is left unspecified which of the following two possible versions of the charge is at issue: Is it that such heretical readers of Wittgenstein's early work happen to leave themselves in the position of being unable to tell a satisfactory alternative story of their own (given, that is, the specific character of the textual materials at their disposal in Wittgenstein's later corpus)? Or is it that the very nature of their reading of Wittgenstein's work is such as necessarily to leave them in the position of being unable to tell any minimally coherent alternative story (regardless of the specific features of the materials to be found in Wittgenstein's later corpus beyond the single general feature that these materials do contain criticism of his early work)? My aim in this essay is to dispose of this second version of the charge (thus I hope paving the way for more fruitful discussion of the first on other occasions).

\section{The Miracle of the Recantation}

One way of getting a better handle on this aspect of what is thought to be scandalous about resolute readings is to look at how putative refutations of them formulate the second feature of the charge. Here is how one commentator, Ian Proops, describes the feature of resolute readings that makes them immediately vulnerable to the criticism of espousing an objectionable form of mono-Wittgensteinianism:

[Those who favor the New Reading] tend to be skeptical of the traditional or 'standard' view that the later Wittgenstein came to regard a number of central Tractarian doctrines as seriously mistaken... They question this view because they have to. If the Tractatus contains no substantive philosophical doctrines, there can be nothing of substance for Wittgenstein to have later repudiated. ... If the New Reading is correct, there can be no room for an interpretation that involves attributing any substantive philosophical position to the Tractatus. ${ }^{18}$

Notice that the charge here is not that New Readers must tell a rather implausible tale about the reasons why Ludwig recanted those of his early views that he came to see 
were mistaken. The charge is that on the New telling there was nothing in his early work for Ludwig to recant. The startling accusation leveled at New Readers here is that the very nature of their creed debars them from so much as being able to acknowledge the established historical fact of Ludwig's Recantation! If this is right, then it immediately suggests a delightfully straightforward strategy for demonstrating to them, once and for all, the error of their ways-a strategy that permits one to sidestep all of the finer points of Tractarian Hermeneutics. It goes as follows: simply seek out those passages in Ludwig's later work where he evidently is concerned to recant something in his early work. Getting straight exactly which detail of the early work each such passage professes to recant, and exactly why, might be devilishly difficult (partly because it requires that we understand the early work). But the beauty of the situation is that complete clarity on such niceties is not required. If it is evident from the general tone of each such passage that it is written in a spirit of recantation, then this is all that is really needed. And it is undeniable that passages characterized by such a tone are legion in the later corpus. So even if the search for a smoking gun inside the text of the Tractatus proves inconclusive, the mass of circumstantial evidence (drawn from post-Tractarian writings) against the New Readers becomes overwhelming. If they have to hold that Ludwig never changed his mind about anything he believed when he wrote the Tractatus, then the sheer quantity of such passages constitutes telling external evidence that their reading cannot be right. (In the context of this dispute, when people speak of "internal evidence," they mean considerations that bear on a reading of the work that can be gathered from a careful reading of the text of the Tractatus itself, and by "external evidence," considerations that bear on it but are drawn from sources outside that text. $)^{19}$ Instances of such external evidence are easy enough to find, if one operates with a sufficiently permissive conception of how to identify them. You just look for places in the later writings where Ludwig says things such as "I used to think ...," "contrary to my earlier view ...," "whereas the author of the Tractatus Logico-Philosophicus held...," and so on. The evidential value of each such exhibit lies in the fact that it shows Ludwig to have later been concerned to put forward criticisms of his earlier self; and this shows that those who favor the New Reading must be mistaken. ${ }^{20}$

Does the bare existence of such putative "evidence" drawn from the later work suffice to show that the resolute approach to reading the Tractatus must be misguided? Let's call this "the basic initial question." A negative answer to this question ought in itself to be perfectly neutral with respect to assessing the further merits of any particular approach to reading the Tractatus. Thus, for example, a critic of the resolute reading might hold that a resolute approach is mistaken and that this can be seen in part from 
a careful examination of the specific sorts of critical remarks about his early work that Wittgenstein later makes-remarks which, if they reflect a proper understanding on later Wittgenstein's part of his early work, should be taken to cast serious doubt on the viability of a resolute approach to understanding the early work. One could hold this, even while agreeing with resolute readers that any examination of such remarks, however carefully conducted, ought never to serve as a substitute for having an internally motivated, reasonably philosophically coherent, textually grounded account of what the author of the Tractatus himself thought he was up to. The interest of such remarks in this context is not that they somehow spare us the labor of having to arrive at such a reading of the early work, but rather that they can furnish us with helpful guidance in trying to arrive at one. Conversely, resolute readers need not deny that such critical remarks in the later corpus can, indeed, serve as a useful additional source of evidence for figuring out what Wittgenstein, when writing the Tractatus, thought he was up to in philosophy. The question for them ought, at this stage of the debate, to be the following: Can such remarks figure in a coherent narrative of Wittgenstein's development and yet be read as criticisms of the Tractatus on a resolute understanding of its philosophical aim and method? So there may be plenty of room for a dispute between resolute readers and their critics, even if all parties to the dispute answer the basic initial question in the negative. The discussion that would then ensue might be a long and arduous one, but possibly also quite worthwhile. To adjudicate what would here be under contention between resolute readers and their critics would now require a painstaking process of sifting and weighing the evidence, closely examining each of the many rather different things that Wittgenstein says in his later work about his earlier work and assessing in each case its bearing on particular points at issue in the dispute.

This essay will not be a contribution to that dispute, but rather to addressing the primary obstacle that stands in its way, as long as critics of resolute readings hold that a mere framing of the basic initial question (supplemented, of course, with textual exhibits that indicate that later Wittgenstein was concerned to criticize something in the Tractatus), in effect, clinches the debate. This line of criticism can only have the sort of immediate bearing on the dispute that these critics imagine it does if resolute readers are obliged to hold, not only that the author of the early work aimed to prosecute a program of philosophical clarification that rested on no substantive philosophical doctrines, but also that he succeeded in that aim. ${ }^{21} \mathrm{~A}$ commitment to the first of these claims evidently does not entail a commitment to the second. Does a commitment to resolution, nonetheless, somehow entail a commitment to all-out monoWittgensteinianism? 


\section{What Makes a Reading Resolute?}

[Some of the most baffling beliefs of the infidels are to be explained here, such as (1) what they take Ludwig's original aim to have been in writing The Old Testament and why they think it ends in The Vision of the Ladder, (2) how they have the audacity flatly to deny that most sacred tenet of the early Ludwigian creed, namely, The Dogma of the Paradox, and why they think The Paradox is not even required for an understanding of The Vision, and (3) finally, how on their version of The Vision the ladder appears to have lots of little rungs that can be seen only in the darkness of night and vanish in broad daylight.—J. C.]

\section{The Avowed Aim}

The first phase of the dispute between resolute readers and their critics has tended to center on how to understand the following climactic ${ }^{22}$ moment in the Tractatus:

My propositions serve as elucidations in the following way: anyone who understands me eventually recognizes them as nonsensical, when he has used them-as steps-to climb out through them, on them, over them. (He must, so to speak, throw away the ladder after he has climbed up it.) $)^{23}$

The next two sections of this essay provide a brief account of what will be meant here by "a resolute reading of the Tractatus," ${ }^{24}$ first by saying a bit in this section about what is involved in climbing up and throwing away this ladder on any resolute interpretation of it, and secondly, by saying a bit in the next section about which sentences of the work might make up the rungs of the ladder, thereby indicating ways in which the genus of resolute readings admits of a variety of species. Beyond this, I will have nothing further to say in these pages about the internal commitments of such a reading. In particular, this essay will refrain from rehearsing any of the (exegetically or philosophically motivated) "internal" reasons why an open-minded reader might want to look with sympathy on such an interpretative approach to the Tractatus. Its burden will rather be to clarify the "external" commitments of such a reading insofar as they pertain to an understanding of the relation between Wittgenstein's early and later work-and thereby to explore the question whether such an approach to reading Wittgenstein commits one to an intrinsically objectionable form of monoWittgensteinianism.

In section 6.54 of the Tractatus, the author of the work does not ask us to understand his sentences, but rather to understand him. Resolute readers take this particular nicety of formulation to be tied to the way in which we are supposed to come to see, regarding those sentences of the work that are at issue here, that there is nothing that could count as understanding them. The primary characteristic that marks out a reading of the Tractatus as "resolute," in the sense of the term at issue here, is its rejection of the 
following idea: what the author of that work, in section 6.54 , aims to call upon his reader to do (when he says that she will understand him when she reaches the point where she is able to recognize his sentences as nonsensical) is first to grasp, and then to apply to the sentences of the work, a theory that has been advanced in the body of the work-a theory that specifies the conditions under which sentences make sense and the conditions under which they do not. ${ }^{25}$ In order to be able to give content to the idea that we are able to grasp the commitments of such a theory, a commentator must hold that there is a fairly substantial sense in which we can come to "understand" the sentences that "explain" the theory, despite the fact that we are eventually called upon to recognize these very same sentences as nonsense. Resolute readers hold that to read the Tractatus in this way is seriously to underestimate what is involved in the request that we come to recognize these sentences as nonsense.

On standard readings of the book, the point of a significant number of the sentences of the work is to achieve the formulation of an adequate set of theoretical criteria of meaningfulness. These criteria when applied to the very sentences that adumbrate them yield the verdict that they do not meet their own criteria and thus are to be condemned as nonsensical. Resolute readers are unhappy with any such reading for a variety of reasons. For the present purpose, however, it will suffice to note that they are committed to rejecting any such reading because they are committed to rejecting the idea that the author of the work aims to put forward substantive theories or doctrines. Wittgenstein tells us that the kind of philosophy he seeks to practice in this work consists not in putting forward a theory, but rather in the exercise of a certain sort of activity—one of elucidation. ${ }^{26}$ The core commitment of a resolute reading for the purpose of this essay lies in its insistence that a proper understanding of the aim of the Tractatus depends upon taking Wittgenstein at his word here. A close reading of the text guided by this commitment leads us to the following gloss on his early understanding of the aim of this activity:

Early Wittgenstein aimed to practice a conception of philosophy in which philosophy is not a matter of putting forward theses, doctrines, or theories, but consists rather in an activity of elucidation; and any apparent theses that are put forward in the course of that activity, if it succeeds in its aim, are to be revealed as either (1) initially philosophically attractive yet in the end only apparently meaningful (Unsinn), or (2) either genuinely meaningful (sinnvoll) or merely tautologous (sinnlos) but only once clarified and hence drained of their initial philosophical eros. ${ }^{27}$

Let's call this "the avowed aim." If one adopts it as a point of departure for reading the text and allows oneself "strictly to think it through," ${ }^{28}$ resolute readers take a proper understanding of the avowed aim to have far-reaching exegetical consequences. It is perhaps not an exaggeration to say that, once this business of strictly thinking it 
through gets underway, many of the further commitments of resolute readers can be seen to fall into place as corollaries that follow from it. I will confine myself here simply to mentioning three such corollaries.

\section{Three Corollaries}

The first pertinent corollary (of a resolute rejection of an intended commitment on the part of the author of the work to any theory or doctrine) is the rejection of any intended commitment to an ineffable theory or doctrine. This means that resolute readers are bound to reject the widely held view that the relevant "propositions" of the work (namely, those concerning which Wittgenstein said, at $\$ 6.54$, that they are to be recognized as "nonsensical") are to be "understood" as conveying ineffable insights that the reader is to "grasp" even though the author cannot "express" them. On standard readings of the work, the alleged insights here in question are held to be individuated through an identification of substantive constraints on sense adumbrated through the aforementioned criteria on meaningfulness set forth in the body of the work. It is through the "violation" of these constraints that the sentences in question are revealed as simultaneously meaningless yet able to convey something determinate. The form of their meaninglessness is supposed to highlight, in each case, a particular feature of the general conditions on sense specified by the theory in question. This requires that the meaninglessness of these sentences has, in each case, a logically distinct and specifiable character. It becomes, on standard readings, a central burden of the theory (supposedly adumbrated in the book) to give content to this idea of logically determinate forms of nonsense-where each of these forms of nonsense is alleged to acquire the potential for communication that it specifically possesses in virtue of its violation of a distinct requirement on sense laid down by the theory. This commits standard readers to the idea that the sort of nonsense that is at issue here must come in a variety of logically distinct kinds.

This brings us to the second pertinent corollary: the rejection of the idea that the Tractatus holds that there are logically distinct kinds of nonsense. This is sometimes put by saying that the Tractatus aims to show that there is no such thing as substantial nonsense. From the perspective of a resolute reader, it makes little difference whether the candidate criteria for lending substance to nonsense involve considerations of verifiability, bipolarity, logical well-formedness, or some other putative respect in which a "proposition" is held to be intrinsically flawed because of its own internal logical or conceptual structure. Part of what the Tractatus seeks to show, according to resolute readers, is that all such "criteria of meaningfulness" cannot do the sort of work to which we want to put them in our philosophical theorizing. Any reading of 
section 6.54 that takes the recognition on the part of a reader there called for to require a substantive employment of such criteria qualifies as an instance of an irresolute reading, as long as it is committed to ascribing to the Tractatus a theory that its author must endorse and rely upon (if he is to be able to prosecute his program of philosophical critique) and yet which he must also regard as nonsense (if he thinks through the commitments of his own theory). ${ }^{29}$

At a minimum, what a resolute reading seeks to avoid here is the mess that commentators get into when they refuse to (allow that they are, at the end of the day, supposed to) throw away the following paradoxical idea:

The author of the Tractatus wants its reader to reject the sentences of the book as nonsense on principled grounds; yet, in the very moment of rejecting them, the reader is to continue to retain a grip on these grounds by continuing to identify, grasp, and believe that which these sentences would say, if they had a sense..$^{30}$

Let's call this "the paradox." 31 To be resolute in one's approach to the Tractatus involves taking this paradoxical idea itself to form a part of the ladder that we, as readers, are meant to climb up and throw away (rather than taking it to be an account of what it is to throw away the ladder). Thus, it involves taking the sort of recognition that readers of the work are called upon to attain in section 6.54 to require a recognition that the intermediate stages which we, as readers, seem to occupy (when we take ourselves to be able to identify, grasp, and believe what these sentences intend to convey) are aspects of the illusion that the work as a whole seeks to explode-that they are themselves rungs on the ladder that we are asked to climb up and throw away.

The third corollary has to do with how one ought to conceive the details of the Tractarian procedure of elucidation-and, in particular, the role of the many notational devices (the Sheffer stroke, the truth tables, the special bracket notation for quantification, etc.) that are introduced in the course of the book. It is evident that logical notation is supposed to play some sort of important role in a reader's ascent up the ladder. A standard reader will assume that the notation at issue here is one that is to be constructed so as to reflect the requirements of the theory that are laid down in the book: only those sentences the theory deems permissible will be constructible in the notation; and those sentences the theory deems nonsensical will involve illegitimate constructions forbidden by the syntactical rules governing the employment of the notation. It should by now be evident that it is not open to a resolute reader to construe the role of logical notation in Tractarian philosophical clarification in anything like this way. According to a resolute reader, the forms of logical notation employed by the author of the Tractatus (in order to make certain philosophical confusions manifest) must be elucidatory instruments whose employment is not itself 
supposed to require commitment (on the part of those engaged in an elucidation) to any particular philosophical theses.

We are familiar in ordinary critical discussion with procedures in which confusion in thought can be brought to a person's attention through a procedure of reformulation-in effect, through substituting one expression for another. This is most commonly accomplished by substituting one expression in the speaker's native language for another. But if the speaker is familiar with a foreign language, then that familiarity can be exploited to bring further elucidatory resources to bear on the situation. Thus, an equivocation involving "or" in ordinary English can be brought to a speaker's notice, if he speaks Latin, by asking him whether he wants to translate his English sentence into Latin using "aut" or "vel." No "theory of Latin" is required in order for the speaker to take advantage of this elucidatory tool. All that is required is knowledge of how properly to translate English sentences into Latin ones. By being forced to reflect upon what is involved in the task of having to choose one of these Latin expressions over the other, the speaker can be made to realize that he has been hovering between alternative possibilities for meaning his words without determinately settling on either one. ${ }^{32}$ According to resolute readers, this is what philosophical nonsense is for the author of the Tractatus: an unwitting wavering in our relation to our words-failing to make genuine determinations of meaning, while believing that we have done so. ${ }^{33}$ And the Tractatus's understanding of the character of nonsense, according to resolute readers, is internally related to its understanding of the proper role of logical notation in philosophical clarification.

If our English speaker above did not know Latin, but instead had been taught an appropriately designed logical notation (in which each of these two different possible translations of the English sign "or" corresponds to a different symbol in the notation), then exactly the same clarification could be effected using this notation. No theory of the notation is supposed to be here required, merely a mastery of its proper use. What is needed here-to paraphrase Tractatus, §4.112—is not a commitment to some doctrine, but rather a practical understanding of how to engage in a certain sort of activity. The forms of notation to which the Tractatus introduces us, of course, involve degrees and dimensions of designed regimentation (in our use of distinct signs to express logically distinct modes of symbolizing) well beyond a simple distinction in the use of signs merely to mark two different ways of using a single particle of speech such as "or." In principle, however, if our aim is restricted to the Tractarian clarification of thought, then the point of the exercise of mastering and applying such notation and the justification of the procedures involved need not differ in any essential way from those involved in the case of asking someone to translate "or" as either 
"vel" or "aut." The difference here (in the character of the exercise and the procedures it involves) is one of degree not of kind. The forms of notation introduced by the Tractatus therefore are not conceived by its author as requiring independent theoretical justification; and, if they did, this would defeat their purpose. They are put forward as proposals. If we try this notation, we will see that it allows us to become clear (when there is something we want to say) about what we want to say; and (when there is not) it allows us to become clear about the character of our failure in our having unwittingly failed to say anything. With respect to understanding his purpose in introducing us to these instruments of logical notation, we may be said to understand the author of the Tractatus each time we recognize how these alternative forms of expression (which the notation makes available) enable the recognition of nonsense. ${ }^{34}$ It is in this way that the notation is meant to serve as a device that facilitates a reader's ascent up the rungs of the ladder.

\section{Rumors of a List}

Beginning in the next section, I will attempt to furnish a provisional specification of some of these rungs. The extent to which one regards an exercise along these lines as a fairly straightforward matter (rather than one requiring considerable delicacy) will depend largely upon how closely one thinks the body of sentences that make up the rungs of the ladder coincides with the body of sentences that make up the text of the Tractatus. To see why an issue of some complexity can open up here, two things need to come into focus. First, one needs to see that there is nothing in the characterization of a resolute reading furnished above that requires resolute readers to agree with one another on this issue. Second, one needs to notice that, in section 6.54 of the Tractatus, the author of the work does not ask the reader to recognize all of the sentences of the work as nonsense. Rather the reader is told that those of the sentences in the work that are to serve as elucidations are able to serve their purpose only through the reader's eventually (through gradually working her way through the book) coming to recognize them as nonsensical. ${ }^{35}$ This leaves it open for a resolute reader to claim that not every sentence in the book forms a part of a stretch of elucidatory discourse. Only those sentences that are thus to be surmounted (or defeated) ${ }^{36}$ form rungs of the ladder that is to be thrown away. Which sentences are these? ${ }^{37}$ I will attempt to address this question in the next section of the paper, by trying to specify some of the rungs in the form of a list.

Two things should be true of each of the numbered propositions that figure on such a list: first, it should be a sentence that can be associated with a philosophical thesis that readers of the Tractatus might be inclined to ascribe to the work, and, second, it 
should be a sentence that resolute readers take to be an example of Tractarian elucidatory nonsense. If a given standard reader compiles a set of sentences of the first sort and a given resolute reader compiles a set of sentences of the second sort, then the intersection of those two sets will constitute the list of the sentences about whose role within the dialectical strategy of the Tractatus they disagree most. ${ }^{38}$ If they can come to agreement about the sentences which belong on such a list (i.e., on which sentences form the intersection of their two lists), then they will be in position to specify with a useful degree of further precision how the terms "standard reading" and "resolute reading" are to be understood at the outset of their dispute. Armed with such a list, they can say that what makes something "a standard reading" of the work (for the purpose of their dispute) is its ascription of these theses to the work (as integral elements of the philosophical doctrine that its author seeks to impart and defend), so that in order to understand the work we must understand them. What makes something "a resolute reading" (for the purpose of their dispute) is its adherence to the claim that as long as we continue to ascribe to the author (as doctrines that he seeks to uphold) what these sentences (seem to) say, then we have yet to complete the task of reading that he has set us, and as long as we fail to realize this we fail to understand him.

According to resolute readers, to take an item on the list to be a rung of the ladder is to take it to belong to this aspect of the task that the author of the work has set us. The reader reaches a moment in which she understands the author (and what he is doing with one of his sentences) each time she moves from a state of appearing to herself to be able to understand one of these sentences to a state in which it becomes evident to her that her earlier "state of understanding" was only apparent. This point is reached not through the reader's coming to be convinced by an argument that forces her to believe that such-and-such is the case, say, by convincing her that the sentence fails to meet certain necessary conditions on sense. (Why should she ever believe the conclusion of such an argument, if she takes herself still to be able to understand the sentence in question? As long as she is able to do this, doesn't she have good reason to question the premises of the argument?) Rather, the point is reached, in each case, by her experience of the sentence (and the sort of understanding it can seem to support) undergoing a transformation. Each such moment of "understanding the author" involves, in this sense, a change in the reader. Her sense of the world as a whole, at each such moment, waxes or wanes, not by her coming to see that $p$ (for some effable or ineffable, propositional or quasi-propositional $p$ ), but rather by her coming to see that there is nothing of the form "that " (of the sort she originally imagined) to believe. So a point of understanding the author is reached when she arrives at a moment in her relation to a given form of words when she is no longer able to 
sustain her original experience of "understanding the sentence." The task of thus overcoming each particular appearance of sense (that each such rung on the ladder at first engenders in a reader) is an arduous one. The form of understanding that is at issue here for resolute readers can be attained only piecemeal, ${ }^{39}$ sentence by sentence. ${ }^{40}$ (That is to say, every reader must begin life qua reader of the Tractatus as a standard reader and climb her way up from there to a different way of coming to understand her task as a reader. To attempt to skip this stage in one's evolution qua reader of the Tractatus is to undertake to miss the experience of the work altogether. ${ }^{41}$ Thus, by the lights of resolute readers, standard readers participate in an essential aspect of the experience that the Tractatus seeks to engender in its reader: namely, the production and exhibition of illusory understanding. But, to put the point in psychoanalytic terms, they resist the telos of the exercise by falling in love with their symptom.) Since they hold that the Tractatus has no general story about what makes something nonsense, resolute readers are obliged to hold that these moments of recognition that a reader is called upon (in section 6.54) to attain must come one step at a time. This is contrary to the spirit of most standard readings, according to which there can be a possible moment in a reader's assimilation of the doctrines of the book when the theory (once it has been fully digested by the reader) can be brought to bear wholesale on all of the (putatively nonsensical) propositions that make up the work. ${ }^{42}$ According to such a reading of the Tractatus (and, starting with the Vienna Circle, many a philosophical project that takes itself to be influenced by the Tractatus), once we have equipped ourselves with the right theory of language, we can determine where we have gone right and where we have gone wrong in philosophy simply by applying the theory to each of the things we are drawn to say when speaking philosophically. Here we encounter the first respect in which resolute readers are committed to a significantly heterodox degree of mono-Wittgensteinianism: according to them, Wittgenstein, early and late, rejected such a wholesale conception of how progress in philosophy is to be achieved-philosophical clarity must be won piecemeal, one step at a time.

\section{Diagramming the Ladder}

[This section is the longest in the paper, quite muddled, and very hard to summarize. Our author takes to making and seeing lists. (1) An actual list is presented in which each item on it is meant to correspond to one of the rungs as seen by Ludwig himself in The Vision of the Ladder. (2) Not content with a merely terrestrial list, the infidel here revives an apocryphal account of a second vision apparently had by some now-forgotten saint. (Some scholars, I believe, refer to this as The Vision of the First List.) This second vision is of a divine list, and our author claims that what is there seen can illuminate the nature of the ladder that Ludwig 
saw (upon which the faithful are to ascend to Heaven). Things then become very abstruse as new vistas in infidel theology are opened up with respect to a variety of topics. The first of these pertains to (3) the shape of the list that appears to the nameless saint that somehow is supposed to correspond to the shape of the ladder that appears to Ludwig in his Vision. (Mysterious mention is made in this connection of "evil sentences" - possibly a reference to Satanism?) He then (4) offers an explanation of the way that the items on the list seen by the nameless saint are supposed to correspond to the rungs on Ludwig's ladder. (Equally mysterious mention is made here of accepting a proposition and its negation-possibly a reference to Buddhism?) Perhaps dissatisfied with his previous answers, he then begins to go around in circles, and (5) appears to answer for a second time the very same questions previously answered in (3) and (4). Finally, we come to (6) issues in infidel dogmatics concerning the limits of the extent to which infidels are obliged to agree with one another in their answers to any of the foregoing questions (and thus why a variety of factions are now battling for control of their sect). Here, as promised, we get our first glimpses of the vulnerable underbelly of their blasphemous creed that I mentioned in my opening remarks-J. C.]

\section{An Actual List}

Notice the indefinite article. There are many possible variations on the actual list below that would have sufficed for our present purpose-though none of them without its troubles. As we shall soon see, a reader constrained by nothing more than a bare commitment to resolution will encounter a variety of sorts of difficulty in trying to offer a specification of the rungs of the ladder in anything that approximates the form of a list. The difficulties that arise here will later prove instructive in clarifying the sorts of philosophical and exegetical difficulty that must beset any attempt to offer anything approaching a resolute account of the relation between the thought of the early and that of the later Wittgenstein. ${ }^{43}$

Rather than specifying the rungs by picking out swatches of text drawn from the Tractatus in the form of particular quotations, I do so, on the actual list below, by specifying particular lines of "thought" that either figure centrally in the book or are naturally provoked by those that do and to which commentators (standard and resolute alike) have rightly attached particular importance. This allows us to achieve a higher level of generality in specifying rungs of the ladder than would be possible if we confined ourselves to the letter of particular local formulations of each of these as they surface and resurface over the course of the text. ${ }^{44}$ So, in that spirit, I offer the following sample of candidate rungs:

1. A proposition is able to represent a state of affairs because it pictures it.

2. A proposition is a logical picture of a state of affairs when the fundamental elements of the proposition, the simple names, are logically combined in a fashion that parallels the manner of combination of the fundamental elements of the state of affairs, the simple objects. 
3. Thought and language are able to represent reality because they mirror the logical form of reality.

4. The logical form that language and reality share cannot be expressed in language.

5. The features of reality that underlie the possibility of sense (or: the features of language that underlie the possibility of representation) are there all right, even if they cannot be expressed.

6. These features, though they cannot be expressed, can be conveyed by appropriately structured forms of nonsense.

7. These nonsensical "propositions" are not mere nonsense-they are not utterly devoid of logical structure.

8. Such "propositions" involve determinate violations of logical syntax.

9. Each such violation is coordinate with an (inexpressible) insight into an (ineffable) aspect or feature of reality.

10. Each such insight can be "conveyed" through the employment of the corresponding piece of nonsense.

11. What is brought out into the open in each such case, through its transgression, is a general condition on the meaningfulness of propositions.

12. The totality of such conditions constitutes the limits of (our, my) language.

13. The limits of language are the limits of the (our, my) world.

14. It is the role of a proper theory of language to demarcate these limits.

15. It thereby demarcates the boundary between sense and nonsense.

16. It thereby also demarcates the limits of the (my, our) world.

17. The demarcation of these limits enables one (me) to contemplate from above (outside, sideways on) our (my) language (world) as a bounded totality.

It is important here that each of the items on this list be taken to correspond to a sentence, not a thought. The foregoing is a list of examples of candidates for sentences that ought to be associated with rungs on the ladder. The point of furnishing such a sample of candidates is to attempt to gesture at the sorts of sentence that might be held by a resolute reader to belong on what I shall henceforth call "the first list."

\section{The First List}

Notice the definite article. The expression "the first list" will not serve its intended purpose in this essay if one takes it to be here defined simply through an enumeration of some actual items in some definite order-say, the items on the actual list 
above in the order given. As we shall see, the point here applies both to the items themselves and to their order. The items exhibited on the above actual list are meant to furnish a preliminary indication of the character of the first list by specifying some appropriate possible candidate sentences for inclusion on it and by displaying them in a candidate arrangement. Leaving aside constraints on there being world enough and time for the completion of such an exercise, an excessively precise specification of the character of the first list would, at this point, be dialectically premature. It would beg a number of questions that will matter at later points in this essay. So we shall content ourselves here with a less than fully determinate characterization. This necessarily involves a certain degree of idealization. There are three significant dimensions of idealization in play here, each of which serves a particular purpose (and each of which can be seen to be associated with certain peculiarities of the actual list given above). The first of these has to do with the shape of said list, the second with its contents, and the third with the ways in which a bare commitment to resolution underdetermines what one ought to say about either. In what follows, my discussion of each of these dimensions shades into the other two at various points, but in the interests of perspicuity some effort is made to keep them apart.

\section{What Is the Shape of the Ladder?}

First, there is the question of how and where such a list should begin. In the actual list given above, the point at which the sequence starts is chosen fairly arbitrarily. One could, for example, certainly begin further back. But, more importantly, what "further back" means here depends in large part upon what one thinks the order of the items on the list is supposed to correspond to. Let us begin by asking: what might "further back" mean for a standard reader attempting to construct some counterpart to such a list for his own purposes? If we ask a standard reader to compile a collection of Tractarian theses and then instruct him now to arrange them in the right order, what order would that be? Well, one way he could interpret this request, in going about creating such a list, would be to have the order of the sentences correspond simply to the order in which the relevant theses figure in the book. For such a reader "further back" here might thus simply mean earlier on in the book. The rungs of the ladder, on such an understanding, would correspond to a structure that is "in the book" on a fairly literal understanding of that phrase. Let us call such a list-in which each sentence on it is associated with a thesis and occurs in the order in which the correlative remark occurs in the book- "a standard reader's list." (We will have more to say about such a list below.) On such a construal, the numbering system of the Tractatus may be understood as something like the perspicuous ordering of a set of commitments-in which 
the most fundamental commitments correspond to the integers and the increasingly secondary commitments correspond to the increasingly lengthy decimal figures that are accordingly subordinated to each of the remarks with numbers of comparatively shorter length that they succeed.

Just as all resolute readers must begin life qua readers of the Tractatus as standard readers; so, too, their conception of how the work is ordered must begin as one that participates in a standard reader's conception of what this must entail-and there it will remain as long as the task of reading the book is conceived to be one of (doing anything in the vicinity of) understanding what each of its sentences say. This means that all readers of the work must begin by working with something like a standard reader's understanding of the numbering system of the Tractatus-taking the apparent significance of that numbering system more or less at face value. If an understanding of the author of the work, however, requires a recognition that there is nothing that can count as understanding what each of these sentences (that are to serve as elucidations) say, then this conception of the ordering of "thought" within the text must eventually yield to another.

What then might "in the right order" mean for a resolute reader? It might at first appear as if she has two rather different ways of going here. Which way she should go about arranging items on her list might seem to depend upon whether she takes the sequence of items to correspond to an order of dialectical steps that is present in the structure of the work itself and that unfolds as one moves sequentially through the sentences of the book (so that the proper shape of the list depends on which sentences figure comparatively earlier in the text and which comparatively later) or whether she takes it to correspond to an order of discovery that unfolds in the course of a reader's coming to terms with the work (so that the proper shape of the list depends upon which sentences are likely to be recognized as nonsense comparatively earlier by a reader in the process of assimilating the work and which comparatively later). ${ }^{45}$

These two different ways of understanding the shape of the list may appear to correspond to two different ways in which a resolute reader might try to unpack the metaphor of a ladder. Each of these, in turn, is differently related to the initial (mis)understanding of the metaphor that she will see a standard reader as prone to go in for-that is, the understanding of the metaphor that any reader will go in for, prior to having achieved an understanding of the author (and the character of the activity in which he is engaged). On a standard reading, the ladder is to be thrown away in a single motion: the rungs of the ladder represent the sentences that set forth the elements of substantial theoretical doctrine that the work seeks to impart, and the 
reader becomes obliged to throw all of these away at once, when the theory is fully in place and can be applied to the body of sentences that advance it. Whereas, as we have seen, on any resolute reading, the ladder is thrown away bit by bit since the process of recognition required is of necessity an arduous and piecemeal one. But on the first of the two ways that a resolute reader might try to unpack the metaphor (where the order of the rungs of the ladder corresponds to the order in which lines of "thought" occur in the text), it might look as if the standard reader's conception of at least the general shape of the ladder should be allowed to stand, even if his conception of what is involved in throwing away something of this shape needs to be contested. Can it really be allowed to stand? Or to ask a related but comparatively tractable question: might such a resolute reader's list coincide with a standard reader's list? When we return to this issue below, we will see that it cannot. So there is some pressure here for a resolute reader to move to the second way of unpacking the metaphor. On the second way of unpacking the metaphor (in which the order of the rungs of the ladder corresponds to an order of discovery on the part of a reader), neither of these features of the standard reader's way of unpacking the metaphor may be retained. On this second way of unpacking the metaphor, as different readers work through the Tractatus, the shapes of the ladders they climb may vary.

The dawning of a realization that the apparent sense of a particular line of "thought" (initially apparently present in the book) is being caused to collapse in on itself (through the character of its development in the work) is the sort of experience that can have drastic implications for one's apparent grasp of other apparently logically related lines of "thought" (also initially apparently present in the work). Thus the shape of the ladder any particular reader climbs, on this way of unpacking the metaphor, depends partly upon which (apparently doctrinal) footholds in the text give way comparatively earlier in the course of her assimilation of the work and which give way comparatively later. As we think this through, we will begin to see that, on this second way of unpacking the metaphor, the idea of the ladder's having a determinate shape starts to require delicate handling.

Both the temporal and the spatial dimensions of the characterization of such an ascent up the ladder require delicate handling. First, let us consider the temporality of the ascent. What (are we to suppose) is realized by such a reader when? The realization that a formerly apparently weight-bearing foothold in the text is starting to vanish into thin air, as soon as it dawns, will be felt by a reader to spell some degree of trouble for other such apparently weight-bearing footholds. But of what sort, and how much? The impending character of the trouble ahead will be apprehended at first only inchoately and thus the severity of its degree will initially not admit of any 
precise measure. So talk of "what is realized when" here might appear to require some additional parameter that allows for talk of a continuum of grades of realization. (The recognition that something you took for sense is nonsense, is in this respect, as in many others, quite different from the recognition that something you took for true is false: sense and nonsense are not two poles of a single bipolar something that has the rough shape of a thought. If something turns out to be false, then inferences can immediately be drawn from it about what else must be false. If something is nonsense, then no inferences can be drawn from it. One is left with unclarity as to where one now stands with respect to much that one previously took to be the case, when one suddenly is no longer able to acquiesce in —not just the truth, but-the very intelligibility of a "thought" that one previously took to be true. ${ }^{46}$ So how are we to unpack the metaphor here? When climbing a real ladder, we need not generally concern ourselves overly with the grades of being of each of the rungs. We might try to supplement the metaphor here with talk about how firmly planted a foot is on a rung. We might try to take comfort in the thought that the temporal dimension of the process (which we might think has more to do with the ascent up the ladder) perhaps doesn't matter, inasmuch as the idea of a ladder's having a shape is basically a spatial metaphor.

But how is its spatiality to be unpacked, on this second way of unpacking the metaphor? Delicacy is required here for two reasons since (1) it belongs to the nature of the case that the triggering of any such sequence of successively collapsing rungs can only be initiated once a given reader is already quite far along in her effort to orient herself in the text, and (2) such a collapse necessarily exerts an acute dialectical pressure both backward and forward onto other footholds in the text, well beyond the initiating moment itself. Assuming for the purpose of argument that it is clear enough which moment in the text initiates the sequence of falling textual dominoes, questions may arise immediately about which domino can be said to have fallen second and which third, if the dialectical pressure immediately and simultaneously spreads both forward (toward the concluding) and backward (toward the opening) numbered remarks in the text. This may suggest that there are hopelessly severe limits here on the degree of precision that can be placed on the idea of the order in which things unfold for such a reader. But what is our picture of "precision" here and in what sense are we unable to attain it?

When thinking about how to unpack the metaphor, there is a tendency only dimly to make out that neither a strictly logical nor a merely psychological account of the shape of the ladder will quite do here. One then responds to this dimly felt difficulty by oscillating in one's construal of the matter between these alternative understandings of what might be at stake, without stably settling on either one. ${ }^{47}$ (This 
oscillation in one's thinking is part and parcel of the sort of confusion that is to be worked through in a successful ascent of the ladder.) If the specification of the moments in the dialectic we pass through in an ascent of the ladder were to be identified with a description of psychological events as they transpire in an individual subject, then it would become mysterious how the items arranged on the actual list above could ever purport to be anything more than a characterization of a sequence of mere psychological contingencies in, say, my experience of reading the book (and thus mysterious in what sense that order could accurately reflect or fail to reflect anything of possible general interest to us here). If, on the other hand, it is supposed to be a specification of the steps in an argument to a conclusion, then what conclusion is it converging on? (Saying it's a reductio doesn't help-if this characterization is to be understood literally rather than merely metaphorically. That would simply mean that the conclusion to be affirmed is the negation of some original assumption. What assumption? The specification of a conclusion or an assumption is only possible where what is to be specified is something that makes sense.) For the author of the Tractatus, not only should we not confuse the order of events in a psychological episode of thought with the order of steps in a logical chain of thought, but we should also not identify either of these with the order of clarification in an elucidatory train of "thought." The sort of perspicuity we seek in the ordering of our thought in philosophy for Wittgenstein, both early and late, must always be distinguished both from the sort of descriptive accuracy we seek in empirical psychology and from the sort of inferential validity that we seek in logical argument. For the ultimate aim in the sort of philosophy that Wittgenstein seeks to practice is a sort of total dissolution of the problems that neither the mere provision of accurate description nor the mere augmentation of properly justified true belief (however important these may be as secondary means) can ever deliver on their own. Accurate description and valid reasoning each bring with them a certain ideal of clarity, but in neither case of the sort that is Wittgenstein's ultimate quarry-the sort that can make philosophical problems (of the kind that he seeks to address) completely disappear. It is to this end that we climb the ladder.

So what does a resolute reader seek to capture in ordering the items on the list? What is to be captured by such a reconstruction is neither merely what happens first and then what happens next and so on in a particular reader's experience while (possibly uncomprehendingly) merely moving through the text, nor a specification of what is to be inferred first and what is to be inferred second and so on if the reader is to become rationally entitled to some (propositional or quasi-propositional) insight. What is to be captured rather is how the illusion of sense that the reader attaches to this sort of sentence is revealed to be an illusion and how this exerts pressure on the 
illusion of sense that she attaches to this other sort of sentence and so on. Notice I say here: this sort of sentence. It is not that there is some magic handful of seven or eleven or thirty-four sentences that are the evil sentences that confuse us, so that one can confine oneself to that determinate set of culprits and look upon all the other sentences in the vicinity as mere accomplices to the crime. The culprits do not admit of being rounded up in that way. This means that there is an ineliminable degree of choice that enters into the presentation of a train of elucidatory "thought." For one must always work with particular examples of sentences, where the particular examples one chooses will affect the precise details of how the dialectic should be presented. If this is right, then the appropriate sequence of apprehensions on the part of a sensitive reader ought to admit of a variety of equally well-founded alternative reconstructions, each having equal claim to being, in a sense, a perfectly accurate specification of the series of stations through which the reader's train of dialectical "thought" may be said to have passed. The point of a perspicuous arrangement of sentences that occur in the book (and ones like them) is not to capture precisely what actually happened at some point in time to some particular reader, but to arrange things so that something may happen for a general reader. What a perspicuous arrangement of elucidatory remarks seeks to characterize is the order of steps that enables the reader to come to see how the philosophical problems with which she wrestles draw their life from her only apparently conferring on certain sentences a determinate method of symbolizing. It is such sentences and the order in which their elucidation proceeds that we seek to represent through our list. Having said this, the following two points should by now be clear about a proper unpacking of the metaphor: (1) the shape of the resulting ladder, on some reconstruction of it, may correspond at best only loosely to any actual sequence in which the corresponding textual footholds occur in a properly bound copy of the book, and (2) this need in no way be a sign that our reconstruction of the shape of the ladder fails to do justice to the structure of the dialectic that is "in the book" (now on a considerably less literalminded understanding of that phrase).

\section{What Counts as a Rung?}

If one fully enters into the spirit in which the items on it are put forward, then it will soon become evident that even in the case of the so-called "actual list" given above a variety of dimensions of reconstruction and idealization are already in play. First of all, one could certainly fill in the list in far greater detail. Each of the lines of "thought" in question is indicated only in a highly schematic fashion, admitting of far greater specification. But, far more importantly, almost every item on the list is meant to 
indicate a number of other equally pertinent items. Taking the most straightforward case of this first, at many junctures an item on the list could be replaced with something that has the form of its philosophical opposite, without rendering its candidacy for inclusion on the list any less appropriate. Thus, a realist-sounding thesis, such as 3 on our actual list above, could be replaced by its antirealist counterpart:

3a. Reality is representable in language because it mirrors the logical form of thought and language.

This, in turn, could be modified to take on a more palpably idealist-sounding edge:

$3 \mathrm{~b}$. Our world is representable because it mirrors the logical form of our language.

Or, if you prefer, you can have a solipsist-sounding variant:

3c. My world is representable because it mirrors the logical form of my language.

There are standard interpretations of the Tractatus on offer that advocate each of 3 , $3 \mathrm{a}, 3 \mathrm{~b}$, and 3c, arguing in favor of the candidate item's role as a central doctrine of the work. Thus, for example, much of the secondary literature on the Tractatus has come to assume the form of a debate between those who hold that the direction of explanation should flow from the nature of reality to the nature of language and those who hold that this order of explanation should be reversed (though there are also interpretations which hover unstably between these options without ever settling clearly on either). Resolute readers hold that each of the philosophical positions that results from privileging either of these directions of explanation figures equally as a rung on the ladder that we are invited to climb up and then throw away. ${ }^{48}$ For such readers, one has failed to understand the aim of the work as a whole if one takes oneself to be obliged to try to figure out which of such opposed options we are supposed finally to settle upon: the Tractatus aims to show that the sense of any of 3, 3a, $3 \mathrm{~b}$, and $3 \mathrm{c}$ depends on the others and that they all stand or fall together-that, strictly thought through, realism, idealism, and solipsism all collapse into one another. ${ }^{49}$

On a standard reader's list, we can include only one of 3,3a, 3b, and 3c; whereas there is nothing that debars a resolute reader from placing all four of these items on the same list. So we are now in a position to answer a question that came up before: might a resolute reader's list coincide with a standard reader's list? No. For standard readers, such (putatively) philosophically/logically incompatible "propositions" crowd one another out as candidate rungs on the ladder because such propositions are to be associated with genuine, albeit ineffable, insights into the nature of thought, language, and reality, and their negations are to be associated with denials of those insights. For resolute readers, these items need not crowd one another out as candidates for inclu- 
sion on the first list since the rungs of the ladder they represent are all equally associated with merely apparent insights into the nature of thought, language, and realityall equally to be overcome. This has implications for how a resolute reader ought to conceive of the continuation of the actual list given above. For a resolute reader, at many points, the above list can, and should be, continued in any of several different directions, as it were ${ }^{50}$ —each equally pertinent to specifying candidates for inclusion on the first list. Similarly, many of the items that already figure on the above list could be unpacked in either of two ways, where each way would be associated with one of two opposed philosophical doctrines. Thus, for example, 2 admits of both a radical atomist and radical holist variant, where, once again, each of the variants in question has frequently been ascribed to the author of the Tractatus by standard readers, and where the truth of each has been understood to depend on the falsity (and thus intelligibility) of the other. The two variants at issue here might be specified as follows:

2a. A proposition means what it does (solely) in virtue of the (prior and independent) meaning of the names of which it is composed and the logical relations into which these are (then) combined.

2b. An expression means what it does (solely) in virtue of the logical role that it plays in the totality of propositions in which it can occur.

Here, too, much of the secondary literature on the Tractatus has assumed the form of a debate between (i) those who hold that the direction of explanation should flow from the nature of the fundamental elements of the proposition (above all, names and the process by means of which meaning is first somehow independently conferred upon them) to the nature of the proposition (understood as a combination of such antecedently available elements) and (ii) those who hold that this order of explanation should be reversed. And there is a parallel debate about the relation between the nature of simple objects and that of states of affairs. Do the objects first exist and then enter into certain combinations? Or are they what they are only in virtue of their antecedently fixed possibilities of combination? The opposed theses here might be specified as follows:

$2 a^{\prime}$. A state of affairs is the sort of complex it is (solely) in virtue of the (prior and independent) character of the elementary objects out of which it is composed and the particular sort(s) of logical relation into which these have been combined.

$2 b^{\prime}$. An object is the sort of element it is (solely) in virtue of the antecedently fixed possibilities of combination into which it can enter and thus can be identified as the object it is only through a specification of the totality of states of affairs in which it occurs. 
Here, too, resolute readers will hold that either of the philosophical positions that thus results (from privileging either of these directions of explanation) figures equally centrally as a rung on the ladder that we are invited to climb up and throw away.

At this point, the very idea that there is something that corresponds to placing all of the items on the list "in the right order" can threaten to come apart on us. Even in the rather minimal actual list given above, not all of the propositions that are indicated are sequentially ordered with respect to one another. Starting with item 5 on the list, I have indicated possible (sometimes perhaps apparently minor, sometimes perhaps apparently momentous) variants on the rung in question through a sort of parenthetical shorthand. Each occurrence of this parenthetical notation indicates the possibility of a further (sometimes apparently logically or philosophically opposed) candidate item for the list. This suggests that a proper representation of that which we seek here should not be something of the linear form of a mere list, but rather something with an added dimension that would permit the representation of branching sequences. But we should be careful here not to confuse the retrospective view (of the overall shape of things gradually attained through one's ascent up the ladder) with the prospective view (of someone engaged in an ascent). Even in climbing a tree one can only climb one branch at a time. In any actual movement of "thought" in one's ascent up the ladder, one branch must be explored before another (because it will only be with the benefit of hindsight that certain branching clusters can be seen to have a parallel standing in the larger scheme of things). Nevertheless, certain questions can arise about each further item on the actual list whose possibility is indicated by my parenthetical notation. If each one were spelled out so that it could figure as a separate numbered item on the list, then how should, say, the realist, idealist, and solipsist variants on any one of them be ordered with respect to the others? Is this a good question? As we try to think these two questions through, it is bound to become less and less clear, on a resolute understanding of the metaphor of the ladder, what the expression "to climb a rung of the ladder" is any longer supposed to mean if it is supposed to designate a form of transition between rungs and if each of the items that figure separately on the first list is to be counted as a separate rung.

As we shall see, in response to questions about how things on the first list are to be ordered, an intramural squabble may break out among resolute readers. Though they agree with each other that no preferred order of explanation (from, say, the nature of reality to the nature of language or vice versa) should be ascribed to the author of the work, it is open to a resolute reader to hold that this still leaves room for the idea of a preferred order of elucidation. In their writings about the Tractatus, resolute readers 
certainly tend to construct narratives that (at the very least) strongly suggest that they think that there is an order in which things are supposed to unfold in the dialectical strategy of the work. ${ }^{51}$ But exactly how such narratives should go is something about which they can disagree. And this, in turn, has bearing on questions concerning how the idea of placing all of the items on the list "in the right order" should be spelled out. The bare commitment to resolution in fact leaves plenty of room for alternative dialectical narratives and lively disagreements about such matters.

Though they may not be able to agree on how to order them, what resolute readers will agree on is that if any member of a set of parenthetically indicated variants on the actual list above belongs on the first list, then all of the other variants (i.e., including the original numbered item of which the parenthetically indicated ones are variants) belong there as well. For what all of the items on the first list are supposed to have in common-that is, what marks them out as sentences belonging on the first list-is that each of them expresses a metaphysical commitment that figures in the Tractatus as a philosophical temptation that the author intends to help the reader to overcome. On a resolute understanding of the method of the Tractatus, in which these candidate answers to metaphysical questions are to be made to vanish through the vanishing of the questions themselves, at the end of the day, such clusters of answers either have to have been made to vanish all together or not at all—regardless of whether they purport to be about "language," "thought," or "reality," or whether they purport to be about "the," "our," or "my" language (or thought, or reality). You cannot resurrect a piece of nonsense from the grave of semantic emptiness merely by adding or subtracting a "not," or by substituting a "my" or an "our" into a mere sequence of signs. To raise it from the grave, you must confer a determinate method of symbolizing on the propositional sign; and once you have done this, you have thereby also conferred a sense on certain counterparts of it (such as those that can be formed in the appropriate manner by introducing a "not" into the propositional symbol). ${ }^{52}$ Conversely, a bringing to light of what turns out to have been a merely apparent success in conferring a method of symbolizing on a string of signs will adversely affect not merely the apparent intelligibility of a single string, but that of numerous other (merely apparently logically related) propositional signs. What this suggests is that if resolute readers (in their attempt to unpack the metaphor of the ladder) are to make useful sense of expressions such as "to climb a rung of the ladder," then each individual rung on such a ladder must be identified (not just with an individual sentence taken in isolation from its dialectical context within the work as a whole, but rather) with a whole cluster of remarks considered in relation to other such clusters. 


\section{What Counts as a Rung? And What Is the Shape of the Ladder?-Take Two}

We saw that for a standard reader the numbering system of the Tractatus can be understood as something like the perspicuous ordering of a set of commitments-in which the most fundamental commitments correspond to the integers and the less fundamental ones to the increasingly lengthy decimal figures. If, however, the sentences that figure on the first list are to be recognized as something other than commitments to be ascribed to the author of the work-and, indeed, are eventually to be recognized by a reader as nonsense, so that both they and their (apparent) negations belong equally on the list-then a quite different conception of how the numbering system of the Tractatus permits a perspicuous presentation of the dialectical structure of the work ought at some point to come into focus. Consider the following sort of remark that, in writing about the Tractatus, a commentator may find himself wanting to make:

The rendition of the metaphysics of facts in the 2.0s is not intended to stand on its own as a piece of metaphysical theorizing....

The incoherence of the $2.0 \mathrm{~s}$ is . . overcome by the say-show distinction elaborated in the $4.12 \mathrm{~s}$. We are led to the say-show distinction by the way that the earlier remarks pull themselves apart. At this point, we can throw away the earlier remarks: there is no theory of the constitution of the world, no ontological theory with the generality to which Russell's theory of types aspires. The pursuit of theory, of description, of representation at this level of generality is the pursuit of an illusion..$^{33}$

There are many examples of such prose in the writings of resolute readers-prose in which reference is made to how a comparatively early swatch of sections in the book ought to be understood (at a particular juncture in the unfolding of the dialectic reached at a given point in the narrative of the commentary) in the light of some comparatively later swatch of sections.

There are two things of interest here. First, if it is right that the incoherence of, say, the $2.0 \mathrm{~s}$ is fully recognized and overcome only in the light of a proper appreciation of the significance of something elaborated in, say, the $4.12 \mathrm{~s}$, then there is a sense in which even a fairly minimal characterization of the dialectic of ascent can require that the same items occur (at least) twice in any perspicuous ordering of the rungs of the ladder through which a reader must pass-on a comparatively earlier pass through these items (say, the 2.0s), it is recognized that they partake of a certain incoherence, but it is only on a comparatively later pass that a full appreciation of the character of this incoherence may dawn. A reader is led to an appreciation of the significance of the later cluster of remarks only given an inchoate recognition that the remarks in the earlier cluster do not quite make sense (that they pull themselves apart), and this later appreciation, in turn, enables a full recognition that there is no sense to be made 
of the remarks in the earlier cluster (that they are simply nonsense). Second, what is also of interest here is how the numbering system continues to furnish a commentator with a way of orienting himself in the structure of the work (by picking out, say, the $4.12 \mathrm{~s}$ as a significant cluster of successive remarks that bears in a particular way on another such cluster, say, the 2.0s) even as the reader's conception of how "thought" is "ordered" in the book undergoes such radical transformation-as a putative understanding of (what at first comes into view as) a series of logically interlocking theoretical commitments gradually gives way to the recognition of an illusion. In the course of an ascent up the ladder, a sequence of numbered sections may at first take on one aspect (say, a realist aspect), then another, (say, an idealist aspect), and then yet another (in which the two sets of members of such pairs of aspects are seen collectively to collapse into one another). The significance of the numbering system of the work has an important role to play in allowing a reader to track these successive shifts in aspect that (at successive moments in an ascent up the ladder) whole sequences of remarks may undergo at once. A dispute between two resolute readers about the order in which things are supposed to unfold in the dialectical strategy of the work will therefore often be in no small part a dispute about why the sections of the work are numbered just as they are.

The spatial and linear features of a ladder here threaten, once again, to mislead us if the metaphor is construed too literally, especially when combined with too simpleminded an understanding of the point stressed earlier, namely, that the recognition of Tractarian nonsense must proceed piecemeal. What these related forms of literal-and simplemindedness may occlude is the point that has just been emphasized in the previous paragraph: namely, that there be successive episodes of holistic apprehension - of global aspects dawning - that attend an ascent up the ladder. In climbing the Tractrarian ladder, though you can take only one step at a time, nonetheless, at every point in the ascent, you must keep track of (what now appears to be happening in) remarks elsewhere in the book as viewed from the vantage you have just attained in your ascent. From the point of view of a resolute reader, therefore, the expression "to climb a rung of the ladder" is best reserved for cases of apprehension of the sort touched on in the previous paragraph (and it may thereby acquire a far more useful sense than the previously unhelpful one of merely somehow moving from a particular item on the first list to an elusive "next" item on that list). That is, it is best reserved for those moments, in working through the book, when the assimilation of a fruitful set of remarks triggers an episode of significant rethinking, enabling one to re-apprehend-to see in a whole new light-the character of the connection between the fruitful remarks and a whole host of other remarks in the book, so that 
one now understands the significance of those other remarks (i.e., their role within the dialectical strategy of the work as a whole) in a significantly new way. Even if one restricts the sense of the expression of "to climb a rung of the ladder" in this way, it can still remain quite surprising how many rungs one must climb in order to ascend the ladder of the Tractatus. In accordance with this usage, it makes perfect sense, for example, to speak of certain rungs of the ladder as (available to be) climbed only on successive rereadings of the whole book.

Notice: on this new way of talking, not every separately numbered remark in the book (or every separately specifiable sentence on the first list) will any longer count as a rung; rather only a sequence of numbered remarks (or a collection of appropriately arranged items on the first list) will now constitute a rung and then only via a connection that comes into view for a reader between that sequence (or collection) and other remarks elsewhere in the book. On such a way of talking, though it is still the case that the numbered sections of the work can be said to "make up" the rungs of the ladder, it is no longer right to think of each such section as itself constituting an individual rung. Moreover, a given collection of remarks can figure more than once in an ascent of the ladder-in the climbing, as it were, of more than one rung. (And a given remark can figure in more than one such collection. $)^{54}$ What recommends this sort of employment of the expression "to climb a rung of the ladder" to a resolute reader is something that itself helps to bring out a profound point of difference between standard and resolute approaches to reading the book. In taking the book, as a standard reader does, to offer something that approximates the presentation of a theory, there is nothing in principle that debars an appropriately brilliant and attentive reader from taking in the point of the book as a whole in a single sequential reading of it. Whereas in taking the book, as a resolute reader does, to involve the aforementioned sort of elucidatory exercise in undoing our attraction to certain confusions (and to the apparently meaningful sentences that we call upon to express them), a full assimilation of the work due to its very design requires successive passes through the same sets of remarks and thus multiple readings of the whole text. A notable feature of any attentive reader's experience of the book, namely, that a seemingly countless number of attempts at assimilating it as a whole appear to be required in order to be able to orient oneself in the book, may now therefore take on a new aspect. This feature of a reader's experience of the book may initially come dimly into view as nothing more than an apparent consequence of some degree of literary or expository failure on the part of the work. (Indeed, on a standard understanding of its aim, there is no reason for this feature of the book ever to cease to appear to be a sign of anything other than poor design.) On a resolute understanding of the aim of 
the work, this feature of a reader's experience of the work may now come into focus as a constitutive aspect of the method of the work.

\section{Further Intramural Dispute}

We saw that a dispute between two resolute readers about the order in which things are supposed to unfold in the dialectical strategy of the work will often in no small part be a dispute about why the sections of the work are numbered just as they are. This point can now also be reformulated as follows: a dispute between two resolute readers can assume the form of a disagreement about what constitutes a climbing of a rung of the ladder (in the demanding sense just given to this expression). The third dimension of idealization mentioned above comes with needing to allow for the possibility of yet a further sort of disagreement between resolute readers-one that bears immediately on this one.

The original point of the actual list (of candidate items for inclusion on the first list) was to specify some examples of the sort of thing that one finds in the Tractatus that a resolute reader is apt to view as forming part of the target of the work (rather than part of its doctrine), thereby allowing us to put some flesh on the previously rather bare-boned metaphor of a ladder (and the related metaphors of climbing it and throwing it away). But as long as resolute readers disagree about the details of how their general program for interpreting the Tractatus is to be implemented-why, as it were, the sections of the work are numbered just as they are-then there is also room for disagreement about what properly belongs on the first list (and thus exactly how the details of the text should enter into a full unpacking of the metaphor). It is important to see that a mere shared commitment to a generically resolute approach to reading the work will not of itself provide sufficient common ground to resolve such a disagreement. The proper demarcation of the first list turns on the proper resolution of all such disputes. The concept of the first list here therefore pertains to this common topic that resolute readers may find themselves in disagreement about (and thus not to any determinate specification of its contents that might be gleaned by reading some supposedly canonical article or book by any particular resolutely minded commentator). What makes someone a resolute reader of the Tractactus is that there are many sentences in the book that she will want to earmark for inclusion on the first list for the sorts of reasons touched on above. What a commitment to resolution underdetermines is just which, and how many, such items should be placed on the first list, how they should be clustered, and how the clusters should be arranged.

There are two further issues here-the first having to do with what is already on the actual list and the second with what is not (yet). The first has to do with whether 
every item there marked out for inclusion belongs on the first list, the second with what it means to continue, as it were, the series here. With regard to the second, resolute readers (even if they agree about all of the items on the actual list) may disagree about how far into the text of the Tractatus a continuation of the list ought to penetrate. Do all of the sentences which specify features, for example, of the underlying conception of the activity of philosophical elucidation (which the text seeks to practice and into which it seeks to initiate its reader) themselves constitute rungs of the ladder that we are eventually meant to throw way $?^{55}$ Any attempt to adjudicate such a question immediately introduces a host of issues pertaining to how one ought to conceive the overall character and scope of the list. The question here at issue might be put as follows: what does it mean to complete the list? And how can you tell if you have gone too far? A remark of T. S. Eliot's is pertinent here: "[I]t is often true that only by going too far can we find out how far we can go." ${ }^{56}$ We will begin to see why in section VIII.

\section{An Avowedly Heterodox Degree of Mono-Wittgensteinianism}

[Finally, issues concerning the Gospels are broached. The infidel scholar begins to speak openly about his heretical beliefs and practices, as well as about his unabashedly blasphemous account of the relation between The Old Testament and The New Testament. (1) He begins by shamelessly trying to minimize his past sins on the ground that they were always only venal and never cardinal. Then he claims to be able to show that (2) the aims, (3) the methods, and even (4) the devils mentioned in each of the Testaments can somehow aid in the interpretation of the corresponding passages in the other. The latter discussion also alludes to unsavory practices among the infidels pertaining to the exorcism of evil spirits. - 1 . C.]

\section{Disapproval and Incredulity}

Presented with (perhaps a slightly longer version of something like) the actual list above and the news that resolute readers think that the author of the Tractatus is no less concerned than the author of the Investigations to help us overcome our attraction to sentences such as these, standard readers tend to be left with a version of the following question and an attendant reaction of incredulity: "But what then is the difference between early and later Wittgenstein? There can be no difference! If you allow all of the theses on the first list to count as objectionably metaphysical already by his early lights, then haven't you failed to leave room for anything in his early work that can subsequently count only by Wittgenstein's later lights as objectionably metaphysical?"

Let's call this "the incredulous question" and the attitude shared by those who are inclined to pose it "Incredulity." It matters for two reasons. First, it is their supposed vulnerability to the complaint lodged here that sometimes constitutes the heart of the 
charge directed against resolute readers by their critics that they go in for an unacceptable degree of mono-Wittgensteinianism; and, secondly, it is the supposition that the very idea of resolution itself must entail nothing short of precisely this severe form of mono-Wittgensteinianism that makes resolute readers seem so easily vulnerable to refutation via external evidence drawn from the later writings. It is worth distinguishing the incredulous question from the following one (with which it is often confused): "Aren't resolute readers necessarily committed to some undeniably heterodox degree of mono-Wittgensteinianism?" Let's call this "the disapproving question" and the attitude shared by those who are inclined to pose it "Disapproval." The point of the next few sections of the paper is to help bring out why it matters that we not conflate these questions. A resolute reader may plead innocent to the charge leveled by the first question (the one that invites Incredulity), whereas she must plead guilty to the charge leveled by the second question (the one that invites Disapproval).

Starting with section VII, we will turn to why a resolute reader need not invite Incredulity. In this section, I will confine myself to touching on why (in their insistence on certain moments of continuity in Wittgenstein's development) resolute readers cannot help but excite Disapproval. ${ }^{57}$ So, in this section, we will see why resolute readers are, indeed, committed to a heterodox degree of monoWittgensteinianism, and, starting in section VII, why their mono-Wittgensteinianism may remain, nonetheless, in certain respects quite mild.

Since, for the purpose of this paper, all that is required is to show how grounds that warrant Disapproval do not suffice to license Incredulity, the ensuing discussion of moments of continuity in Wittgenstein's philosophy may be brisk and superficial. I will indicate three interrelated moments of continuity in Wittgenstein's conception of philosophy that are emphasized in the work of resolute readers, and which, taken collectively, clearly constitute undeniable evidence of an avowedly heterodox degree of mono-Wittgensteinianism on their part: the first pertains to the aim of the activity, the second to its method, and the third to some of its obstacles. These three examples are hardly meant to exhaust the significant moments of continuity in Wittgenstein's philosophy to which resolute readers have attached importance in their writings. But they suffice to show that their approach to reading Wittgenstein is bound to occasion Disapproval.

\section{Continuity in Aim}

Consider the following pair of remarks from the Tractatus and the Investigations respectively, the first of which we have touched on before (in our discussion of the avowed aim of the early work): 
The object of philosophy is the logical clarification of thoughts.

Philosophy is not a theory but an activity.

A philosophical work consists essentially of elucidations.

The result of philosophy is not a number of "philosophical propositions," but to make propositions clear. ${ }^{58}$

If one tried to advance theses in philosophy, it would never be possible to debate them, because everyone would agree to them. ${ }^{59}$

The considerable differences in the style and emphasis of these passages notwithstanding, resolute readers will hold that a genuine (if limited) continuity in the conception of the activity pursued in the two books from which they are drawn is registered here- a continuity that the immediate juxtaposition of these two passages may serve to highlight. In the first of these, Wittgenstein gives voice to an aim that the second shows continues to remain central in his later philosophy, namely, the aspiration to practice philosophy in such a way that it does not issue in a doctrine or a theory, but rather in the practice of an activity - an activity that he characterizes, in the first, as one of elucidation or clarification-an activity that he says does not result in philosophische Sätze, in propositions of philosophy, but rather in das Klarwerden von Sätzen, in our attaining clarity in our relation to the sentences of our language that we call upon to express our thoughts. ${ }^{60}$ And the second emphasizes a feature of this aspiration that is already present in his early work, namely, to put forward remarks that can survive clarification yet continue to retain their status as directed at matters philosophical only at the expense of their no longer appearing to admit of disagreement. One can, of course, try to take the remarks put forward in the Tractatus as theses (and hence take them as remarks one can disagree with); and indeed, the entire activity of Tractarian elucidation depends upon the reader's willingness to do just this. But, if successfully conducted and fully pursued to its end, the effort will reveal that the remarks in question were unable to bear the weight of a philosophical thesis. ${ }^{61}$

Standard readers may agree that there is an appearance of continuity here; but they will also think that the previous paragraph vastly overestimates its significance. When early Wittgenstein says his aim is not to put forward a doctrine, what he really means, according to standard readers, is an effable doctrine. For the early Wittgenstein certainly does, on standard readings of him, aim to put forward a number of substantive metaphysical doctrines, only the doctrines in question cannot be expressed, but must rather be conveyed by other means. Standard readers take there to be doctrines that the Tractatus fully aims to espouse, even if it cannot express them, and it is just these doctrines that they take the later Wittgenstein, in his criticisms of his earlier self, to be centrally concerned to criticize. It is clearly not open to resolute readers to understand 
the relation between early and later Wittgenstein in this way. Since for many standard readers these are the only terms in which they can envision a plausible understanding of the relation between the two, this gives rise to the presumption that resolute readers, in their zeal to be resolute, altogether deprive themselves of the resources required to furnish a coherent account of the relation between early and later Wittgenstein. But, as we shall soon see, their insistence on the moment of continuity touched on here (as well as the two to be touched on below) still leaves resolute readers with ample room to find significant points of discontinuity between Wittgenstein's early and later conceptions of a form of philosophical practice that eschews theses-points of discontinuity both with regard to his conception of the forms of philosophical engagement and criticism that such a practice requires and with regard to his later assessment of the extent to which his earlier conception of such a practice is able to achieve its own ends or live up to its own understanding of the commitments it involves.

\section{Continuity in Method}

A second way in which resolute readers are committed to a degree of monoWittgensteinianism that standard readers are bound to frown upon is in their seeing a moment of continuity in Wittgenstein's conception of the method by means of which philosophical clarification is effectuated. This brings us to another pair of strikingly parallel passages, the first of which we have seen before:

My propositions serve as elucidations in the following way: anyone who understands me eventually recognizes them as nonsensical, when he has used them-as steps-to climb out through them, on them, over them. (He must, so to speak, throw away the ladder after he has climbed up it.) ${ }^{62}$

My aim is: to teach you to pass from a piece of disguised nonsense to something that is undisguised nonsense. ${ }^{63}$

Each of these passages tells a reader of these works about a sort of recognition she must achieve in order to understand the author. In the first of these remarks, we are told that a number of the author's propositions are to serve as elucidations by ourthat is, the reader's-coming to recognize them as nonsensical. In the second of these remarks, we are told the author's aim is to help us pass from something that is a piece of disguised nonsense (so that, at first, we will not recognize it to be the nonsense it is) to something that is shorn of its disguise (so that, at the end of the day, we are no longer able to mistake it for something that has a sense). But how can the recognition that a proposition is nonsense ever elucidate-ever shed light on-anything? It is natural to suppose that the only way to answer this question is to suppose that the 
author of the work must be operating with some highly distinctive conception of nonsense of his own-one that carves out a privileged space for a special class of nonsensical sentences that have the capacity to convey sorts of truth that neither perfectly meaningful nor merely nonsensical sentences are able to express. This supposition, as we have seen, lies at the heart of the standard reading; and we have seen that resolute readers hold such a supposition to be mistaken in connection with Wittgenstein's early work. Now we see that they view this supposition to be no less mistaken when it comes to interpreting his later work.

\section{Continuity in Devils}

Their view of the mistaken character of this supposition takes us straight to our third and final pair of strikingly parallel remarks:

We cannot give a sign the wrong sense. . . Every possible proposition is legitimately constructed, and if it has no sense this can only be because we have given no meaning to some of its constituent parts. (5.4732-3)

When a sentence is called senseless, it is not as it were its sense that is senseless. (500)

These remarks underscore our third moment of continuity. Many readings of the later work incorporate features of standard readings of the early work in their account of the nature of (what later Wittgenstein calls) "grammar" - a parallel that resolute readers are apt to see as presupposing the very misunderstanding of "the logic of our language" that early Wittgenstein was already centrally concerned to criticize. ${ }^{64}$ They will take the above remark from the Tractatus to draw attention to the misunderstanding in question, and they will take its counterpart from the Investigations to indicate that that criticism remains in force in the later work. But, more importantly, this last pair of quotations touches on a fundamental obstacle that stands in the way of the overcoming of confusion and the achievement of clarity of a sort that Wittgenstein seeks in philosophy, early and late.

The obstacle in question has both a theoretical and a practical aspect. Its practical aspect lies in our capacity to enjoy certain sorts of apparent experiences of meaningexperiences that take the form of our imagining that we are able to understand what a sentence says when, in the relevant sort of case, there actually is no determinate "thought" of the sort that we had imagined. Its theoretical aspect lies in the sorts of accounts we are attracted to in our philosophical theorizing about meaning. These mutually reinforce one another. In our theorizing about those sentences that we take to be meaningful, we are drawn to an account according to which the meanings of the parts of a proposition can be fully identified as the parts they are independently 
of our understanding of the particular propositional whole in which they figure and apart from the context of use within which that proposition acquires application. This leads us in our theorizing to the idea of there being a special kind of nonsense that arises when there is a failure of fit between the parts of the proposition or between the proposition and its context of use. And this seems to correspond to something we experience in our practical intercourse with certain sorts of sentence: a conflict between the sort of sense we are antecedently inclined to assume the sentence must have and our realization that the sort of sense that we wish to ascribe to it does not really amount to something that we can understand. The theoretical tendency seems to find confirmation in the character of our experience of trying to understand such sentences and our experiences with such sentences draw us to such theories. ${ }^{65}$ So we arrive, however inchoately, at the idea of a sign having "a wrong sense" or "a senseless sort of a sense."

These twin aspects of the obstacle in question can be connected to two related dimensions of continuity in Wittgenstein's philosophy. The overcoming of the obstacle in its practical aspect is a potentially infinite task. There is no set of marks or features that can enable one to tell-from within, as it were-whether one is making sense or not. Posed in the thrall of a possible case of the hallucination of meaning, the question as to whether we are really making sense or not admits of no fast or simple answer. It can only be settled through an arduous process of clarification-over the course of which it becomes clear either what sense there is to be made here or that there was no sense (of the sort that we originally took there to be) to make. Neither on Wittgenstein's earlier nor on his later conception of philosophy can the task of clarification arrive at a definite terminal point-a point at which it is clear that philosophical confusion can no longer arise, so there is no longer any call for the activity to have to continue. ${ }^{66}$ Hence the task of clarification is a potentially infinite one. But the task of overcoming the obstacle in its theoretical aspect is a finite (albeit formidable) one. It involves thinking through our attachment to certain very particular sorts of ways of thinking about meaning to the point where they collapse in on themselves. The task of exorcising these particular ways of thinking plays an equally central (albeit very different) role in Wittgenstein's early and later philosophies.

\section{The New Way of Thinking against the Background of the Old}

[Even a child knows that the true meaning of The Old Testament is only revealed to those who interpret it in the light of The New Testament. In this section we are introduced to the lunatic infidel doctrine that the reverse is somehow equally true. The infidel scholar (1) attempts to derive this bit of blasphemy through 
a Trinitarian gloss on Ludwig's offhand remark that a true believer ought to carry with him at all times a single volume in which both Testaments are bound together. Our author then begins to meander. After (2) a brief excursus on the peculiar dietary practices of his sect, (3) he suddenly takes to whining about the reading habits of the Church Fathers and, in particular, their inability to attend to even minor recitations of who begat whom in The Old Testament without immediately associating them with glorious New Testament passages such as The Sermon on the Builders or The Parable of the Mouse and the Rags. (4) He claims that this not infrequently causes the Church Fathers to see builders or mice in The Old Testament where there are none.-J. C.]

\section{Bound Together}

This is a good moment to pause and ask what a remark such as the following is doing in the preface to Philosophical Investigations:

Four years ago I had occasion to re-read my first book (the Tractatus Logico-Philosophicus) and to explain its ideas to someone. It suddenly seemed to me that I should publish those old thoughts and the new ones together: that the latter could be seen in the right light only by contrast with and against the background of my old way of thinking. ${ }^{67}$

Let's call this "the prefatory remark." Standard readers, on a cursory reading of it, can take it as a bit of textual evidence that the doctrinal schema must be sound. This allows them to have a sort of a story about why he might have wished the Tractatus to be bound together in a single volume with the Philosophical Investigations. But why does he say that "the latter could be seen in the right light only against the background of my old way of thinking"?

Before we take up this question, it is worth noting that, faced with a volume in which these works were bound together to form a single work, we would be presented with a material realization of the problematic with which the first two sections of this paper were concerned. ${ }^{68}$ Our question could be reformulated in this way: to what extent should the resulting volume be understood to be a single work by one and the same author, and to what extent should it be understood to encompass two heterogeneous works produced by a pair of authors concerned to pursue very different, and sometimes even opposed, tasks and aims? I take it that the execution of this request (to have the work thus materially bound together) is meant to provoke just such questions in a reader-questions that are meant to stay with us throughout our activity of reading in the resulting volume. The combination of moments of unity and duality in such a mode of presentation are meant to make clear that these halves of the volume are already intellectually bound up in one another, before they come to be physically bound together, in ways that render a consideration of the respective bearing of each on the other mutually illuminating to a degree unlikely to be appreciated if each is read merely successively and separately. An arch way to put this point would be say that there is something right about going Trinitarian here: the author of the resulting 
twofold volume would be a single being who exists as three indissoluble personsEarly, Later, and Wittgenstein.

Members of a Trinitarian sect of mono-Wittgensteinians will want to place special emphasis on our earlier question: why "only against the background of my old way of thinking"? For this suggests that what is in the pages of the Tractatus is not simply a recurrence of confusions also to be found in the less difficult writings of lesser philosophers and that it is this difference that recommends those early pages for inclusion in the single volume at issue here. The presence of the "only" suggests that, if we want to see his new way of thinking in the right light, we need first to see it against the background of features of his old way of thinking that he takes to be both peculiar to that way of thinking and peculiarly important to an understanding of the new way of thinking. Otherwise any of a variety of other backgrounds would serve just as well. Which features of his old way of thinking are at issue here? And how do they serve to form the background against which his new way of thinking can be seen in the right light? Are they features of his old way of thinking that he takes to be mistaken to a degree that is peculiar to that way of thinking? Or are they ones that he takes to be essentially correct in a respect that was originally peculiar to the old way of thinking? Is what is at issue here that which he is concerned to repudiate or that which he is concerned to inherit in his old way of thinking?

It is a mistake to think that we need to choose between these options. We can only see what Wittgenstein is most concerned to repudiate in his old way of thinkingand, thereby, what is most original in that way of thinking-against the background of that which he is most concerned to inherit in his earlier way of thinking. Having failed to identify the latter, we are in no position to identify the former. The aim of the previous section of this paper was briefly to highlight some of those aspects of his old way of thinking that resolute readers are apt to think he was most concerned to inherit. The aim of the later sections of this paper will be to indicate some of the aspects of the old way of thinking that he is most concerned to repudiate. The suggestion (of these parts of the paper taken together) is that these jointly constitute the background against which we are asked to see his later philosophy. If we are able to achieve such a view, Wittgenstein thought it would enable us to see his new way of thinking in the right light, enabling us to see what in his old way of thinking he later most seeks to overcome and hence what in his "new" way of thinking is, indeed, new.

\section{A One-Sided Diet}

Wittgenstein is famous for warning against the dangers of nurturing one's philosophical theories on a one-sided diet of examples. ${ }^{69}$ Part of the point of broadening the diet is to allow something to become visible that otherwise remains invisible- 
namely, how one's assumptions regarding what must be the case are in the thrall of a philosophical preconception. The preconception funnels one's attention onto only those aspects of the phenomena that one antecedently expects to find. One takes oneself already to know what one would find if one were to look and see; and the one-sided diet confirms these antecedent expectations. So far, so good. This dimension of Wittgenstein's later thinking has not been neglected. But the character of its reception has itself been subject to a certain partiality-or one-sidedness. The topic that matters here is taken to be the following: how one-sidedness in diet can blind one to certain philosophical temptations, thereby constraining one's appreciation of the sort of thing that a philosophical temptation is and what its overcoming might involve. But an appreciation of this sort cannot be had apart from another; and this complementary dimension of Wittgenstein's later thinking has remained comparatively neglected.

Just as there is, throughout Wittgenstein's later writing, an alternation between a voice of philosophical temptation and a voice of philosophical correction; so, too, there is a concern with a danger of merely exchanging one sort of false conception (fed by a premature temptation to insist) for another (fed by a premature insistence that the temptation be silenced). It is the relation between these twin dangers-and how each can feed on and sustain the other-that the choreography of the alternation of voices in the later writing is in part designed to help bring to a reader's awareness. ${ }^{70}$ Commentary on Wittgenstein's later writings has tended to be far less sensitive to his efforts to forestall this second form of partiality in our philosophical thinking in which (nurtured by a false confidence that we have seen to the bottom of the problems) we take ourselves to stand ready to discharge the task of philosophical correction. At the level of reading the text, what goes neglected therefore are the equally numerous warnings in Wittgenstein's later writings issued against the dangers of nurturing one's conception of philosophical correction on the complementary sort of one-sided diet. Part of the point of broadening one's diet in this regard is again to allow something to become visible that might otherwise remain invisible.

Only now what needs to come into view is, first, something about the character of Wittgenstein's later writing, and, second, something about us-his readers-in our approach to the text. What needs to come into view first is the partiality of the many attempts in the text on the part of the voice of correction to silence its interlocutor, and how utterly these efforts to attain philosophical closure are shown (in the subsequent development of the text) to fail to bring the philosophical dialectic to an end. What needs to come into view, second, is how our conception of the activity of correction itself can suffer from no less damaging forms of partiality and blindness than 
any it seeks to undo. For a false preconception of what is involved in the task of philosophical clarification also funnels our attention-now onto only those aspects of Wittgenstein's efforts to avoid false conceptions that we antecedently expect to find in the text. What is needed now is something that might be able to show us that we are self-deluded in our belief that we already stand fully oriented with respect both to what the successful prosecution of philosophical criticism itself requires and to what later Wittgenstein thought it required. This suggests that much might be gained if only we could place Wittgenstein's practice of his later activity of philosophical clarification alongside the practice of another-one that closely resembles it in some ways, yet differs from it in just the ways required to help highlight that which is significantly new in the new way of prosecuting the task. The difference between the two would serve to bring into greater relief aspects of the later activity that we do not notice because we take ourselves already to have the character of that activity properly in view. So what is required here is a very special sort of object of comparison (i.e., an exemplification of a strikingly similar yet profoundly different practice of philosophical clarification)—something that it is not easy to come by.

\section{Lop-Sided Reading}

It should be evident that we can now bring together our two previous topics: the topic of that which was to be bound together and that of partiality or one-sidedness in one's approach specifically to Wittgenstein's later philosophy. Our discussion of the latter led us to see how a certain tone-deafness in one's parsing of the voices in Wittgenstein's text can distort one's appreciation of how the clarification of the problems therein is to proceed, thereby constraining one's very conception of wherein that activity consists and what its prosecution might involve. This, of course, suggests a reason for placing the Tractatus in the first half of a single volume. But in order for that early practice of philosophical clarification to be "placed" (in the sense of that term at issue) alongside the later, we must avoid the danger of allowing our view of it, too, to be merely refracted through the lens of our false conception of the later work. This, of course, is a danger that attends the employment of any object of comparison in philosophical elucidation: rather than seeing the old examples from the perspective afforded by the intended object of comparison, we see the latter only through the distorting lens of the picture that has been nurtured through our prolonged commerce with the former. So, too, with the two halves of the bound volume: if we merely bring our antecedent partial conception of the later work to bear on the early work, eagerly setting about to right it of (what we take to be) its wrongs, we deprive ourselves of an encounter with it (and the tremendous originality of its own 
conception of philosophical clarification)—-thereby depriving it of its intended force as a potentially instructive object of comparison. If this is right, that is, if the overcoming of a certain partiality in our reading of the later work is to be overcome in part through our coming to see wherein the genuine (as opposed to the standardly supposed) partiality of the earlier work lies, then we run the risk of missing both in missing either.

This is a good moment to cast a glance at the form that standard book-length treatments of Wittgenstein often assume. ${ }^{71}$ What such a glance, if appropriately directed, can bring to light is a kind of damage that Wittgenstein's teaching has been made to suffer in the course of its ongoing putative dissemination-a kind of damage that is wrought by a lopsided approach to reading Wittgenstein's work. What I have in mind here is a kind of approach in which the old way of thinking is viewed through the lens of the new to such a degree that the reader is no longer able to recover any independent view of the former. It is this approach to reading Wittgenstein (and the conception of the relation between the early and the later work that it engenders) that leaves those who are attached to it with the impression that resolute readers have left themselves with no room for a story that accords his later criticisms of his early work an appropriately severe weight. If we think of the book that Wittgenstein wished to publish (through binding its two halves into the single volume with one set of covers) as a Bildungsroman, then the following mostly seems to be true of the literary criticism to which it has been subjected: the beginning of the story is always read by those who have done much more than just peek ahead to the later chapters, thereby running the risk of depriving themselves of an experience of a first reading of the novel (and hence of a kind of reading of the later chapters that depends upon a nonretrospective understanding of the earlier chapters). Readings of the early work tend to be controlled by antecedently determined conceptions of how the story is supposed to come out, gleaned from perusing critical remarks about it in the later work prior to properly attempting to encounter it on its own terms.

In the guise of introducing us to the teaching of the Tractatus, the aforementioned book-length treatments of his thought typically begin by displaying a set of philosophical views that are simultaneously supposed to represent (1) the central doctrines that the author of the Tractatus aims to establish as true and (2) the central doctrines that the author of the Investigations aims to overthrow. Many of the views thus displayed are ones that a resolute reader would wish to include on the first list (i.e., a list of targets that early and later Wittgenstein share); whereas in these book-length treatments, the overriding aim is to exhibit substitution-instances of the doctrinal schema ("early Wittgenstein believes $p$ and later Wittgenstein believes not- $p$ "), where much 
more than just the bare outline of the schema has already been decided upon prior to a proper encounter with the early work. ${ }^{72}$ For a resolute reader the way in which much that is notably new first emerges on the scene with the advent of Wittgenstein's new way of thinking cannot come into view through such a partial approach to the old way of thinking. Yet if these are the only materials that one has at one's disposal out of which to construct a narrative about how the new way of thinking represents a break from the old, then it is little wonder that one ends up with a story according to which, even if the answers in the earlier book were wrong, the questions were not.

\section{A First Sort of Indiscriminateness}

From the point of view of a resolute reader, the distortion wrought by these standard book-length treatments of Wittgenstein's thought goes well beyond a mere mistaking of the role that the sort of item that belongs on the first list is intended to play in the dialectical strategy of the Tractatus. For these books tend indiscriminately to lump together items of this sort with a whole variety of other sorts. There is a range of different sorts of indiscriminateness in play in these narratives. We will consider two of these-the first here and the second in the next section of this paper. Both sorts are largely due to the determination of commentators to fit most of the philosophical topics present in either of the two (usually separately bound) books into a single nexus of unity-namely, that of the doctrinal schema. What the remainder of this paper will try to show is that this can lead to misunderstandings, not only of the philosophical aspirations of the early work, but equally of those of the later work. For in underestimating the philosophical achievement of the early work, one underestimates the depth at which the investigations in the later work are pitched.

The first sort of indiscriminateness has to do with the first cost of an overeagerness to display eventual targets of the later thought: a failure to distinguish at all carefully between what is central and what is peripheral to the concerns of the Tractatus. I will confine myself here to furnishing one sample of the first sort of indiscriminateness. In the early chapters, devoted ostensibly to the Tractatus, in the aforementioned booklength treatments of Wittgenstein, there prominently figure (introduced so that they can subsequently serve as targets for the putatively new way of thinking inaugurated by the Investigations) mentalistic doctrines of a sort that do not figure prominently in the Tractatus itself. Insofar as such doctrines surface at all in that text, they do so en passant and always only as objects of criticism. Their relative lack of prominence is tied in part to the ways in which the author of the Tractatus took "the great works of Frege" 73 already to have largely disposed of doctrines of this sort (in particular, through his various critiques of psychologism) ${ }^{74}$ Although early Wittgenstein's attitude toward 
such forms of mentalism is not easily reconstructed from a study of the text of the Tractatus alone, a proper understanding of his attitude toward them there is not unimportant to the task of properly entering into the spirit of his early thought. But all hope of properly orienting oneself in the text is lost if one's reading of the Tractatus is guided by the assumption that the sorts of philosophical doctrine that lie most ready to hand as objects of criticism in the opening sections of the Investigations ${ }^{75}$ must therefore figure among the central doctrines of the early work. ${ }^{76}$ Once this sort of distortion is corrected for in one's reading of the early work, the following sort of question can acquire a commendable urgency: why is it that certain doctrines apparently deemed sufficiently confused to warrant a role only on the outer periphery of the target range of the Tractatus later come to be positioned so close to the center of the target range of the Investigations? To understand this, we must better understand why later Wittgenstein comes to think that philosophical criticism needs to start at a much earlier point than the author of the Tractatus ever did. We will return to this topic in section IX.

\section{Unwitting Commitments}

[The infidel scholar begins to wax esoteric. He claims to be able to find buried doctrines in The Old Testament. This apparently requires that we look beyond the mere letter of the text to something like the spirit in which it was written or revealed. The main points of the two sections here seem to be as follows: (1) The Church Fathers are to be castigated for not having detected these hidden doctrines-the fact that they were buried apparently is no excuse for having failed to noticed them. Our author tries to show that the presence of these buried doctrines in The Old Testament clears the members of his sect of the most serious charge that the authorities of the Church have brought against them-namely, their failure to acknowledge the Miracle of the Recantation. (2) Finally, it is explained that it is only with the aid of these doctrines that a full interpretation of The New Testament may finally now be attempted.-J. C.]

\section{A Second Sort of Indiscriminateness}

Moving now to the opposite end of the spectrum, let us turn to a very different sort of indiscriminateness that a resolute reader may be pained to find in standard booklength treatments of Wittgenstein's thought. As we saw in section III, standard readers take there to be substantive doctrines that the Tractatus fully aims to espouse, even if it cannot express them (because they are ineffable); and it is just these doctrines that they take the later Wittgenstein, in his criticisms of his earlier self, to be centrally concerned to criticize. And we also saw that resolute readers take there to be no doctrines of this sort that the Tractatus wittingly aims to espouse. The two italicized phrases in this last sentence furnish a pair of clues as to how a resolute reader might wish to 
understand at least one aspect of the discontinuity between the old and new ways of thinking. If we follow out the suggestion that comes from combining these two clues, we arrive at the following formulation-one that allows us to see how the incredulous question may fail to hit its mark:

Any philosophical commitments that Wittgenstein is later concerned to criticize in his old way of thinking are moments in it of a sort that his old self would have been unable to recognize as sufficiently contentious to require special vindication-let alone vindication through the activity of constructive philosophical theorizing (i.e., the sort of activity that it is the whole point of Tractarian elucidation to supplant).

I will henceforth refer to such moments in the Tractatus as "unwitting commitments." To say that they are unwitting commitments is to say that the author of the work would not have been prepared, at that time, to see them as open to challenge: they are not in view for him as commitments. To say that each of them is an unwitting commitment is to say that the author of the work is nonetheless committed to (1) there being something intelligible to think along the lines represented by each, and to (2) affirming in each case the truth of what is thereby thought. As we shall see, the crucial problem arises here, for the author of the Tractatus, not so much in his entitlement to (2) — as it might for other authors—but rather already in his entitlement to (1). To make any one of these commitments fully explicit is already to bring our author into conflict with himself.

In the next section of this paper, I will attempt to specify some of these unwitting commitments in the form of a list-as a means of introducing the concept of the second list. Once the possibility of such a list is firmly in view, it should be conceded that a resolute reader is able to accord a central place in his reading of the later work to its criticisms of the early work. This brings us to the second sort of indiscriminateness (on the part of all standard readers and some resolute readers): the failure to distinguish between the items that belong on the first list (merely apparent commitments) and those that belong on the second list (unwitting commitments).

A brief sketch of an example of how on a resolute reading there can be room for unwitting commitments in the Tractatus is perhaps in order here. ${ }^{77}$ According to most resolute readers, the Tractarian activity of elucidation employs the tools of logical notation in order to clarify propositions. Sentences are to be translated into this notation. The outward appearance of the signs employed by the notation is designed to correlate with the symbolic structure of the proposition. The task of translating our sentences into such a notation requires that we attain clarity about what it is that we want to say with our words. ${ }^{78}$ The Tractatus holds that, prior to the translation of a meaningful proposition into such a carefully designed notation, the real logical 
structure of the proposition is not easy to gather from its appearance-it remains hidden beneath the outward (surface-syntactical) clothing in which it is wrapped in ordinary language. If a sentence is successfully transposed into the notation, then the logical structure of the proposition is brought to the surface, where it can now lie perspicuously open to view. According to resolute readers, if we are to take the avowed aim of the early work seriously, then it is essential to appreciate that a commitment to the employment of such notation does not itself constitute part of a doctrine about anything for the author of the Tractatus. He saw the significance of the notation as resting upon (not some bit of philosophical theory purporting to establish its significance, but rather) its use. ${ }^{79}$ Its significance as a tool of clarification was to be demonstrated through its practical application in the context of the activity of making the philosophical problems completely disappear. The notation would expose the nature of our confusion and would help to lay bare when we had only apparently conferred a determinate method of symbolizing on our signs. The proof of its value would lie in the pudding of its results. Not only was it not to rest upon a philosophical theory, it was supposed to help wean us from our attachment to such theories.

But it is also open to resolute readers to hold that there were, underlying the author of the Tractatus's understanding of the efficacy of this elucidatory tool, latent philosophical commitments that he himself failed to uncover and interrogate-commitments of a sort that will figure on the second list—such as that there are essential features of language, that they can be captured by such a notation, that they otherwise remain hidden, that their mode of presentation in such a notation allows the true structure of our thought to lie directly open to view, and so forth. So a resolute reader may, on the one hand, respect the avowed aim of the work, claiming each of the following three things (regarding the early understanding of the practice of philosophical clarification) and holding that early Wittgenstein himself attached great importance to each: (1) that the employment of such a notation did not require its employer ever to say anything about the logic of our language, (2) that part of the point of mastering such a notation was to demonstrate that the sentences to which we are attracted in philosophy (ones that apparently do say something about the logic of our language) can be shown not to say anything, precisely by our coming to see that there is no way to translate them into the notation, and (3) that such a mastery of the notation itself allows the logic of our language to be shown (without anything "about" it ever having to be said), thereby enabling us to attain a clear grasp of the logic of our language through our attaining a clear view of what we do say when we employ language meaningfully. A resolute reader may also, on the other hand, account for Wittgenstein's later criticisms of his early self by claiming each of the following 
three further things (regarding early Wittgenstein's understanding of the significance of the notation thus employed), while holding that early Wittgenstein himself attached no importance to these things because they were invisible to him: (1) that this understanding itself carried unwitting commitments along with it, (2) that this, in turn, colored his conception of what is revealed by the notation, and (3) that this imported a philosophically nontrivial set of conceptions regarding what logic, language, and clarity themselves are.

A resolute reader therefore need in no way be committed to the idea that Wittgenstein's own self-understanding of what he was doing in the Tractatus is unmistaken. Such a reader need only be committed to the view that if we want to understand what the author of the Tractatus thought he was up to (at the time of writing the book), then we need to be clear about the terms of that original self-understanding. But claiming this is perfectly consistent with maintaining that that self-understanding proved to be, in various respects, deluded. If resolute readers are perfectly free to ascribe misconceptions to early Wittgenstein, then this means that the following is far too coarsegrained a question to allow for a division of readers into those who are resolute and those who are not: Are there important differences between early and later Wittgenstein? As is this question: Did later Wittgenstein regard the author of the Tractatus as committed to problematic metaphysical theses? ${ }^{80}$ What question will effect a proper division? We already know that this question divides them: Did the author of the Tractatus understand himself (rightly or wrongly) to have found a way to do philosophy that eschews any commitment to a metaphysical thesis? But merely having this question in view does not permit a formulation of the significant differences that separate commentators when what is at issue is a proper understanding of the relation between the author of the Tractatus and that of the Philosophical Investigations. ${ }^{81}$

\section{Reading the New in the Light of the Old}

The unwitting commitments matter here. What can be hard to understand is how the author of the Tractatus could have been able to view everything in his philosophical work through them and yet have been unable to see these commitments themselves as being in the slightest degree weighty-let alone see them, as he later did, as coming heavily laden with philosophical freight. This is difficult to understand. But not to be able to understand this is not only to fail fully to understand the Tractatus; it is to fail fully to understand the Investigations (and, above all, those sections of the Philosophical Investigations centrally concerned with the criticism of the author of the Tractatus Logico-Philosophicus). For the difficulty of understanding this feature of how things looked to the author of the Tractatus Logico-Philosophicus is internally related to the 
difficulty of understanding a central aspect of the teaching of the Philosophical Investigations. The prefatory remark asks us to view the Investigations against the uniquely illuminating background afforded by the Tractatus. This requires that we be able to view the later work through the lens of the earlier (and not just the other way around).$^{82}$ As we have seen above, most contemporary Wittgenstein scholars are drawn to read the pair of works together in, as it were, a single direction, taking their point of departure in Wittgenstein's work from the new way of thinking and working their way back to the old. Because they are thus drawn to view the Tractatus through the lens of the Investigations, it has become singularly difficult for them to imagine their way back into anything like early Wittgenstein's original position. ${ }^{83}$ This requires, above all, coming to appreciate what would have struck him as philosophically contentious and what would have struck him as merely obvious - the kind of thing to which (if one were to happen upon the peculiar idea of attempting to advance it in the guise of a thesis) everyone ought to agree.

If there are weighty philosophical commitments that later Wittgenstein is concerned to criticize in his old way of thinking that his earlier self would have been unable to recognize as such at the time of writing the Tractatus, then these will be the ones that readers comparatively better versed in Wittgenstein's later work will be least competent to separate out and properly assess (namely, as ones that possessed the peculiar sort of weightlessness that they did for the author of the Tractatus). As connoisseurs of the Investigations, it may, of course, be all too easy for them to pick out just these commitments as ones that are seemed by later Wittgenstein to be of great portent and thus evidently somehow important to a proper philosophical treatment of the Tractatus. But if they are always readers of the Investigations first and only readers of the Tractatus second, then they will be unable to appreciate the surreptitious role that these commitments play in holding up the edifice of the early philosophy. On the contrary, as disciples of the Investigations, they may be all too eager to regard these commitments as necessarily portentous and thereby fall into the error of assuming that they must have seemed no less portentous to the author of the Tractatus. They will therefore see these not just as commitments present in the Tractatus but as ones undertaken. This is primarily what occasions the second form of indiscriminateness: these readers will be happy to include sentences giving voice to such commitments on a single list together with the many other sorts of sentence they are inclined to lump together under the single broad heading: Doctrines the Author of the Tractatus Aims to Establish and the Author of the Investigations Aims to Overthrow. From the point of view of some resolute readers (including this one), such readers of Wittgenstein not only thereby conflate the varieties of role that different kinds of moment of 
philosophical reflection play in the Tractatus but they show themselves therein to be unable to exercise a form of discrimination essential to an appreciation of how Wittgenstein's old way of thinking bears on his new and vice versa.

We earlier touched on the topic of a lop-sided approach to reading Wittgenstein. This approach can be seen to exact an additional cost here. For the achievement of any degree of appreciation of some of the central lessons of the later work involves nothing if not a cultivation of an exquisite degree of sensitivity to just how philosophically momentous and altogether noninnocuous precisely these unwitting commitments are. ${ }^{84}$ Yet much of the point of these later lessons will be missed, if one tries to assimilate them without having acquired some antecedent sense of how someone as hell-bent on avoiding philosophical theses as the author of the Tractatus could have persisted in viewing commitments such as these as philosophically innocuous. Indeed, some of the sorts of misunderstanding that we have just touched upon (that flow from the aforementioned one-sided approach to reading the Investigations) are arguably part of what Wittgenstein hoped to forestall through the prefatory remark.

We are now in a position to bring a number of points together. The criticisms of the very idea of a resolute reading that have hitherto concerned us in this paper (from the basic initial question to the complaint of the incredulous inquirer) rest upon a failure to get any of the following five things a resolute reader may hold into focus: (1) that a commitment to resolution does not preclude a reader of the Tractatus from distinguishing between items that belong on the first list (i.e., apparently substantive commitments that are to be discharged as merely illusory) and those that belong on the second list (i.e., undischarged commitments that are unwittingly retained as such), (2) that a proper reading of the Tractatus requires an appreciation of how the unwitting commitments can persist in the face of the avowed aim, (3) that such an appreciation is something that the Philosophical Investigation aims to impart, (4) that therefore a proper appreciation of both the unwitting commitments of the Tractatus and the correlative teachings of the Philosophical Investigation requires that each of these works be read in the light of the other, and thus (5) that in the absence of a resolute reading of the early work something central to the teaching of the later work must go missing in our reading of it.

\section{Another List}

[Our author returns to making and seeing lists. (1) An actual list is presented in which each item on it is meant to correspond to one of the buried doctrines that the young Ludwig himself inexplicably failed to see at the time of his Vision of the Ladder. (2) Again, not content with a merely terrestrial list, the infidel 
revives yet another apocryphal account of a vision, apparently also had by some nameless saint (possibly the same one as before, though there is also a suggestion that perhaps this vision was enjoyed by Ludwig himself after he returned from his wanderings in the desert). Some scholars, I believe, refer to this as The Vision of the Second List. In any case, this second vision is, again, of a divine list. (3) Our author then becomes preoccupied with comparing these four lists, two actual and two spiritual. It turns out that each is quite different from the others. (4) We then return to issues in infidel dogmatics concerning the limits of the extent to which infidels are obliged to agree with one another, how their discussions ought to be conducted, and what to do about the zealots in the sect. Our author gives some hints as to why he himself favors a mild form of heterodoxy and finds zealotry distasteful. The larger point of the whole section seems to be that what is seen in The Vision of the Second List illuminates both why the Miracle of the Recantation transpired and why The New Testament had to be written.-J. C.]

\section{Another Actual List}

Again, there are many possible variations on the actual list below that would have sufficed for our present purpose-though none of them is without its troubles. As we shall soon see, a reader constrained by nothing more than a bare commitment to resolution will encounter a variety of sorts of difficulty in trying to offer a specification of the unwitting commitments in anything that approximates the form of a list. Once again, the difficulties that arise here will be instructive in clarifying the sorts of philosophical and exegetical difficulty that must beset any attempt to offer anything approaching a resolute account of the relation between the thought of the early and that of the later Wittgenstein. ${ }^{85}$

Before we turn to the actual list below, it might help briefly to remind ourselves what sorts of moment in his early work are singled out for attention in Wittgenstein's later criticisms of it. Here is a representative passage that, I take it, attempts to summarize an aspect of how things looked to his early self at the time of writing the Tractatus:

But now it may come to look as if there were something like a final analysis of our forms of language, and so a single completely resolved form of expression. That is, as if our usual forms of expression were, essentially, unanalysed; as if there were something hidden in them that had to be brought to light. When this is done the expression is completely clarified and our problem solved.

It can also be put like this: we eliminate misunderstandings by making our expressions more exact; but now it may look as if we were moving towards a particular state, a state of complete exactness; and as if this were the real goal of our investigation. ${ }^{86}$

This is a characterization of how things came to look to the author of the Tractatus at the time of writing that book. It is a characterization of some of the implicit philosophical preconceptions that came with his earlier practice of eliminating misunderstandings by subjecting the sentences that occasioned them to his earlier procedures of 
interrogation-preconceptions regarding what must be involved in the prosecution of such an activity for eliminating philosophical perplexities (that it must involve, e.g., a transition from a state of comparative inexactness in our mastery of language to a state of complete exactness in which our relation to our words and their essential possibilities of meaning can be laid completely bare and open to direct view). The target in this passage therefore is not the set of items that figure on the first list-the philosophical doctrines that (resolute readers must hold) already figured as candidates for dissolution through the activity of clarification in the Tractatus. Rather the target here (resolute readers may hold) is the undissolved metaphysical residue that came with his early understanding of what such an activity must itself involve (an uncovering of hidden structure) and the (exact and essential) character of that which is thus brought to light.

Again, rather than specifying the commitments here at issue by picking out swatches of text drawn from the Tractatus in the form of particular quotations, I do so again, on the actual list below, by specifying particular preconceptions about how things must be that figure centrally in the book and to which any sensitive reader of the Investigations cannot help but attach importance-only now what are at issue are philosophical conceptions from which the author of the Tractatus failed to wean himself (rather than, as before, ones from which he attempts to wean his reader). Again, this procedure will allow us to achieve a higher degree of clarity and generality in specifying the relevant sorts of commitment than would be possible if we confined ourselves to the letter of their manifestations in the text. The need for such a procedure, with respect to the items on this list, is even greater than with the previous list because (though some figure fairly explicitly in the text) many of the relevant commitments are incurred in a relatively oblique, peripheral, implicit, or otherwise indirect fashion, and several are, as it were, textually off-stage. So, with these provisos in mind, I offer the following candidate formulations of some of the unwitting commitments:

1. The logical relations of our thoughts to each other can be completely shown in an analysis of our propositions.

2. These relations can be displayed through the employment of a logically absolutely perspicuous notation.

3. Through the employment of such a notation, it is possible for propositions to be rewritten in such a way that the logical relations are all clearly visible.

4. A proposition must be complex. ${ }^{87}$

5. Every proposition can be analyzed. ${ }^{88}$

6. Logical analysis will reveal every proposition to be either an elementary proposition or the result of truth-operations on elementary propositions. 
7. All inference is truth-functional.

8. There is only one logical space and everything that can be said or thought forms a part of that space.

9. There is such a thing as the logical order of our language.

10. Antecedent to logical analysis, there must be this logical order-one that is already there awaiting discovery-and it is the role of logical analysis to uncover it.

11. By rewriting them in such a notation, what propositions our propositions are will become clear. ${ }^{89}$

12. By rewriting them in this way, it will also become clear what all propositions have in common.

13. There is a general form of proposition and all propositions have this form.

14. In its thus becoming clear what propositions are, it will also become clear how misleading their appearances are-how much the outward form disguises the real hidden logical structure.

15. A logically perspicuous notation is the essential tool of philosophical clarification.

16. Through our inability to translate them into the notation, despite their resemblance in outward form to genuine propositions, certain strings of signs can be unmasked as nonsense, that is, as strings of signs to which no determinate meaning has been given.

17. All philosophical confusions can be clarified in this way.

18. By demonstrating the significance of this tool and its application in the activity of clarification, the problems of philosophy have in essentials been finally solved.

Each item above is associated with something that a resolute reader may hold that the author of the Tractatus (1) was committed to (given his conception of how philosophical elucidation proceeds and the role that a perspicuous logical notion must play in it), (2) would not have taken to be in any way inconsistent with his aspiration to eliminate metaphysics (by means of an activity in which no philosophical theses are propounded), and (3) would not have taken to be a contentious theoretical commitment (let alone one that was somehow peculiarly his).

\section{The Second List}

As with "the first list," the expression "the second list" will not serve its intended purpose here if defined through an enumeration of some actual items in some definite order-say, the items on the actual list above in the order given. The actual list above is of examples of candidate formulations of philosophical commitments that 
underlay the conception advanced in the Tractatus of how the activity of philosophical clarification ought to proceed. The point of furnishing such a sample of candidates is to attempt to gesture at the sorts of thing that might be held by a resolute reader to belong on the second list. To say that an item belongs on the second list is to say that it is the sort of thing that a resolute reader ought to hold is to be counted among the unwitting commitments retained by the author of the Tractatus. As we shall see, there is plenty of room for disagreement about what ought thus to be counted.

\section{Comparing Lists}

The point of the first actual list was to bring out how the doctrinal schema distorts our understanding both of the avowed aim and the avowed method of early Wittgenstein's philosophy, thereby occluding important moments of continuity between his old and his new ways of thinking. The moment of continuity in aim is to find a way to do philosophy that does not consist in putting forward philosophical theses. The moment of continuity in method is to specify a series of steps that a reader can take that will allow her to pass from a state of philosophical perplexity to one of clarity in which the philosophical problems completely disappear. A proper arrangement of the items on the first list would be a specification of how the early method is to achieve the aim. The point of the second actual list is to bring out how, within an acknowledgement of these overarching moments of continuity, due weight can be given to the incessant effort on Wittgenstein's part in his later writing to purge himself of (what he evidently took to be) the deeply rooted philosophical misconceptions of his earlier self. The second actual list thereby attempts to illustrate the extent to which, from the standpoint of his later thinking, there was an entire metaphysics of language tacitly embodied in his earlier method of clarification.

It is instructive to notice how many of the questions that were of concern in connection with the first list have no application in regard to the second. Let's first consider questions regarding the shape of the list. We saw before that questions about how properly to understand the philosophical dialectic in the Tractatus were related to questions about how to arrange items on the first list. One's understanding of the book could be sharpened through reflection on which items should come comparatively earlier and which comparatively later on the first list. Such reflection can no longer pay the same dividend when it comes to the second list. We can give it a shape. But there is nothing which is the shape it had for the author or was meant to have for a reader of the Tractatus. The philosophical preconceptions which figure as separate numbered items on the actual list above certainly do form a kind of unity-to hold 
any one is naturally to begin to slide into holding many of the others. But, as long as all of the items on it properly belong on that list, not much sense is to be made of the following question: which ones did the author of the Tractatus take to be comparatively primitive and which comparatively derived? In this respect, the linearly ordered structure of a list is no longer really apposite here, and some other arrangement (a circle?) would serve better.

The whole point of the second list is that all the items on it figure as equally primitive in his thinking. And this means: once one goes about making such a list and begins to see how long it can become, one begins to see how much hidden dogmatism there is in the book. To see some of these items as requiring derivation from the others would be to allow at least some of them to come into view as the sort of thing (1) to which one may not yet be entitled since a nontrivial commitment is incurred, (2) to which one can then labor to vindicate one's entitlement, and (3) to which one can then have acquired entitlement (having successfully discharged that labor). Wittgenstein's later criticism of his early self (insofar as it pertains to those aspects of his old way of thinking that correspond to items on the second list) is not directed at instances of step (2) or step (3) in this thinking, but at his inability even to get to step (1). This is not to say that there is no point in arranging things on the second list. ${ }^{90}$ It is only to say that there is no point in asking the following: which arrangement, from the point of view of the author of the Tractatus, is a placing of items in the right order? To allow the items in question to come into view on an understanding of each that coherently admits of such a question regarding its relation to the others is to have them in view for oneself in a way that they were never in view for him.

Now let's consider the sort of issues that invited the employment of a parenthetical notation in the representation of the first of our two actual lists. No parentheses occur in the second actual list. But, more to the point, parentheses cannot play the role here that they did formerly. (Instead we now find a different form of notation for which no need was felt formerly: the italics.) What is at issue in the first actual list are commitments that for the author of the work are merely apparently substantive (though for the reader they can only gradually come clearly into view as such); whereas what is at issue now in the second actual list are commitments that are neither merely apparent nor philosophically innocuous (though for the author they cannot come clearly into view as simultaneously neither). With the first actual list, at many junctures, an item on it could have been replaced with something that had the form of its logical opposite, without threatening its candidacy for inclusion. Recall the main respect in which the first actual list differed from a standard reader's list. For standard readers, logically incompatible propositions crowded one another out as candidate items because they 
were to be associated with genuine (albeit ineffable) insights into the nature of thought, language, and reality, and their negations were to be associated with denials of those insights. For resolute readers, (apparently) opposed items did not crowd one another out as candidates for inclusion on the first list since they were all equally to be associated with merely apparent insights into the nature of thought, language, and realityall equally to be overcome. In this respect the items on a resolute reader's version of the second list resemble those on a standard reader's version of the first list: in both cases, the negations of the items on the list do not belong. ${ }^{91}$ Any alternative understanding of the items on the actual second list above (that would admit of their negations also being placed on the list) would threaten the underlying conception of the logic of our language (that underwrites the logically perspicuous forms of notation upon which the activity of Tractarian elucidation relies). This conception requires that there be a significant asymmetry for the author of the Tractatus between the items on the second list and their negations (and hence between the items on the second list and those on the first) — an asymmetry that his understanding of the activity of philosophical clarification both requires and to which it cannot be entitled.

Tremendously delicate questions attach to the issue of where one should draw the line between the first and second lists. The line cannot be a bright one. These questions become particularly evident if one considers any of items $5,6,12,13$, or $17-$ items in which the surface form of the proposition already strongly suggests that what must be at issue is an attempt to quantify over all (possible) propositions-a fairly reliable (though not surefire) ${ }^{92}$ telltale surface-syntactical sign, by the lights of the author of the Tractatus, that no determinate method of symbolizing has been conferred on a propositional sign. And many of the other items have surface-syntactical forms that bespeak a corresponding aspiration to attain such an apparently maximal degree of quantificational generality - an appearance characteristic of many of the merely apparently meaningful sentences that constitute rungs on the ladder. So, once explicitly formulated (as a self-standing set of mutually self-supporting commitments) and collectively exhibited (as a list of commitments expressed in propositional form), it is difficult to see how the resulting sentences could escape a sustained encounter with Tractarian elucidatory procedures with their pretensions to intelligibility unscathed. ${ }^{93}$ Having achieved a full appreciation of the unsustainably fragile character of the items on the second list, there are two options open to a resolute reader at this point. The first is for her to take this as evidence that these items do not belong on the second list at all, but rather on the first list (and hence that there is no second list). The second is for her to take this as evidence that the author of the Tractatus was remarkably able to blind himself to the character of the apparent commitments here incurred. As we 
shall see in the next section of this paper, there is good reason to think she will only be able to make sense of the author of the Investigations (and his criticisms of the author of the Tractatus) if she takes the second option.

\section{Mild, Severe, and Zealous Mono-Wittgensteinians}

The differences between the first and second lists explored immediately above relate to clarifying how resolute readers may attach a kind of significance to the items that occur on the second list that standard readers cannot. The differences between the first and second lists explored immediately below relate to clarifying how resolute readers may thus differ from one another-differences that the mere shared commitment to resolution does not suffice to resolve. As with the first list, the proper demarcation of the second list turns on the proper resolution of these differences, and the concept of it relates to the topic over which these readers differ.

So we are now in a position to return to the matter that was left hanging at the end of our discussion of the first list: namely, why it is that, even if resolute readers agree about the items now on the first actual list, they are likely to differ over how it ought to be continued? For any quarrel about what properly belongs on the second list (and, as it were, how short it is) is, at one and the same time, a quarrel about the first list (and, as it were, how long it is) and vice versa. For, in this intramural contest between resolute readers, moving something off the second list usually means moving it onto the first. This internal connection between the topics of the two quarrels notwithstanding, the one over the second list is in some respects of a very different sort than the previous one, as we shall now see.

Their shared commitment to resolution requires of resolute readers that they agree on the following point: there are things that belong on the first list, including most of what is ascribed to the Tractatus by standard readers. Their shared commitment to resolution does not, however, oblige them to agree on this point: there are things that belong on the second list. Some resolute readers may wish to place (perhaps along with many others) all of the items on the actual list immediately above on to the second list; some may wish to place only a few of these on to it (perhaps along with a few others, moving the rest to the first list); and some may wish to place none there, holding that a proper understanding of the Tractatus requires that all apparent candidates for the second list are only merely apparent candidates and, before the end of the day is reached, are to be sucked back onto the first list. ${ }^{94}$ These possible differences in how a resolute reading is to be filled out correspond to positions along a spectrum of degrees of mono-Wittgensteinianism. The longer the second list: the milder the mono-Wittgensteinianism. The shorter: the more severe. If the second list shrinks to 
the point of vanishing into thin air, the degree of mono-Wittgensteinianism threatens to become toxic, inasmuch as it would appear to leave the resolute reader in question vulnerable to the basic initial question and thereby open not only to Disapproval (as any resolute reader must be) but also to Incredulity (as no resolute reader as such need be).$^{95}$

Let us call a resolute reader who holds that there are no unwitting commitments in the Tractatus a "zealous" (as opposed to a merely "mild" or a comparatively "severe") mono-Wittgensteinian. ${ }^{96}$ We need to be clear about what the mild, severe, and zealous interpreters are in disagreement about. The question that distributes them across a spectrum of comparative degrees of severity is one that we encountered at the end of our discussion of the first list: how many of the aspects of the underlying conception of the activity of philosophical elucidation (which the Tractatus seeks to practice and into which it seeks to initiate its reader) themselves constitute rungs of the ladder that we are eventually meant to throw away? A zealous interpreter maintains that the entire underlying conception of the activity is brought to implode on itself: everything on the second actual list is not only the product of a succumbing to philosophical temptation but also self-consciously put forward by the author as something that is to be recognized as such by his reader. It is only with this last clause that the moment of difference between the zealous and mild interpreters is broached, as their disagreement is not about the de re standing of the commitments of the author of the Tractatus. On the contrary, a main part of the point of mild mono-Wittgensteinianism is to be able to make sense of later Wittgenstein's efforts to dissolve the philosophical preconceptions that give rise to the unwitting commitments. ${ }^{97}$

Now how can the mild and zealous interpreters make progress in their conversation with one another? A bare commitment to resolution does not represent a principle to which any party in such an intramural squabble can appeal. But it does introduce an important constraint on how the squabble is to be adjudicated. Here is the basis of the constraint: if resolution requires a piecemeal understanding of how elucidation proceeds (as I have argued it must), then there ought not to be any wholesale way to dispose of the second list by collapsing into the first. For such a wholesale determination would require the reintroduction of a set of substantive criteria for determining what is (and what is not) nonsense. The constraint on adjudication therefore is the following: the mild and zealous interpreters' differences over how to implement their shared program for reading the Tractatus can be resolved only by turning it into a reading of the book that is no longer in the slightest degree programmatic. ${ }^{98}$ A resolute program for reading the book must be transformed into (i.e., completely spelled out as) a detailed reading of the book before it is in a position to demonstrate which 
apparent commitments are actually discharged and which (if any) are not. Her demurral from this constraint does not license a zealous interpreter to wrap herself in a mantle of purity and declare herself to be the more faithful adherent of a formerly shared resolute conception of how to read the Tractatus. Correlatively, it is not a demurral that can entitle her to view the mild mono-Wittgensteinian as somehow backsliding on the original ground of their agreement. ${ }^{99}$ On the contrary, denying the constraint is itself a form of backsliding-in particular, one of falling back into the basic mistake of the standard reading: namely, imagining that there is some criterion through which, or Archimedean point from which, the collective nonsensicality of the sentences in the book can, in advance of our interrogating them individually, simultaneously be ascertained. The only way the zealous mono-Wittgensteinian can be entitled to declare herself the victor in this squabble is by furnishing a detailed reconstruction of the entire dialectic of the Tractatus-demonstrating, step by step, how and where in an ascent up the ladder each of the (putatively merely apparently) "unwitting" commitments comes to be dissolved. A declaration of victory in this dispute in the absence of the provision of such a full reading would simply be a gesture of dogmatism.

This has a bearing on the terminology that I am seeking to introduce here. The terms "mild," "severe," and "zealous" can only be taken to distinguish degrees of resoluteness if one is fundamentally confused about what a commitment to resolution as such involves. The bare idea of resolution requires the following: if there are undischarged philosophical commitments in the book, then they are unwitting. There is nothing in the bare idea of resolution, however, that either requires or precludes that we accept or deny the antecedent of that conditional. ${ }^{100}$ So the threefold distinction introduced here between mild, severe, and zealous is a distinction along a spectrum of degrees not of resoluteness but of mono-Wittgensteinianism. ${ }^{101}$

We saw above that it is only on a misunderstanding of what resolution requires that a critic can take the bare existence of unsifted "external" evidence to be probative in a case against resolute readings as such. But (regardless of what one thinks its standing is in a dispute between standard and resolute readers) such evidence, once sifted, does threaten to become quite probative in the dispute between mild and zealous interpreters of Wittgenstein. More to the point, the zealous alternative robs a resolute reading of what strikes me as potentially its most significant contribution to an understanding of Wittgenstein's philosophy: namely, its capacity to illuminate why and how the new way of thinking is best understood against the old and what sort of criticism of the old way this is meant to involve. ${ }^{102}$ This point, taken in isolation, is not dispositive. ${ }^{103}$ Pending, however, the full implementation of a resolute program for inter- 
preting the Tractatus, it seems to me that, at least with regard to this particular intramural dispute, the present balance of available evidence ("internal" and "external" taken together) tips more than mildly in favor of a mild mono-Wittgensteinianism.

\section{The Old Way of Thinking against the Background of the New}

[We learn (1) about a kind of magic annotation of the text that can cause the buried doctrines in The Old Testament to rise to the surface for all to behold, (2) how, according to the infidel reading of The New Testament, philosophical demons are to be exorcized, especially those that are released by the satanic ink employed to reveal the hidden doctrines of the Mosaic Law, (3) how the two Testaments are to be placed with respect to each other if one is so unfortunate as to have separately bound copies of each, and finally (4) about the infidel teachings regarding Moses himself, including a blasphemous suggestion that he perhaps did not exist. (An illusion here to the mysterious epigraph from Freud?)—J. C.]

\section{Why Italics (Instead of Parentheses)?}

We saw above that there was no room (in specifying candidates for the second list) for the sort of parenthetical notation employed on the first actual list. The time has come to explain its successor: the notation of italics deployed on the second actual list. The inapplicability of the one sort of notation is internally related to the need for the other. The first sort of notation has no place because the commitments in question on the second list cannot be discarded as merely apparent. They must surreptitiously play a genuinely weight-bearing role in the elaboration of the early philosophy; and this means, for example, as we just saw, that their (putative) negations cannot join or replace them on the list. This raises the need for a form of notation in the specification of candidate items for the second list that highlights the logical or modal force of the commitment that would go missing in a complementary candidate item that sought to modify the modal dimension of the commitment-for example, by placing the relevant aspect of the commitment within the scope of a negation.

In the actual list above, the italicized expressions in each of the above sentences indicate the occurrence of a moment of (what would count by later Wittgenstein's lights as) metaphysical insistence - a moment in which a requirement is laid down. The feature of the items on this actual list that marks them out as the sort of thing that properly belongs on the second list is the way in which their insinuation of such a requirement escaped the notice of the author of the Tractatus. In some of these cases, the note of metaphysical insistence comes with an emphatic accenting of the italicized expression (such as "completely," "absolutely"); in others, the metaphysically emphatic note is already present (prior to any emphasis introduced by italicization) in the apparent modal force of the expressions themselves ("all," "every," "must"). So, 
in some cases, the role of the italics is to raise the note of insistence to a metaphysical register; in others, merely to highlight the presence of such a note. Thus, for example, if the italics were simply omitted from items 1 and 2 on the list and the adverbial expressions (formerly italicized) are construed as having their point relative to an elucidatory purpose, then the resulting sentences could easily be construed as saying something that would be perfectly innocuous by Wittgenstein's later lights. ${ }^{104}$ With items 3 through 7,12,13, and 17, the moment of metaphysical insistence comes with the modality of expressions such as "all," "every," and "must"—one that insinuates a requirement on how things must be. In items 9, 15, and 16, if the definite article were replaced by an indefinite one, the note of metaphysical insistence would vanish. And so on. This is not to say, however, that the metaphysical moment in each of these remarks is confined to the italicized portion of each. On the contrary, on the one hand, the italicized expression in each case may be understood to induce a moment of philosophical subliming that laterally affects many of the other expressions that occur in each numbered remark above- "proposition," "language," "analysis," "logical," "complex," "elementary," "notation," "thought," "relation," "meaning," "possible," "order," "in common," "general," "form," "clarity," "clarify," "perspicuous," "visible," "problems," "philosophy," "solved"-a moment of subliming to which the author of the Tractatus was himself oblivious. On the other hand, it is perhaps more accurate to put things the other way around: it is the author's tendency to sublime what proposition, language, logic, order, clarity, and so on, are-it is his prior conception of how and what these must be-that induces the requirements that the italicized expressions ("all," "every," "the") above each in its own way reflects. ${ }^{105}$

Each of the items on the list is to be associated with an example of what later Wittgenstein refers to as the dogmatism into which we so easily fall when doing philosophy. ${ }^{106}$ The author of the Tractatus would not have viewed himself as proceeding dogmatically_putting forward theses (that are to be associated with each of the items above) that might be taken by a reader to seem to call for vindication. Rather, he would have regarded each of the above as pertaining to matters that become clear through the process of clarifying propositions, and, in particular, through the adoption and employment of a perspicuous notation-a notation that enables one to avoid "the fundamental confusions" ("of which the whole of philosophy is full") ${ }^{107}$ by furnishing an absolutely clear way of expressing thoughts. ${ }^{108}$ The italicized expression in this last sentence again highlights one such undetected moment of dogmatism. But the freedom from such moments to which the later work aspires will seem easier to attain than it is if one fails to register how much of the ambition of the early program 
of philosophical clarification is to be retained in the later work, both in its peculiarity of method (providing the reader with a perspicuous representation of the possibilities available for making sense) and its peculiarity of aim (making the problems completely disappear). ${ }^{109}$ The task of the later philosophy lies in seeking a way to retain these early original aspirations to perspicuity and completeness while purging them of the metaphysical spirit with which they are unwittingly imbued in the early work. ${ }^{110}$ The point of each of the italicized expressions (in the candidate items for inclusion on the second list) is to underscore a particular moment within his early conception of clarification that must be purged in order that features of its general outline may continue to be of service in his later conception of philosophical clarification if it is to eschew any moment of dogmatism. ${ }^{111}$

\section{A Form of Expression That Strikes Us as Obvious}

Each of the italicized expressions on the above list furnishes an example of how, as later Wittgenstein puts it, the most crucial moments in the philosophical conjuring trick are the ones that are apt to strike one as most innocent. ${ }^{112}$ This directly bears on the evolution of his later philosophy in two ways. First, it is tied to his later apprehension that it is much more difficult to avoid laying down requirements in philosophy than his earlier self had ever imagined-where this is tied in the later work, in turn, to the need to develop a form of philosophical practice that can diagnose, identify, and clarify the precise moments in which such requirements on thinking are first unwittingly laid down, well prior to their manifesting themselves to the thinker as commitments of any consequence. ${ }^{113}$ Second, it required a set of procedures for the conduct of the new activity of diagnosis, identification, and subsequent clarification that would not themselves prove to carry further unwitting commitments in their train (introducing yet a further metaphysics, now newly built into the successor conception of clarification). Hence the need to develop a nondogmatic mode of philosophical correction (an, as it were, further layer of correction directed at each of the moments of correction themselves, and a further layer upon that, and so forth). An elucidatory procedure whose steps are arranged in the form of a ladder is no longer up to this task: the procedure must be able to crisscross in such a way as to allow each step in the investigation devoted to exorcising a philosophical demon to itself be pondered, reassessed, and purged, in turn, of the possible latent forms of overstepping or overstatement that may unwittingly have insinuated themselves in the course of the elucidation of the original misconception. ${ }^{114}$ It is in this context (of cultivating such a nondogmatic mode of philosophizing) that a method of writing characterized by an alternation of voices (including ones of overly insistent temptation and ones of overly 
zealous correction) proves its value and comes to transform the face of Wittgenstein's authorship.

This raises many questions (regarding the aims and methods of Wittgenstein's later philosophy) well beyond the scope of this paper. It will suffice to confine our attention here briefly to the ever-recurring first step in this crisscrossing procedure-a step that has no role and can have no role to play in his earlier ladder-climbing mode of philosophical elucidation: namely, the step in which one seeks to uncover that crucial sleight of hand in the philosophical conjuring trick that is apt to strike one as most innocent. Attention to this step alone (without attending to much else that is also new and no less important in the later work) suffices for our present purpose inasmuch as an appreciation of it suffices to allow us to see: (1) why it is precisely the moments in the early work that correspond to items on the second list that come under repeated fire in the Investigations (while items that belong on the first list essentially never do $)^{115}$ qua criticisms of the author of the Tractatus, and (2) why the moment of discontinuity in question here must become invisible if one imposes the doctrinal schema (thereby permitting moments of discontinuity to come into view only if they correspond to explicit doctrines that early Wittgenstein self-consciously sought to advance and defend and that later Wittgenstein rejected). ${ }^{116}$

Wittgenstein's original aim, in writing the Tractatus, was to bring metaphysics to an end; and the method of clarification he thereby sought to practice, to achieve that end, was to be one that was itself free of all metaphysical commitments. The following remark brings out how his later writing (unlike most of the commentary on it) continues to keep this feature of his earlier thought firmly in perspective while seeking to focus attention on its problematic commitments:

We now have a theory, a "dynamic theory" of the proposition; of language, but it does not present itself to us as a theory. For it is the characteristic thing about such a theory that it looks at a special clearly intuitive case and says: "That shews how things are in every case; this case is the exemplar of all cases." - "Of course! It has to be like that," we say, and are satisfied. We have arrived at a form of expression that strikes us as obvious. But it is as if we had now seen something lying beneath the surface. ${ }^{117}$

This passage brings out nicely why things must go wrong if one's reading of Wittgenstein is organized around the following question: "Which parts of the theory that the Tractatus aimed to put forward did later Wittgenstein think was wrong?" If one reads Wittgenstein in this way, then one is apt to skip over the following seven aspects of later Wittgenstein's interest in (what one thereby calls) "the theory of the Tractatus": (1) that what we are able to see (often with the benefit of later Wittgenstein's help) as heavily freighted philosophical commitments in the early work did not present them- 
selves to the author of the Tractatus as such, (2) that it is the characteristic thing about such "theories" that, at the deepest level, they garner their conviction, not from a conscious intention to put forward an ambitious philosophical claim, but rather from an apparently innocent attention to what presents itself as a special clearly intuitive case, (3) that an unprejudiced view of such a case already appears to permit one (without any additional theoretical underpinning) to exclaim: "That shews how things are in every case; this case is the exemplar of all cases," (4) that it is therefore particularly helpful to look at examples of philosophers who are already in the grip of such apparent forms of clarity in those moments in their thinking that occur prior to any in which they take themselves yet to have begun philosophizing, (5) that it is even better, if one can find one, to look at the example of a philosopher who, in the teeth of an avowed aim to eschew any such commitments, nonetheless falls into them, (6) that the author of the Tractatus is later Wittgenstein's prime example of such a philosopher, and therefore, at least in this respect, his favorite target of philosophical criticism, (7) that the ultimate quarry of philosophical criticism here for later Wittgenstein is never this or that philosophical thesis or theoretical commitment, but rather a characteristic form of expression-one that holds us captive and strikes us as so very obvious that we imagine that it allows us to be able to penetrate the appearance of language and see what must lie beneath the surface.

\section{Aligning the Old and New Ways of Thinking}

"So this is what you are saying: Later Wittgenstein disagrees with early Wittgenstein because he thinks everything on the second list belongs on the first list!" No. First of all, early Wittgenstein does not himself have (in the sense required here: as an available topic for reflection) a second list. Second, later Wittgenstein does not have a first list (in the sense required here: as something that has the form of a linear sequence of steps). What is right in this exclamation is that, from the vantage point of later Wittgenstein, the unwitting commitments could be said in a sense to belong on something like a first list in that they, too, like the items that were to have been placed on the first list, stand in need of philosophical interrogation. But the "in a sense" and "something like" matter here. The first list was supposed to represent the rungs of a ladder; and there is no ladder, in this sense, in Philosophical Investigations: not only because the topic of "the right order" no longer has evident application, but also (mild mono-Wittgensteinians may maintain) because the envisioned task now requires the composition of a very different kind of a book informed by a very different conception of philosophical clarification-one that no longer can take the form of a ladder made up out of philosophical temptations, but must now be made up instead out of 
a crisscrossing series of investigations punctuated by voices other than merely that of philosophical temptation. (That voice must now be joined by other voices: a voice of correction, a voice of reminding, a voice that asks us a question that we must answer for ourselves, a voice that invites us now to imagine the following, a voice that asks us if we can do what the previous voice asks us to do, a voice that asks what we would say if . . . , a voice that teaches us a new way of speaking, and so on.) A linear metaphor of an ascent (a ladder) here gives way to a nonlinear metaphor of a movement that stays close to the ground-of peripeteia (a crisscross). It is open to a mild monoWittgensteinian to take this to be the sign of a severe degree of change in Wittgenstein's thinking. ${ }^{118}$ What makes her a mono-Wittgensteinian is only her insistence on the forms of continuity that invite Disapproval. What makes her a mild one is that nothing in her mono-Wittgensteinianism precludes her from understanding the forms of evolution Wittgenstein's thinking undergoes as being anything less than quite extreme, providing they are consistent with those forms of continuity.

If such a reader wishes to align the old and new ways of thinking so as properly to be able to identify those moments in Wittgenstein's early thought that provide the focal points for critical attention in his later writing, then she most go about the task rather gingerly. As we have seen, what she is seeking to identify are those commitments in the Tractatus that must have appeared to the author of the Tractatus as obvious - to be the sort of thing that anyone who was thinking clearly about the matter in question would have to agree to. But this also has implications for her understanding of the character of the criticism that is directed at the unwitting commitments in the later work. In his later writing, when he draws our attention to such moments in his early thought, later Wittgenstein is seeking to show not only (1) that the crucial moments in the philosophical conjuring trick performed by the author of the Tractatus are always ones that strike him as philosophically uncontroversial, but especially also (2) how these moments in his early thought constitute singularly illustrative exhibits of the sort of philosophical entanglement that the later work as a whole is concerned to display and dispel. Thus without a proper understanding of (1), we must fail also to understand (2), and hence an important dimension of the later work as a whole.

Throughout his later work, Wittgenstein is pervasively concerned to practice a method of philosophical investigation that enables us to locate those moments in the progress of a thinker's reflections in which, unbeknownst to himself, he first broaches philosophical ground-those moments in which, though nothing beyond the obvious seems yet to have been asserted, a note of metaphysical insistence has already crept in and an unwarranted requirement has been laid down. The items on the second list 
help us to see how and why the author of the Tractatus provides the author of the Investigations with his favorite example of such a thinker. Since the crucial moments take place at a stage prior to any at which the author of the Tractatus imagines the activity of propounding substantive philosophical doctrine to have begun, it must also remain unclear in Wittgenstein's later attempted reformulations of his early ideas at which moment he can be said to have successfully pinpointed a transition from the philosophically innocuous to the philosophically momentous. This requires that he circle around such remarks, essaying a variety of formulations, assessing the extent to which a moment of unearned insistence has crept into a wording of one of his early ideas. It is worth noticing how unlike the actual method of the Tractatus such a practice of circling is. ${ }^{119}$ Early Wittgenstein is eager to drive his reader up the ladder, so that he can surprise her at the top. ${ }^{120}$ Whereas later Wittgenstein is concerned, first and foremost, to try to slow his reader down and keep her close to the ground, so that he can spot the precise moment at which she first touches so much as a toe to the bottommost rung of any ladder of words that might appear to enable her to ascend up into philosophical space. ${ }^{121}$

A resolute approach to reading the Tractatus is of especial benefit in helping to bring more sharply into relief this aspect of Wittgenstein's later philosophical practice-the one that is concerned with identifying our moments of transition into philosophy. As long as the assumption remains in place, however, that the aim of the Tractatus is one of propounding a set of substantive metaphysical doctrines, then the importance of the moments in his old way of thinking that correspond to items on the second list must remain invisible. If a reader fails to appreciate the extent to which (what Wittgenstein later regards and criticizes as) the central philosophical commitments of the Tractatus were of such a sort that they were able to appear to its author, at the time of writing, not to be "philosophical doctrines," then that reader will also fail to appreciate wherein the later task of criticism lies-and therefore also how this task applies to the reader himself and his own thinking. He will take the point to be to derail a train of thought that is already far under way and has fully come into view for the thinker as a philosophical theory with a determinate set of commitments. He will thus fail to see that an important dimension of the aim of the investigation is to heighten the reader's awareness of his tendency to stray unwittingly into a moment of metaphysical insistence, while occupying what he takes to be the solid ground of merely affirming things (that anyone thinking clearly ought to view as) innocent of such commitment.

We can now return to the question we left hanging at the end of our discussion of the first sort of indiscriminateness, at the end of section VI. We saw that, once the sort of distortion it introduces is corrected for, the following question can arise: why 
is it that certain doctrines apparently deemed sufficiently confused to warrant a role only on the outer periphery of the target range of the Tractatus later come to be positioned so close to the center of the target range of the Investigations? It is precisely these comparatively offstage moments in the Tractatus that later Wittgenstein wants to show are where the most fateful conjuring tricks-the ones performed by the author of that early work on himself-take place. So, with respect to its bearing on his early thought, the point of reopening questions about how a word can come to be correlated with a meaning, whether a mental act can effect such a correlation, and so on is, not to charge his earlier self (or, say, Frege) with the (e.g., mentalistic) philosophical "theories" that are apt to present themselves as the most immediate temptations in reflecting upon these questions, but rather to bring out how philosophically fateful the character must be of the very first steps taken in any attempted rejection or correction of just such temptations. For it is here, precisely in the vehemence of its rejection of these temptations-especially in its immediate recoil from (a certain picture of) the psychological-that the initial subliming of the logical takes place, mostly offstage, in the text of the Tractatus. ${ }^{122}$

If we fail to appreciate the depth of the antimetaphysical aim of the Tractatus-if we fail to understand the radically antidoctrinal character of the author's undertaking in that book-and look instead for explicit doctrines of the sort we would look for in other books, then most of what we will end up identifying as expressions of its central doctrines are items that figure on the first list- "propositions" that serve as the central targets of the early (and continue to remain targets in the later) work. If equipped with such an understanding of how the old way of thinking aligns with the new, we then set about the task of writing a commentary on the opening sections of the Investigations in which, each time such a philosophical temptation manifests itself, we provide a helpful scholarly indication of which Tractarian doctrine the temptation in question is supposedly to be associated with, we have not only misled the reader of our commentary about the character of the philosophical undertaking of the Tractatus, but we have severely harmed her chances of understanding the character of the investigation before her in the opening pages of the Investigations-and how it bears on the comparatively direct criticism of the early work that first begins several dozen sections further on in the text. In their eagerness to mark the discontinuity between Wittgenstein's early and later philosophies, such commentaries simultaneously obstruct the reader's access to both what is newly distinctive in the later conception of philosophical clarification and what is specifically at issue in its very particular criticisms of what was already comparatively distinctive in his earlier conception of philosophical clarification. 
An insistence on this point in no way commits a resolute reader to having to hold that the discontinuity between Wittgenstein's early and later philosophy is somehow of a lesser magnitude of philosophical momentousness than is supposed by the authors of these (standard) commentaries. It only commits her to having to hold that it must be of a very different sort than commonly supposed-that we need to look at the later writing in an altogether new way in order to comprehend the full enormity of its break with his old way of thinking. Indeed, we are now in a position to see why the degree of continuity in aim and method must be severely limited-and thus why it does not follow that resolute readers as such are committed to holding that Wittgenstein in no way altered his conception of the aim of his philosophizing, its method, or what is involved in liberating oneself or others from philosophical confusions or illusions. Their insistence upon a heterodox degree of continuity notwithstanding, mild mono-Wittgensteinians will be no less insistent in emphasizing a strong contrast between Wittgenstein's early and later understandings of the aim and nature of the activity of philosophical clarification. This, in turn, will be tied to their insistence that we come to appreciate the difference between the sorts of items that belong on the first list and those that belong on the second list. Indeed, the difference between these two sorts of item may take on a further relevance in this connection. For an important respect in which they differ can now be seen to be tied to an important distinction in Wittgenstein's later thinking (one that can have only a very attenuated parallel in his early thinking): namely, the distinction between criticism of a full-blown theory (a form of philosophical commitment some of whose overt assumptions and implications lie open to view to proponent and critic alike) and criticism of a picture ${ }^{123}$ (i.e., a way of looking at things that is like a pair of glasses on our nose through which we see whatever we look at, but which it never occurs to us can be removed). ${ }^{124}$ What the reader of the aforementioned commentary on the Investigations will be deflected from getting into focus is the degree to which later Wittgenstein regards his earlier self as in this sense held captive by a picture of language-that is to say, already standing on metaphysical ground without his having then realized it.

We can now see better why it is precisely its lack of overt commitment to philosophical theory that renders the Tractatus such an ideal object of comparison for the Investigations. It is just this feature of the work that enables philosophical criticism of it to proceed in the absence of the usual distractions presented by the products of fullblown theorizing. This allows for a desirable form of focus in an investigation that seeks to excavate and characterize the role that a picture can play in the funneling of philosophical thought. Early Wittgenstein's targets of criticism were philosophical theories of thought, language, and reality, and the primary aim was to achieve freedom 
from such theory; whereas later Wittgenstein's primary objects of criticism are the forms of philosophical fixation and insistence that come with being held captive by our pictures of thinking (as, e.g., a kind of inner process), language (as, e.g., a game to be played according to rules), and reality (as, e.g., that which is coordinate with description). ${ }^{125}$ And this is correlated with a fundamental difference in aim: to achieve freedom from the forms of philosophical fixation and insistence attendant upon being held captive by a picture-a dimension in aim that is both necessarily absent from his early work (given its subservience to various forms of fixation and insistence-such as in its conception of the role of a Begriffsschrift in philosophical elucidation and what is revealed through its application) and necessary to (so he later thought) the successful completion of the task that he already sets himself in that early work (of making the problems completely disappear). Not only are resolute readers as such therefore in no way precluded from taking there to be profound discontinuities between Wittgenstein's early and later thought, but, on the contrary (if later Wittgenstein viewed his early work as an exemplary illustration of how, in philosophy, one can take oneself to have resolutely eschewed all metaphysical commitments while still remaining knee-deep in them), then a resolute reading may help us to attain a better understanding of why later Wittgenstein took his early work to be the expression of the metaphysical spirit in philosophy par excellence.

\section{Moses and Mono-Wittgensteinianism}

This raises the question: how does one go about telling which moments (in a work such as Philosophical Investigations) are ones in which later Wittgenstein is concerned to advance criticisms of the Tractatus? The tendency here is tacitly to assume something like the following: if a passage does advance a criticism of his early work, then it, of course, is not concerned thereby, at one and the same time, also to mark a point of continuity with that work; and vice versa. This assumption is seldom made explicit, but it implicitly structures a good deal of commentary on Wittgenstein's later work. Mild mono-Wittgensteinians will hold not only that this assumption is not generally sound, but that it is only a mild exaggeration to say that roughly the opposite is true: some moment of commonality in philosophical target and/or aim can be seen to obtain between almost any passage in the Investigations (starting with its opening paragraphs and working forwards) and any number of moments in the Tractatus (starting with its closing paragraphs and working backwards). And it is even less of an exaggeration to say that one can usually perceive a further moment of fundamental opposition within each such moment of continuity-sometimes due to the presence of an unwitting commitment (that plays a weight-bearing role in the architecture of the 
Tractatus and figures later as a target of criticism) and sometimes because of the manner in which the criticism of the target is prosecuted (especially where the target is a form of philosophical theorizing that the early and later work are equally concerned to exorcize, but in very different ways).

If one chooses a passage from the Investigations more or less at random, it will often exhibit the aforementioned sort of complexity in its relation to Wittgenstein's early work. If one looks at, say, section 79 , here are some of the topics that come to the surface already in just the brief compass of an excerpt from it: "names," "reference," "existence," "propositions," "truth" and "falsity," "descriptions," "definitions," "identity" "statements," "use," "meaning," the relation between "meaning" and "use," "fixity" of meaning, "deciding" or "determining" what one means, the "independence" (or "dependence") of the truth of one proposition from (or on) that of another. ${ }^{126}$ With respect to these topics, later Wittgenstein certainly has a bone, in each case, he wants to pick with early Wittgenstein. But with respect to each, in the process of conducting this quarrel, there are also numerous moments at which, not only are aspects of the target under criticism in part ones that were already in his sights at the time of writing the Tractatus, but, in fact, he is often at pains to preserve crucial aspects of his earlier criticism of them. This dual movement of inheriting and elaborating his most valuable early insights in the very process of prosecuting his most vehement criticisms of his earlier self renders his later treatment of the ideas of his early work exceedingly delicate and dialectical.

We must be able to see Wittgenstein in this passage (i.e., section 79) trying to show his earlier self, not merely that a sentence such as "Moses did not exist" might be able to mean any of various things depending upon the context of use (because early Wittgenstein could not possibly have been more committed to that point ${ }^{127}$ ), but rather that the sorts of difference in what this form of words ("Moses did not exist") might be taken to mean in the examples adduced (in the subsequent portion of the passage) cannot be captured in terms of (even) a (resolute) Tractarian understanding of what ought to count (and what not ought to count) as a genuine difference in symbol. ${ }^{128}$ The mere slogan "meaning depends upon use" cannot mark a moment of discontinuity in philosophical conception between the Tractatus and the Investigations; but a full appreciation of the kinds of difference that differences in use here make to differences in meaning can. The point here is not just that the Tractatus's method of clarification would be powerless to elucidate the sorts of differences of meaning here at issue (neglect of which leads to philosophical confusion), but rather that the earlier method of clarification and its attendant reliance on certain tools of logical notation brings with it a substantively impoverished conception, not just of how to go about 
individuating such differences in meaning, but of what it is that one thereby individuates.

"Are you saying that later Wittgenstein would not permit the employment of logical notation in conducting a philosophical clarification of what someone means by his words?" No. First, there is no call in the later work for such a ban on logical notation. ${ }^{129}$ (A novel form of notation can often be very useful in identifying and clearing up confusions. $)^{130}$ Second, the main point is here missed: it is not the mere fact of an employment of such notation that is the culprit but rather the misconceptions that may accompany its employment. The object of the critical task here is to bring into focus the extent of early Wittgenstein's captivity to a certain picture of what is shown through the use of such notation and the forms of insistence that this gives rise to (some examples of which are detailed on the second list). One cannot exorcise these misconceptions by simply banning the notation (though once they are exorcised, the notation will be drained of a significant portion of its original philosophical eros). When the old and new ways of thinking are properly aligned, later Wittgenstein, in a passage such as this and those that follow, can be seen as indicating (1) how the earlier (mis)conception of what is shown in clarification is implicitly shaped by unwitting commitments to certain (mis)conceptions of what is involved in the analysis of propositions, ${ }^{131}$ (2) how this insinuates a particular understanding of the character of (the supposed chasm between) surface and depth grammar, and finally (3) how (this conception of) what is thus revealed through the employment of the notation, in turn, gives rise to a (further shaping of the) conception of what is really of interest to us in philosophy, namely, the underlying form of the thought, which is necessarily hidden from view and can only be brought to the surface with the aid of a logical notationa notation that captures all and only that which is essential to the logical form of the thought. That is to say, on a proper alignment of early and later Wittgenstein, it can begin to come into view how the targets here are the items on the second list.

\section{A Final List}

[Sadly, our author's mania for making and seeing lists recurs. (1) An actual list is presented in which each item on it is to correspond simultaneously to one of the buried doctrines that the young Ludwig inexplicably failed to see at the time of his Vision of the Ladder and to something that he did see at that time. Each item on this list is held also to correspond to something that the mature Ludwig was concerned to criticize in The Old Testament and at the same time something he was not concerned to criticize but rather to promulgate in The New Testament! Alas, the madness of the infidel doctrine here speaks for itself. Passing mention is even made here of a fourth list, but fortunately the suggestion is not pursued. (2) Again, not content with a merely terrestrial list, the infidel revives yet a third apocryphal account of $a$ vision of a 
divine list (though no reputable scholar has ever alluded to a Vision of the Third List). (3) Our author then begins to muse over what is seen in the vision of the third list. (4) He becomes engrossed in the most pitiable fashion in contemplating these many lists, three actual and three spiritual, abruptly concluding with final reflections on infidel dogmatics and injunctions to the members of his creed to go in for a mild form of their heterodoxy. A lost soul if there ever was one!-J. C.]

\section{A Final Actual List}

Each of the items on the list below corresponds to a moment in Wittgenstein's work, early and late, that a mild mono-Wittgensteinian may take to mark either a moment of continuity or one of discontinuity, or (alternating between variant understandings of the sentences that figure on the list) both. It would be a gross understatement, with regard to the list below, merely to say that there are many possible variations on it that would have sufficed for our present purpose. What is still true is that a reader constrained by nothing more than a bare commitment to resolution will encounter a variety of sorts of difficulty in trying to offer a specification of what belongs on this list-partly, though not merely, because of the difficulties that must attend any attempt to specify the items that belong on each of the previous two lists. Nevertheless, once again, the difficulties that arise here are immensely instructive in clarifying the sorts of philosophical and exegetical difficulty that must beset any attempt to offer anything approaching a resolute account of the relation between the thought of the early and that of later Wittgenstein.

Now, with respect to the third list, it becomes well-nigh impossible to specify the relevant items in a useful way without remaining fairly close to the wording of swatches of Wittgenstein's own text. But some delicate degree of abstraction is still required inasmuch as the items in question must also be able to mark moments of continuity. For this requires that they can be closely correlated to sentences in both the Tractatus and the Investigations. In this spirit, I offer the following small sample of candidate formulations of such moments of continuity/discontinuity in Wittgenstein's thought:

1. Every sentence in our everyday language is in order as it is.

2. There must be perfect order even in the vaguest sentence.

3. A sentence of ordinary language must have $a$ definite sense. ${ }^{132}$

4. An indefinite sense would not really be a sense at all.

5. In philosophy, we are driven to seek elsewhere, in the abstract features of an ideal language, what is already to be found in the most concrete features of our everyday language. 
6. Philosophical misunderstandings are often caused by superficial analogies between forms of expression drawn from different regions of language.

7. Such misunderstandings can be removed by substituting one form of expression for another.

8. What does not get expressed in the signs (words) themselves comes out in their application (use): what the signs (words) fail to express their application (use) declares.

9. In order to gather the logic (grammar) of what is said, we must consult the context of significant use.

10. In philosophy the question, "Why do we actually use this word or this proposition?" repeatedly leads to valuable insights.

11. The object of philosophy is the logical (grammatical) clarification of thought(s).

12. Philosophy is not a theory but an activity.

13. The result of philosophy is not a number of "philosophical propositions," but to make propositions clear.

14. Anyone who understands me eventually recognizes certain of my sentences as nonsensical.

15. We cannot give a sign the wrong sense.

16. Every possible proposition is legitimately constructed.

17. If a sentence has no sense, this can only be because we have given no meaning to it.

18. Logic (grammar) must take care of itself.

19. We cannot draw a limit to thought. That would require that we could think both what can be thought and what cannot be thought.

20. Strictly thought through, idealism can be seen to collapse into pure realism.

21. Doubt can exist only where there is a question; a question only where there is an answer; and this only where something can be said.

22. The solution of the problem lies in the vanishing of the problem.

This list has been rather haphazardly created. Part of my point below will be that such a list is not all that hard to create, once one has developed the forms of sensitivity required to make one at all. And, once one has created such a list, it will not be at all clear how it should be ordered. Each of the items on this list are to be associated (on one understanding of it) with (1) a particular unwitting preconception about how things must be and how philosophy must proceed that falls out of the early conception of clarification (and therefore is to be included on the second list), and (on 
another understanding of it) with (2) something that may be ascribed to both the author of the Tractatus and the author of the Investigations without obviously misrepresenting either (i.e., something that might therefore be included on a possible fourth list devoted merely to detailing moments of continuity in Wittgenstein's thought). It is in this latter connection that the parenthetical notation plays its role here (serving a very different purpose than before): namely, helping to bring into sharper relief such moments of continuity by allowing for the reformulation of his earlier ideas into his preferred later idiom.

\section{The Third List}

As with its predecessors, the expression "the third list" will not serve its intended purpose here if defined through an enumeration of some actual items-say, the items on the actual list above. The actual list above is of examples of candidate formulations of sentences that may equally well be taken by a resolute reader alternately in either of the two relevant ways: first, as candidate specifications of requirements that are laid down in (because not separable from) the course of the Tractatus's development of its own parochial (and, by Wittgenstein's later lights, problematic) conception of how the activity of philosophical clarification ought to proceed, and, second, as candidate specifications of those comparatively global aspects of his understanding of the activity of philosophical clarification that are shared by both the author of the Tractatus and the author of the Investigations. The point of furnishing such a sample of candidates is to attempt to gesture at the sorts of thing that might be held by a given resolute reader to belong on the third list. As long as intramural disputes between resolute readers of the sorts canvassed above continue, questions regarding the candidacy of particular sentences for the third list must also remain in dispute.

\section{What Belongs on the Third List?}

I have drawn the first five items on the actual list above from what is essentially a commentary on certain sections of the Tractatus —one that is initiated in $\$ 97$ and continues through the following sections of the Investigations. ${ }^{133}$ This is an autobiographical fact about me and where I first went to look for items to place on the third list. I take it that something like these items might have arrived on the list by a very different route, inasmuch as they each represent the sort of thing that an attentive reader of the Tractatus might find herself with occasion to say in writing about the teaching of that work. Taken out of context, some readers of Wittgenstein might take any of the first four items to suggest metaphysical elements present in the old way of 
thinking that the new seeks to undo. On the other hand, read within their dialectical context (i.e., §§97ff. of the Investigations), they do not obviously represent exclamations on the part of a voice in the grip of a wayward philosophical temptation. ${ }^{134}$ Part of my point in placing some items with this particular provenance on the actual list above is to bring into sharpest possible relief the degree to which moments of breathtaking continuity surface even in those later passages whose concern is focally one of criticizing the Tractatus. ${ }^{135}$ This means that even in those stretches of the later writing where criticism of the Tractatus reaches its highest pitch, candidates for the third list are still not in short supply. Conversely, as a matter of the mere letter of their formulation, the majority of the remaining items, starting with the eighth, on the actual list above are most easily recognized as corresponding to sentences from the Tractatus. Yet I take it that they each represent the sort of thing that an attentive reader of the Investigations might find herself having occasion to say in writing about the teaching of that work. One point of the exercise of attentively trying to construct a candidate third list of one's own is to discover the (possibly surprising) extent to which the following is true: you don't have to look far or wide in Wittgenstein's writings to find items that belong on it.

It is important here, again, that each of the items on the third list corresponds to sentences, not thoughts. Each sentence on it admits of alternative understandings of how much its affirmation commits us to, and thus of what it says. Would the author of the Investigations want to agree with that which his earlier self here would, in each case, want to affirm in affirming the item in question? When we come to the items on the third list, if we try to locate the differences between early and later Wittgenstein in this area by sorting them into the items early and later Wittgenstein agree on and those they do not, then (qua narrators of the story of Wittgenstein's development) we are lost. The only accurate thing to say here, at this hopelessly unhelpful level of generality, is perhaps the following: later Wittgenstein agrees with early Wittgenstein about each of these items (in wanting to affirm a sentence that the other would affirm), and he disagrees with him about each of them (in not wanting to affirm precisely what the other would thereby affirm). For there are significant aspects of the Tractatus's unwitting commitments that substantially color its early understanding of each of the philosophical issues associated with the items on the above list. For example, his early understanding of what is at stake in each of the following expressions (at least some one of which figures in each of the items on the list above) is implicated in the surreptitious metaphysics of the early work: "order," "perfection," "form," "vagueness," "definiteness," "sense," "logic," "language," "application," "use," "context," "say," "show," "philosophy," "abstract," "concrete," "ideal," "language," 
"everyday," "clarity," "clarification," "theory," “sign," "proposition," "thought," "strictly thought through," "solution," "problem," "vanishing."

This collection of expressions, considered as a set, nicely epitomizes both the extent of the continuity and the discontinuity in Wittgenstein's philosophy. ${ }^{136}$ A significant moment of continuity can be uncovered by reflecting on the parallels in Wittgenstein's early and later philosophies that can be associated with how these expressions occur in the Tractatus and the Investigations respectively. Yet a significant moment of discontinuity in Wittgenstein's philosophy can also be uncovered by reflecting on the points at which these parallels begin to give out (with respect to the manner in which each of these expressions occurs in the Tractatus and the Investigations respectively). What marks a sentence out as belonging on the third list is that it simultaneously invites alternate construals of terms such as these-on a first construal, the sentence in which it figures says something that early Wittgenstein has it at heart to say; on a second construal, it says something that later Wittgenstein equally has it at heart to say-where what each would mean would in part be importantly the same and in part importantly different.

\section{Putting the Three Lists Together}

In reflecting upon what to make of the items on the third list, in the context of trying to understand the relation between early and later Wittgenstein, one way of going extremely wrong is to take the possibility of constructing such a list itself to constitute a proof of the truth of some very severe variant of mono-Wittgensteinianism. But there is also an opposite way of going extremely wrong here. It takes its departure from the following (in itself perfectly sound) thought: any sort of understanding that the author of the Tractatus is able to have of any of the items on the third list must be shaped through and through, at every point, by his (metaphysically emphatic) understanding of the items on the second list. This is true as far as it goes: any attempt to construe the third list as a list of things that early and later Wittgenstein "simply agree about" may run the risk of attributing to later Wittgenstein an allegiance to items on the second list-that is, to the very commitments of the Tractatus that he is later most concerned to single out for criticism. What this shows is the following: one must be careful about taking items on the third list to represent unproblematic formulations of points of common ground between the early and later philosophy. But it would be equally point-missing to go to the other extreme and to construe the items on the third list as merely a set of ambiguous sentences that coincidentally each admit of the relevant pair of alternative understandings. It would be the ultimate in perverse poly-Wittgensteinianism to conclude that early and later Wittgenstein, while 
agreeing about nothing of importance, are for some reason happy each to call upon almost precisely the same forms of words to express their respective utterly incommensurable philosophical aspirations. Clearly the truth must be somewhere in the middle, between these two unhappy extremes (of overly zealous mono-Wittgensteinianism and overly intractable poly-Wittgensteinianism); and the telling of it is nothing if not a delicate matter, requiring exquisite care.

By reflecting upon what belongs on each of our three lists, the true complexity of the relation between early and later Wittgenstein can come into view. All three lists involve sentences that figure (or appear to be implied by sentences that figure) in the Tractatus. Commentators (such as standard readers) who wish sharply to emphasize the discontinuities in Wittgenstein's development tend to move, when identifying the early doctrines that are criticized in the later work, indiscriminately between items drawn from the first and those from the second list (as if the mere existence of items of the second sort sufficed to show that what resolute readers say about items of the first sort must be mistaken). Commentators (such as zealous mono-Wittgensteinians) who wish sharply to emphasize the continuities in Wittgenstein's development tend often to distinguish items belonging on the third list from those that belong on either of the other two, but fail not only to distinguish those that belong on the second list from those that belong on the first (as if they were all figured in the Tractatus as rungs of the ladder to be thrown away), but, in so failing, thereby also fail to appreciate the extent to which later Wittgenstein, in his criticism of items on the second list, is at one and the same time concerned to criticize his earlier self's understanding of the supposedly "shared" items on the third list. When the first (standard) note of sharpness is introduced into a narrative of the story of Wittgenstein's development, the most interesting moments of continuity are obliterated. When the second (zealous) note of sharpness is introduced, the already devilishly difficult task of balancing these moments against those of equally profound discontinuity becomes impossible.

\section{Conclusion}

I have tried to show in this essay that part of an appeal of a resolute reading may be that it permits the Tractatus to come into focus in a manner that brings distinctions between different sorts of commitment in the early work into relief. It thereby allows one to make good sense of why Wittgenstein is concerned to focus on precisely those commitments that are singled out for criticism in the passages in his later work where he is occupied with the task of criticizing the Tractatus (and thus also of why he is not drawn to mention the Tractatus when singling out for criticism in his later work items 
that figure on the first list-items that resolute readers do not ascribe to the early work). I have also tried to show that if we have the possibility of a mildly monoWittgensteinian approach to understanding Wittgenstein's work as a whole firmly in view, it should be evident that a resolute approach to reading the Tractatus should not be identified with any comparatively severe variant of mono-Wittgensteinianism. One can be simultaneously maximally resolute and mildly mono-Wittgensteinian in one's approach to reading Wittgenstein. Finally, I have tried to show, not only that it is not built into the very idea of a resolute reading as such that it involve an apologia for a severely mono-Wittgensteinian creed, but rather that its central motivation can be to improve upon existing accounts of the discontinuity in Wittgenstein's philosophy. ${ }^{137}$

\section{Notes}

1. Sigmund Freud, Der Mann Moses und die monotheistische Religion (Frankfurt: Fischer, 1975), p. 63 (my translation).

2. Johannes Climacus, Concluding Unscientific Postscript, ed. S. Kierkegaard, trans. David Swenson and Walter Lowrie (Princeton, N.J.: Princeton University Press, 1941), p. 246n (I have amended the translation).

3. To mention only some of the other notable resolute readers: Kevin Cahill, Alice Crary, Edmund Dain, Rob Deans, Piergiorgio Donatelli, Burton Dreben, Juliet Floyd, Warren Goldfarb, Logi Gunnarsson, Martin Gustafsson, Michael Kremer, Oskari Kuusela, Thomas Ricketts, Rupert Read, Matt Ostrow, and Ed Witherspoon.

4. I have allowed myself to speak here, in the first sentence of this paper, of "the resolute reading" because these are the terms in which our critics define their target. From now on, however, I will speak rather of resolute readings. For, as some of my remarks below will help to make clear, there is no reason why there should not be a variety of such readings. A resolute reading is better thought of as a program for reading the book than as itself comprising a reading (in any very demanding sense of the term "reading"). To be a resolute reader is to be committed at most to a certain programmatic conception of the lines along which interpretative questions pertaining to the text are to be worked out. The approach to reading Wittgenstein here at issue is also sometimes called "the austere reading." This seems to me an unfortunate label, as it suggests that the commitment to austerity (i.e., the claim that there is no such thing as substantial nonsense) drives the commitment to resolution rather than the other way around. It is also sometimes called "The New Reading" - another label I am not prepared to use. It is for others to judge how new it is. But it seems to me that various strands of extant resolute readings are anticipated in the writings of all of the following earlier commentators: Hide Ishiguro, Brian McGuinness, Rush Rhees, and Peter Winch. Though neither Peter Geach nor Elizabeth Anscombe could possibly be counted as resolute readers, their writings contain accounts of certain lines of "thought" (along with understandings of why the scare quotes might be in order here) that anticipate themes that 
later become central in the writings of resolute readers; see especially Geach's "Saying and Showing in Frege and Wittgenstein," in Essays in Honor of G. H. von Wright, ed. Jaakko Hintikka, in Acta Philosophica Fennica 28 (1976), pp. 54-70; and Anscombe's "The Reality of the Past," collected in Volume 2 of her Collected Philosophical Papers-the volume titled Metaphysics and the Philosophy of Mind (Minneapolis: University of Minnesota Press, 1981).

5. Meredith Williams, for example, accuses resolute readers of holding (what she calls) the strong continuity thesis; see her "Nonsense and Cosmic Exile: The Austere Reading of the Tractatus," in Wittgenstein's Lasting Significance, ed. Max Kölbel and Bernhard Weiss (London: Routledge, 2004), pp. 6-31.

6. The point here could also be put by saying: at least two Wittgensteins. With the exception of my remarks in the penultimate note, in this essay I will not have occasion to enter into the niceties that make it appropriate to insist that, once one begins distinguishing Wittgensteins, there is no particular reason to stop counting at two. Some hold that an understanding of Wittgenstein's development depends crucially upon the postulation of a further discrete "middleperiod Wittgenstein," fully distinct from either of the other two. Yet others are equally enthusiastic about the idea of a "third Wittgenstein," but wish to reserve this label for yet another, supposedly equally importantly distinctive, thinker who penned On Certainty (and perhaps also Wittgenstein's late writings on the philosophy of psychology and on color). I think there is something to be said on behalf of these claims, but the further issues they raise (in favor of identifying yet further Wittgensteins) go well beyond the scope of this essay. But the general terms of the solution this essay seeks to propose (for avoiding the impasse of mono- vs. polyWittgensteinianism) ought to be perfectly neutral with respect to the topic of the wisdom of multiplying Wittgensteins on grounds other than those addressed here.

7. David Stern actually seems to think there is something heady about this thought. He is dishearteningly representative in his willingness to assume that the standing situation in Wittgenstein scholarship can be summarized as follows: "[I]t is nearly always presupposed that either there was one Wittgenstein, that in essentials Wittgenstein's philosophy never really changed, or that there were two Wittgensteins, that there was a fundamental change between the early and the later philosophy." There are two things that are disheartening here: first, the idea that most commentators fall into one of these two camps (and therefore that resolute readers, since they supposedly do not fall into the latter camp, must fall into the former), and, second, that this could even seem to constitute a sensible principle for classifying commentators. There is perhaps more truth in the claim that the work of many commentators can be so classified than I would like to believe. Nonetheless, "nearly always presupposed" is a grotesque overstatement. Already starting with early work by Elizabeth Anscombe, Rush Rhees, and Peter Winch, there has been concerted resistance to the standard "two-Wittgenstein" view without any hint of an intention of seeking to exchange it for a monolithic one-Wittgenstein view. See especially Rhees's "The Philosophy of Wittgenstein," Ratio 8 (1966): 180-193; Winch's "The Unity of Wittgenstein's Philosophy," in Studies in the Philosophy of Wittgenstein, ed. Peter Winch (London: Routledge, 1969); and my remarks about Anscombe in note 134. But very few commentators, and certainly none of these three, have denied that there are significant discontinuities. Stern continues: "Very 
few interpreters seem prepared to even consider the possibility that these are restrictive and constricting alternatives, or that the best interpretation might well be one that recognizes both continuities and discontinuities in Wittgenstein's philosophical development" ("How Many Wittgensteins?" in Wittgenstein: The Philosopher and his Works, ed. Alois Pichler and Simo Säätelä, Working Papers from the Wittgenstein Archives at the University of Bergen, no. 17 [2005], p. 170). What Stern says here ("very few interpreters seem prepared to even consider") ought to strike one as a bit of a stretch, given that the revelation ("the best interpretation might well be one that recognizes both continuities and discontinuities") is a truism-true about pretty much any interesting philosopher. Plato, Kant, Russell, Heidegger, and Putnam all come immediately to mind as particularly pertinent examples about whom this is obviously true, although it is not at all easy to say how it is true. As it is especially difficult in the case of Wittgenstein to see precisely how properly to balance the continuities against the discontinuities in a full narrative of the character of his philosophical development, an emphatic pronunciation of such truisms can strike one as an empty gesture. The devil lies in the details here. It has been a central motivation of mine in developing a resolute reading of the early work-as well as of Cora Diamond'sto begin to fill in some of the requisite details here. This makes it all the more ironic that Stern claims (as do many others) that Conant, Diamond, and various other resolute readers (must?) hold "the one-Wittgenstein view." I would be happy if this essay were able to put an end to any simpleminded (or severe) ascription of such a claim to a commentator simply on the grounds that she advocates a resolute reading. As will become clear, I personally would not in the least mind the ascription of a nonsimpleminded (i.e., mild) version of the claim.

8. Wolfgang Stegmüller, Hauptströmungen der Gegenwartsphilosophie, vol. 1 (Stuttgart: Alfred Kröner Verlag, 1978), p. 524.

9. Anthony Quinton, "Contemporary British Philosophy," in Wittgenstein: The Philosophical Investigations, ed. George Pitcher (South Bend, Ind.: University of Notre Dame Press, 1968), p. 9.

10. It would take an additional note of several pages, at this point in the dispute, to detail all of the relevant literature, pro and con, on resolute readings. But certainly a good place to begin to get a sense of what such a reading involves are the essays collected in the first half of Cora Diamond's The Realistic Spirit (Cambridge, Mass.: MIT Press, 1991). Peter Sullivan offers a particularly trenchant critique of such readings in "On Trying to Be Resolute: A Response to Kremer on the Tractatus," European Journal of Philosophy 10 (2002): 43-78. It is, in the first instance, a reply to Michael Kremer's "The Purpose of Tractarian Nonsense," Noûs 35 (2001): 39-73. To mention just one collection of material on each side of the fence: see the essays collected in The New Wittgenstein, ed. Alice Crary and Rupert Read (London: Routledge, 2000), which mostly contains essays sympathetic to resolute readings, and those in the July 2003 issue of the journal Philosophical Investigations, which mostly contains articles critical of them. For an interesting attempt to sit on both sides of the fence, see Marie McGinn's "Between Metaphysics and Nonsense: The Role of Elucidation in Wittgenstein's Tractatus," Philosophical Quarterly (October 1999): 491-513. Many further pertinent articles are cited in the notes that follow.

11. The one point on which standard readers and resolute readers are generally able to agree is that they deeply disagree about how to read the Tractatus - and, in particular, how to understand 
its conception of nonsense. Meredith Williams's piece, cited above, does a nice job of laying out some of the basic points of disagreement here. For two particularly vehement statements from standard readers of their agreement with resolute readers on this point (i.e., that there really is deep disagreement here) and on no others, see Hans-Johann Glock's "All Kinds of Nonsense," in Wittgenstein at Work, ed. Erich Ammereller and Eugen Fischer (London: Routledge, 2004), 221-245, and Peter Hacker's "Wittgenstein, Carnap, and the New American Wittgensteinians," Philosophical Quarterly 53, no. 210 (January 2003): 1-23. See also Cora Diamond's reply to the latter, "Logical Syntax in the Tractatus," Philosophical Quarterly 55, no. 218 (January 2005): 178-189. But even about this supposed point of agreement there is controversy. Adrian Moore and Peter Sullivan seem to agree with each other that the differences between standard and resolute readers on even this issue are not as great as either side seems to think, thereby eradicating this one prior fixed point in the dispute. See their contributions to the symposium on "Ineffability and Nonsense," Proceedings of the Aristotelian Society (2003). Moore suggests that "there are ways of construing the two readings whereby... suddenly what seems to make the difference between them has the width of a knife-edge" (p. 180), and Sullivan doubts whether it "has even the width of a knifeedge" (p. 204). There is a way in which I am inclined to agree with Sullivan here; inasmuch as I am inclined to think that the standard reading strictly thought through must, at the end of the day, collapse into a variant of a resolute reading. This is connected to a point to which I will return below: all readers of the Tractatus must begin life as standard readers. But I doubt most standard readers would look upon this as a friendly suggestion for how to achieve rapprochement. The possibility of rapprochement seems to be envisioned by Moore and Sullivan by assuming that a resolute rejection of substantial nonsense could, if appropriately packaged, be agreeable to a standard reader. But Glock and Hacker (in their articles mentioned above), to cite just two examples, seem determined to rule out any form of détente negotiated along these lines. For an excellent discussion of Glock is freatment of this issue, see Edmund Dain's "Contextualion and Nonsemse in Wittgenstein's Tractates," South African Journal of Philosophy 25, no. 2 (2006): 91-101.

12. There are at this point a number of articles devoted in small or large part to a series of attempts to embarrass resolute readers with passages thus drawn from the later philosophy. Two of the rhetorically more refined and polemically more piquant examples of the genre are Peter Hacker's article "Was He Trying to Whistle It?" in The New Wittgenstein, ed. Crary and Read, 353-388 and Ian Proops's “The New Wittgenstein: A Critique," European Journal of Philosophy 9 , no. 3 (2001): 375-404.

13. It is therefore a consequence of a resolute reading that one must reject certain fairly standard sorts of account of how Wittgenstein's thought changed. For example, as we shall see, a resolute reading must reject the idea that Wittgenstein changed his views by giving up, in his later thought, a theory of meaning (or of anything else) that he aimed to put forward in the Tractatus. If, as resolute readings have it, he did not aim to put forward a theory of meaning (or anything else) in the Tractatus, that account of the change in his thought must be rejected. But if one assumes that the only way to account for the profound changes in Wittgenstein's thought is in terms of his having put forward a metaphysical theory or a theory of meaning or both in his earlier thought, and his having given up the theory or theories later, then one will take resolute readers to have no choice but to be committed to "a strong continuity thesis." It is this supposed lack of choice that is at issue here. 
14. For further discussion of this topic, see my "On What Ethics in the Tractatus is Not," in Religion and Wittgenstein's Legacy, ed. D. Z. Phillips and Mario von der Ruhr (Aldershot: Ashgate, 2005), 39-88.

15. "For the clarity we are aiming at it is indeed complete clarity. But this simply means that the philosophical problems should completely disappear" (Philosophical Investigations, trans. G. E. M. Anscombe [Oxford: Blackwell, 1953], §133). The point figures no less prominently in Wittgenstein's Middle Period writings:

As I do philosophy, its entire task is to shape expression in such a way that certain worries disappear.

If I am right, then philosophical problems really must be solvable without remainder, in contrast to all others.

When I say: Here we are at the limits of language, that always sounds as if resignation were necessary at this point, whereas on the contrary complete satisfaction comes about since no question remains.

The problems are solved in the literal sense of the word-dissolved like a lump of sugar in water. (The Big Typescript, ed. and trans. C. Grant Luckhardt and Maximilian A. E. Aue [Oxford: Blackwell, 2005], p. 316)

16. This then leaves the critics of resolute readings with three broad generic options for how to understand the relation between Wittgenstein's early and later thought: (1) they can contend that later Wittgenstein sought to give the correct answers to the questions that he earlier answered incorrectly, (2) they can contend that later Wittgenstein criticized earlier Wittgenstein above all on the ground that he thought that such questions could be answered, or (3) a combination of (1) and (2) in which his earlier answers to certain questions are refuted while his answers to yet other questions are made to vanish along with the questions themselves. It doesn't much matter for the purpose of this essay whether the critic in question prefers option (1), (2), or (3).

17. For a discussion of these issues, see the response to Meredith Williams's criticisms of resolute readings in James Conant and Cora Diamond, "On Reading the Tractatus Resolutely," in Wittgenstein's Lasting Significance, ed. Kölbel and Weiss, 46-99.

18. Ian Proops, “The New Wittgenstein," pp. 375-376.

19. There are in fact typically many types of passage that are brought into play when such "external evidence" is adduced by critics of resolute readings, including both of the following types: passages from the later work criticizing doctrines held by the very early Wittgenstein before he writes the Tractatus, and passages in the later work in which Wittgenstein criticizes what he "earlier" thought subsequent to his return to philosophy in 1929. Not every sort of criticism by a comparatively later Wittgenstein of a comparatively earlier one is therefore relevant to our present purpose. And, in fact, passages in the later work often need to be scrutinized carefully in order correctly to ascertain which Wittgenstein is the intended target of the criticism. The only kinds of passage that are relevant to the topic of the present essay are ones in which the criticisms are directed at misconceptions to which later Wittgenstein took the author of the Tractatus to be committed. From now on in this essay, when I speak of "external evidence," this is what I will mean. This restriction is justified inasmuch as the aim of this essay is to respond to the criticism that resolute readers are unable to account for Wittgenstein's later criticisms of the Tractatus. The introduction of such a restriction, however, threatens to introduce serious 
distortions into our understanding of later Wittgenstein if it is taken to license the assumption that all criticisms of "earlier work" are criticisms of the author of the Tractatus. I will return to this topic briefly, at the end of this paper, in the penultimate note.

20. In practice, what seems to qualify each item on the list as germane is often little more than the fact that the quotation in question contains in it expressions such as "I used to think ...," "contrary to my earlier view ...," etc. This, of course, can raise problems of the sort mentioned in the previous note.

21. The existence of such putatively damning external evidence is bound to be comparatively more awkward for a resolute reader who is willing to go so far as to hold that later Wittgenstein thought that his earlier project of philosophical clarification did not involve any commitments (and thus none that he was later concerned to criticize). I will return to this topic below.

22. Pun intended.

23. Tractatus Logico-Philosophicus, $\$ 6.54$ (my emphases). Quotations from the Tractatus will be drawn from either the David Pears and Brian McGuinness translation (London: Routledge, 1963) or the reprint of the C. K. Ogden translation (London: Routledge, 1981), or some emendation or combination thereof.

24. The characterization of such readings as "resolute" is first due to Thomas Ricketts and first used in print by Warren Goldfarb in his "Metaphysics and Nonsense: On Cora Diamond's The Realistic Spirit," Journal of Philosophical Research 22 (1997): 57-73, at p. 64; cf. also p. 73, note 10. Goldfarb's article lays out some of the issues here in dispute very well. See also Diamond's "Realism and Resolution" (which replies to Goldfarb), 75-86 in the same issue.

25. Notice: this feature of a resolute reading —as, too, with regard to each of the other features to be mentioned below-merely says something about how the book ought not to be read, thereby still leaving much undetermined about how the book ought to be read.

26. For more discussion of this topic, see my "The Method of the Tractatus," in From Frege to Wittgenstein: Perspectives in Early Analytic Philosophy, ed. Erich H. Reck (Oxford: Oxford University Press, 2002), 374-470.

27. It would be a mistake to read this paragraph as saying (as the writings of standard readers sometimes seem to suggest) that we can just go about inspecting sentences and (apart from consulting their context of use) sorting them into categories such as the sinnlos and the sinnvoll. For discussion of this topic, see Cora Diamond, "Crisscross Philosophy," in Wittgenstein at Work, ed. Ammereller and Fischer, 201-220. In the interest of keeping things as simple as possible, I will have nothing further to say about the topic of that which is sinnlos in this paper. For a discussion of some of the points that arise in connection with this topic and how to accommodate them within a resolute reading, see Michael Kremer, "Mathematics and Meaning in the Tractatus," Philosophical Investigations 25 (2002): 272-303.

28. I am alluding here to a formulation of Wittgenstein's regarding what is involved in philosophical elucidation that surfaces in passages such as the following: "[I]dealism, strictly thought 
out [streng durchgedacht], leads to realism."—and: "[S]olipsism, strictly followed through [streng durchgeführt], collapses into pure realism." The first is from Notebooks: 1914-1916; ed. G. H. von Wright and G.E. M. Anscombe, trans. G. E. M. Anscombe (Chicago: University of Chicago Press, 1979), p. 85. (I have emended the translation.) The second is from the Tractatus, 5.64. (I have emended the translation.) For further discussion of the importance in Wittgenstein's work of such a conception of thinking things through, see my "On Going the Bloody Hard Way in Philosophy," in The Possibilities of Sense, ed. John Whittaker (New York: Macmillan, 2003).

29. Many critics of resolute readings notice that resolute readers are committed to one or another of these corollaries without ever managing to get the guiding commitment of such a reading clearly into view. Such critics, for example, may notice that resolute readers are committed to rejecting some particular putatively Tractarian account of what makes some sentences nonsensical (say, an account based on illegitimate syntactical combination), while assuming that a resolute reader must share with the proponent of a standard sort of reading the idea that the charge of nonsense leveled at the end of the Tractatus is to be underwritten by some theory-be it one that is advanced within the body of the work or one that is imported into the work from the outside. These critics thereby assume that these readers must want to substitute some alternative theoretical account of the grounds of sense for the particular one under criticism. These critics then become understandably very puzzled about how such a reading can possibly be thought to be sustainable. For they assume that the discovery that there are no logically distinct kinds of nonsense is itself arrived at through the elaboration and application of a theory of sense that these readers are now committed to viewing as having somehow been successfully articulated by the author of the Tractatus, even though the propositions by means of which it is to have been articulated have been relegated to the status of mere nonsense. This then leads to the criticism that the resulting reading renders the propositions of the book too semantically impoverished to be able to articulate the theoretical resources required to fund the conception of the nature of nonsense that the readers in question are committed to ascribing to the work. I enthusiastically endorse this line of argument as a criticism of a possible (misguided) reading of the Tractatus. But it is a species of irresolute reading that is here criticized. (For further discussion of this point see Conant and Diamond, "On Reading the Tractatus Resolutely.")

30. This idea that we can grasp what certain sentences would say if they had a sense is sometimes called chickening out. See Diamond, The Realistic Spirit, chapter 6, especially pp. 181-182, $194-195$.

31. I am indebted, in rather different ways, for this suggestion to Johannes Climacus, Concluding Scientific Postscript, and to Meredith Williams, "Nonsense and Cosmic Exile." For a less abbreviated version of the repudiation of the claim that Ludwig adhered to anything like The Dogma of the Paradox, see part 2 of Conant and Diamond, "On Reading the Tractatus Resolutely." For discussion of the connection between Climacus's and Wittgenstein's respective ladders, see my "Must We Show What We Cannot Say?" in The Senses of Stanley Cavell, ed. R. Fleming and M. Payne (Lewisburg, Pa.: Bucknell University Press, 1989), "Kierkegaard, Wittgenstein, and Nonsense," in Pursuits of Reason, ed. Ted Cohen, Paul Guyer, and Hilary Putnam (Lubbock: Texas Tech University Press, 1992), and "Putting Two and Two Together: Kierkegaard, Wittgenstein, and the 
Point of View for Their Work as Authors," in The Grammar of Religious Belief, ed. D. Z. Phillips (N.Y.: St. Martins Press, 1996).

32. For further discussion of this example, see Conant and Diamond, "On Reading the Tractatus Resolutely," pp. 61-62.

33. See Tractatus, $§ 5.4733$.

34. A story about this can count as a version of a resolute reading only to the extent that an understanding of the author here rests upon nothing more than a cultivation of the reader's logical capacities-capacities that she exercises whenever she thinks or speaks. These capacities are honed in the context of philosophical elucidation through our learning such things as how properly to parse sentences whose surface grammar confuses us, how properly to employ the fragments of logical notion to which the author of the Tractatus introduces us, and so on. But the point of exercising such comparatively more determinate logical capacities is to refine the antecedently available general capacity that the reader brings with her to an encounter with the text: namely, her ability to discern sense, recognize nonsense, and distinguish the one from the other. It is a mistake to assume (as many standard readers do) that possession of this general capacity is something that the author of the Tractatus aims to confer on his reader through on encounter with the text.

35. For more discussion of this topic, see my "The Method of the Tractatus."

36. The German word in the text of $\$ 6.54$ to which I mean to allude here is überwinden.

37. This question has been pressed by critics of the resolute reading, most notably Peter Sullivan, and it should be pressed. I think it is fair to say that the plausibility of a resolute approach to reading the book will depend partly upon how satisfying an answer this question can be given.

38. Any two standard readers may disagree about which sentences belong in the first set; and any two resolute readers may disagree about which sentences belong in the second set. Thus any talk about such a list in the context of a more general discussion of debates between standard and resolute readers, such as the one that follows, will involve a certain degree of idealization. I will return to this topic in the next section.

39. The term "piecemeal" was, as far as I know, first employed by Warren Goldfarb in "Metaphysics and Nonsense" in connection with this issue. It is important to be clear about what, according to a resolute reading, must be piecemeal here. A remark such as the following introduces the possibility of confusing this issue with another:

Don't get involved in partial problems, but always take flight to where there is a free view over the whole single great problem, even if this view is still not a clear one. (Notebooks, 1914-1916, (2nd edition, trans. G. E. M. Anscombe [Oxford: Blackwell, 1979], p. 23)

Marie McGinn glosses this remark as follows: Wittgenstein "instructs himself not to try to treat each of the problems piecemeal" ("Wittgenstein's Early Philosophy and the Idea of "The Single Great Problem'," in Wittgenstein: The Philosopher and His Works, ed. Pichler and Säätelä, p. 100). What McGinn takes early Wittgenstein to be here instructing himself not to do (in her use of the expression "treat each of the problems piecemeal") and what resolute readers take early 
Wittgenstein to be committed to doing (in their use of the expression "treat each of the problems piecemeal") is not the same thing. I take it that the ambition touched on in the remark from the Notebooks (the ambition to attain a view of the problems of philosophy that allows them all simultaneously to come into view as aspects of "a whole single great problem") is an ambition that Wittgenstein takes himself to have realized by the time of completing the Tractatus. It is tied to the remark in the preface of the Tractatus that "the problems have in essentials finally been solved." The problems have in essentials been solved because the method of their (dis)solution has been found. The application of this method to the problems of philosophy (that require treatment by the method) is for early Wittgenstein, nonetheless, a piecemeal processthat is why the problems have been solved only in essentials, and not in their details. It is the latter distinction (between solving the problems in essentials vs. in their details) that mandates the early procedure of piecemeal interrogation of sentences that resolute readers insist upon. This opposition (between the piecemeal procedure common to the Tractatus and the Investigations and the wholesale procedure of philosophical criticism commonly ascribed to the former) is not to be confused with a more fundamental distinction in philosophical conception between the methodological monism of the early Wittgenstein (who seeks to present the method of clarification) and the methodological pluralism of the later Wittgenstein (who seeks to present an open-ended series of examples of methods-a series that can be continued in both unforeseen and unforeseeable ways). A resolute reader who insists upon things being piecemeal in the former sense need not hold that they are piecemeal in the latter sense (and therefore need not deny that there is this enormous difference in methodological conception between early and later Wittgenstein). The definite article in the title of my paper "The Method of the Tractatus" (a paper which, incidentally, insists upon the piecemeal character of any application of the method) is supposed to mark an important point of difference between early and later Wittgenstein. A resolute reader who fails carefully to distinguish these senses in which something about the early method can be said to be "piecemeal" runs the risk of falling into thinking that a bare commitment to resolution itself entails a needlessly severe form of mono-Wittgensteinianism.

40. The successive publications of a number of commentators bear witness to how considerable a span of time and effort can intervene between a first resolute recognition of the collapse of a particular sequence of rungs and a subsequent resolute recognition of the collapse of a further sequence of rungs. (For instance certain readers-who are now resolute readers-seem to have first noticed that the apparently realist doctrines in the work collapsed well before they realized that their idealist counterparts must fall, too.) That this sort of time and effort can be required to climb the ladder is one of the features of the phenomenology of seriously working with the book to which a resolute reading aims to do justice. One complaint that such readers are apt to have about standard readings is that they make the process of assimilating the teaching of the work look much easier than it is. A slightly arch way to put this point would be as follows: according to resolute readers, the Tractatus is much longer than it looks-a quarter of a century of intensive engagement with the text (judging from my own case) may well not be enough time for a reader to be able to claim to have completed a single ascent of the ladder. This seemingly bottomless character to the task of simply working through the text is one of the respects in which resolute readers are apt to think there is an important affinity between the Tractatus and the Investigations. 
41. Some critics of "the resolute reading" seem to think that resolute readers wish to convince us that there is some general philosophical claim (about, say, the nature of nonsense) that one is supposed to take on board right at the outset and which constitutes the proper starting point for a process of reading through the work. (See John Koethe, "On the 'Resolute' Reading of the Tractatus," Philosophical Investigations 26, no. 3 (2003): 187-204, for an example of this line of criticism.) Such critics have understandably declared themselves to be utterly perplexed about how such a process of reading is supposed to get off the ground if one is supposed to begin by taking on board a commitment to the effect that each sentence one comes across in the course of reading through the book is to be regarded as never anything more than a piece of plain nonsense. There are three basic misunderstandings here. First, it mistakes what resolute readers take to be the termini ad quem (of the activity of reading of the book) for the terminus a quo. Second, it takes resolute readers to share a standard reader's conception of wherein the recognition of nonsense (on the part of a reader) consists: namely, in the application of a set of independently available criteria (for distinguishing sense from nonsense) to the sentences of the book. Third, it takes the discovery that many of the sentences in the book are nonsense to be something that can take place wholesale rather than only piecemeal.

42. At the cost of discouraging some overly zealous professed converts, it should be pointed out here that this also means that there is no such thing as a well-founded moment of wholesale conversion to the program shared by resolute readers. Such an approach to reading the book must prove its interpretative mettle piecemeal, by illuminating how a dialectical ascent up the ladder unfolds rung by rung. This fact has been obscured by the fact that, in many of the early publications of those of us sympathetic to a resolute approach, we were initially concerned simply with highlighting the very possibility of such a program for reading the book. Such programmatic statements, however, are often read by critics (and even by some overly enthusiastic advocates) as if they purported to settle all the relevant basic questions regarding how to interpret the book rather than-as was intended-to unsettle them all, so that they can be settled again one by one. (This is not to deny the presence of infelicities of formulation and thought in these early writings. I would certainly like to omit or reword the occasional sentence or two from here or there in my earlier writings on this topic. I know that Cora Diamond feels the same.)

43. I take the difficulties at issue here not to be ones that are mere artifacts of a resolute account of this relation, but rather to be ones that themselves belong to Wittgenstein's conception of the task of philosophical criticism and, in particular, to his conception of the difficulty of that task.

44. This exercise would be pointless, however, if it were not possible to associate particular passages in the text with some of the entries on this list. I take it to be relatively easy to locate moments in the text that correspond to the following two clusters of items 1-5, 13-17. Items 6-12 on the actual list given here, however, play a rather different role in filling in the structure of the ladder. If one were set (say, as an examination question) the task of finding a passage in the text to associate with each of items 6-12, one might be surprised to discover how hard it is to find textual correlates for any of these items on the list, though it would be quite easy to associate them with things that one finds in standard commentaries on the work. (In fact, it is easier 
to find passages in the text that take issue with these items-especially item 8; see e.g., $\S \S 5.473-5.4733$.) These items therefore do no represent explicit moments of apparent doctrine in the text as much as implicit lines of "thought" into which a reader is naturally drawn: lines of "thought" that appear to provide a way of filling in the missing links that would enable one to pass from the first cluster of items to the second-a way of filling things in that most commentators on the Tractatus have found irresistible. Any specification of the rungs of the ladder in the form of a list will probably require both these sorts of item-both those that figure explicitly in the text as candidate doctrines of the work and those (to which a reader is strongly attracted in making sense of those doctrines) that figure explicitly in the text at most only as targets of criticism.

45. The actual list, given above, is in essence a pastiche, hovering somewhere between these two ways of understanding what the shape of the list ought to be. As a reconstruction of the sequence in which things occur in the text (aside from the fact that it starts things off too late, contains things that are not in the text, breaks off too early, and moves too swiftly), this list allows itself to cheat in all kinds of further ways. Yet the sequence given is even less plausible if it is meant simply to sketch a possible order according to which apparently weight-bearing moments in the text are successively discovered to collapse by some actual reader. The list is purposively constructed so as equally to invite these alternative understandings of how to understand the shape of the ladder. This means that it does not constitute a serious attempt to reconstruct the elucidatory dialectic as it unfolds in the work.

46. This asymmetry in the relations between sense/nonsense and true/false is a source of many of the confusions that the Tractatus seeks to address. Propositions do not have sense-nonsense poles in the way that they have true-false poles, so that there can still be a determinate something that we may take "the" proposition to (be striving to) say when we recognize "it" to be nonsense (as there can still be when we recognize a proposition to be false). Our reluctance to come to terms with how little we are left with if we have failed to make sense yields the peculiar phenomenology of our imagining (in our ascent up the ladder) that we are able to recognize what a piece of nonsense is trying to say even as we recognize that it is nonsense.

47. It is such an oscillation that I have briefly sought to enact in my preceding presentation of the two ways of unpacking the metaphor.

48. Peter Sullivan points out, in "On Trying to Be Resolute," pp. 46-49, that certain resolute readers seem to evince a disproportionate hostility to explanations of features of language via an appeal to features of reality and seem to evince a corresponding tolerance toward the reverse order of explanation. This can make it seem as if resolution had something "particularly to do with repudiating a certain sort of realism" (p. 47). I think it is true that certain resolute readers have written things that appear to contain such a lack of equilibrium in attitude (toward realism and idealism respectively) and that Sullivan is right that, insofar as they endorse the appropriateness of this imbalance, they thereby compromise their commitment to resolution. A full explanation of why one finds this tendency in this body of tertiary literature would require a story about how certain strains of an incipiently resolute reading evolved, early on, out of a rejection of certain realist readings. A no-longer merely incipiently resolute reading, however, should be 
equally committed to rejecting an order of explanation in either direction here, and therefore should not accord realism any privileged status as the target of criticism.

49. See the quotations given in note 28 .

50. If there figures on the list at some point both a certain form of words and its (apparent) negation, then the list can be continued in two different directions. If there figures on the list a triad of (apparently) mutually divergent philosophical options (such a realism, idealism, and solipsism), then it can be continued in three different directions. And so on.

51. With respect to questions about the relation between realism and idealism, a nice example of such a dialectical reconstruction (that offers cogent reasons for privileging a particular narrative about how things are supposed to unfold) is to be found in Thomas Ricketts's article, "Pictures, Logic, and the Limits of Sense in Wittgenstein's Tractatus," in The Cambridge Companion to Wittgenstein, ed. Hans Sluga and David G. Stern (Cambridge: Cambridge University Press, 1996), pp. 59-99; see especially pp. 88-94. With respect to the relation of both of these to solipsism, a further pertinent example of this genre of philosophical exegetical narrative (its author's public lashings of the resolute heresy in his other writings notwithstanding) is to be found in Peter Sullivan's “The 'Truth' in Solipsism, and Wittgenstein's Rejection of the A Priori," European Journal of Philosophy 4, no. 2 (1996): 195-219.

52. For discussion of the distinction between propositional sign and propositional symbol in the Tractatus, see my "The Method of the Tractatus," pp. 398-405.

53. Thomas Ricketts, "Pictures, Logic, and the Limits of Sense in Wittgenstein's Tractatus," pp. 90, 93.

54. This, in turn, means that a remark that on one construal does make sense-and, so construed, can be taken to contain an intelligible proposal (concerning, say, the employment of a certain sort of notation) or a coherent instruction to the reader (concerning, say, how the reader is to relate herself to the sentences in the book) - on another construal (if taken to form a part of one of the aforementioned collections of remarks) may involve an illusion of sense. As long as there are terms such as "proposition," "nonsense," "sign," "symbol," etc., that figure centrally in sentences that a reader is able to take as forming a part of one of the aforementioned collections of remarks, then her "understanding" of those sentences is likely, in turn, to color that reader's "understanding" of all the other sentences in the book in which those terms figure. Whether a given sentence (such as, e.g., §6.54) is nonsense or not depends on how one takes it to be related to the other sentences in the book. The following challenge, commonly leveled at (nonzealous) mono-Wittgensteinians by standard readers, is ill posed: what are the marks or features that single out the sentences of the work, as they stand on the page, as being the ones that make sense from the ones that do not? The apparent inability of resolute readers to answer this question has been taken to constitute an argument against them. What a (nonzealous) resolute reader needs to hold is only that there are certain sentences of the book that a reader can (on a certain construal of them) come to understand-not: that there are certain sentences of the book that the reader is supposed to be able somehow (based on the application of some supposed criteria of meaningfulness) first to separate out from the others as those that are to be understood, 
prior to and independently of struggling with the task of working her way through the task that the author of the work has set us. A propositional sign has a perceptible sense, according to the author of the Tractatus, only given a method of employment; and it belongs to the task that the author sets the reader to discover for herself when, in assimilating the sentences of the book, she has genuinely conferred such a method of employment on her signs and when she has only apparently done so. Apart from a reader exhibiting the sort of use to which she takes the sentences she finds in the book to have been put (apart, that is, from attempting to make out a method of symbolizing that has been conferred upon them), there is no question to be asked regarding the sentences in the book (taken as mere propositional signs) as to which ones make sense and which ones do not. This is why the challenge mentioned above is ill-posed. As the author of the Tractatus might have said, where there is no question there is no answer either.

55. This is related to a question that came up earlier: namely, to what degree a given resolute reader thinks the body of sentences that make up the rungs of the ladder coincides with the body of sentences that make up the text of the Tractatus.

56. T. S. Eliot, "The Music of Poetry," in On Poetry and Poets (London: Faber and Faber, 1969), p. 36.

57. A full discussion of this topic would take us well beyond the scope of this essay. But the three moments of continuity hinted at in this section of the essay should suffice to focus the questions to be explored here. For a brief discussion of further significant moments of continuity, see notes 133 and 134 below.

58. Tractatus, $\$ 4.112$.

59. Philosophical Investigations, $§ 128$.

60. After some correspondence on the topic, Ogden stays with "to make propositions clear" as a translation of das Klarwerden von Sätzen; Pears and McGuinness render it as "the clarification of propositions." Neither of these renderings is ideal; each has something to be said in its favor. Wittgenstein objects to Ogden's translation as follows:

This seems to me wrong now. I think it cannot be the RESULT of philosophy "to make propositions clear": this can only be its TASK. The result must be that the propositions now have become clear that they ARE clear." (Letters to C. K. Ogden [Oxford: Blackwell, 1973], p. 50)

One can see why Ogden might have found this unhelpful.

61. This similarity between the early and the later work, however, is already connected to an important difference. The early work is full of apparent theses that the reader is supposed to come to recognize as merely apparent theses; whereas, in the later work, part of the struggle is to find a way to speak philosophically while systematically eschewing even the appearance of philosophical assertion. I discuss this difference in modes of authorship in my "Putting Two and Two Together: Kierkegaard, Wittgenstein, and the Point of View for Their Work as Authors," pp. 293-303.

62. Tractatus, $§ 6.54$. 
63. Philosophical Investigations, $§ 464$.

64. For further discussion of this topic, see my "Why Worry about the Tractatus?" in PostAnalytic Tractatus, ed. Barry Stocker (Aldershot, U.K.: Ashgate, 2004).

65. For further discussion of this topic, see my "Wittgenstein on Meaning and Use," Philosophical Investigations 21, no. 3 (1998): 222-250.

66. This topic should be distinguished from the topic briefly touched on in note 39: is it possible to attain a perspicuous overview of all of the possible forms of philosophical confusion-so that, even if the task of philosophical treatment never comes to an end, at least the scope and shape of all the possible forms of confusion can be grasped as aspects of a single unity-a single big problem? If this were possible, then, even if there remained, in one sense, an infinite amount of work still to be done, in another, it would be right to say that the really hard part of the task will have been completed and, in this sense, the problems will have, in essentials, all been solved. This is a point on which early and later Wittgenstein sharply diverge; and this, in turn, is connected to the topic of the second list, to which we will turn below.

\section{Philosophical Investigations, p. x.}

68. There is a German edition of the two books bound together that is published by Suhrkamp Verlag (Frankfurt am Main, 1984). In this respect it comes close to respecting this wish of Wittgenstein's (and, to my knowledge, is the only volume published in any language that does so to any degree). This may have come about largely by accident: these are Wittgenstein's only two authorized book-length publications and the Suhrkamp volume in question is Band I of their Wittgenstein Werkausgabe. Those who are inclined to doubt that Suhrkamp was motivated by any desire to honor Wittgenstein's wishes here will find various grounds for their skepticism-including the following: the volume also includes the 1914-1916 Notebooks (the inclusion of which would not have struck Wittgenstein as a merely minor variation on his plan; see e.g., Letters to C. K. Ogden, p. 46), and the volume bears the following title on its cover and spine: Tractatus LogicoPhilosophicus. So there is a sense in which Wittgenstein's book still remains unpublished!

69. "A main cause of philosophical disease-a one-sided diet: one nourishes one's thinking with only one kind of example" (Philosophical Investigations, §593 [I have amended the translation]).

70. This point is first developed by Stanley Cavell in "The Availability of Wittgenstein's Later Philosophy," collected in Must We Mean What We Say? and Other Essays (Cambridge: Cambridge University Press, 1976), 44-72, and is central to the reading of Wittgenstein he offers in The Claim of Reason (Oxford: Oxford University Press, 1979).

71. Arguably part of the way that standard readings of the Tractatus first developed was through commentators attributing to the early work as substantive theoretical commitments a great many of the doctrines that later Wittgenstein is concerned to criticize, so that they could provide themselves with a tidy target at which those criticisms could be directed. Perhaps the now three most classic instances of this genre are Norman Malcolm's Nothing is Hidden (Oxford: Blackwell, 1986), Peter Hacker's Insight and Illusion, rev. ed. (Oxford: Oxford University Press, 1986), and David Pears's The False Prison (Oxford: Oxford University Press, 1987). Malcolm developed his version 
of such a narrative much earlier than the others. Malcolm's 1967 article on Wittgenstein in the The Encyclopedia of Philosophy, ed. Paul Edwards (London: Macmillan, 1967) is a fascinatingly vehement statement of the standard reading, adamant in its rejection of the possibility of an even mildly mono-Wittgensteinian view (probably directed, above all, at Erik Stenius's somewhat idiosyncratic and not at all resolute proposal for such a reading, as put forward in his Wittgenstein's Tractatus [Oxford: Blackwell, 1960]). I say at the beginning of this note that this is only part of the way (that standard readings of the Tractatus first developed) because a full story would also have to take into account the paths of reception encouraged by the work of Russell, Ramsey, Schlick, Carnap, Waismann, Black, Anscombe, Stenius, and many others. A good Rezeptionsgeschichte of the Tractatus has yet to be written.

72. This tendency is reinforced by an academic environment in which commentators spend much of their time studying each other's work and in which most of the commentary there is to study is written by authors whose interest in wrestling with the letter of the text of the Tractatus has mostly been whetted through reading the later work-and through expectations that have been thus formed regarding what sort of philosophy there must be in the early work, as well as what it is they are supposed to do with it once they find it. This generally leads to their getting down to the business of criticizing the Tractatus prematurely.

73. Tractatus, sixth paragraph of the preface.

74. This point acquires special pertinence if one thinks, as some resolute readers do, that the criticism of Frege represents a central task for the Tractatus. This is itself a topic of some controversy now-one that cuts interestingly across the standard/resolute divide. Elizabeth Anscombe, Cora Diamond, Peter Geach, Michael Kremer, Marie McGinn, Erich Reck, Thomas Ricketts, and I have all argued for the importance of the Fregean background to an understanding of the Tractatus. This approach to reading the book has been challenged; see especially Warren Goldfarb's "Wittgenstein's Understanding of Frege: The Pre-Tractarian Evidence," in From Frege to Wittgenstein, ed. Reck; and Ian Proops's "Early Wittgenstein on Logical Assertion," Philosophical Topics 25, no. 2 (1997): 121-144).

75. There are countless relevant examples here, but to mention only one: the doctrine that the meaning of a primitive term is conferred by a mental act of concentration or through a sufficiently emphatic gesture of ostensive definition. One need not enter at all into the commitments of a resolute reading in order to think it is a serious mistake to ascribe a doctrine of this sort to the Tractatus. Without yet having taken a step on the path toward resolution, one can easily begin to worry about the fairly standard ascriptions of such doctrines to the Tractatus in many of the book-length treatments. One consequence of this is that the relation of some of the comparatively early disputesbetween commentators (such as Ishiguro, McGuinness, and Winch) who deny the presence of these doctrines in the Tractatus and commentators (such as Malcolm, Hacker, and Pears) who insist upon the presence of one of these doctrines there-to the comparatively later disputes (between resolute readers and their critics) is by no means a straightforward one. One the one hand, the denial of these doctrines need not push a commentator toward accepting any part of a resolute view of the items that ought to figure on the first list. Yet it is surely no accident that commentators such as Ishiguro, McGuinness, and Winch have proved comparatively receptive to the writings of resolute readers and 
vice versa. For a relevant article by each of the latter three authors, see Hide Ishiguro, "Use and Reference of Names," in Studies in the Philosophy of Wittgenstein, ed. Winch, 20-50; Brian McGuinness, "On the So-Called Realism of the Tractatus," in Perspectives on the Philosophy of Wittgenstein, ed. Irving Block (Cambridge, Mass.: MIT Press, 1981), 60-73; and Peter Winch, "Language, Thought, and World in Wittgenstein's Tractatus," collected in his Trying to Make Sense (Oxford: Basil Blackwell, 1987), 3-17. For a discussion of the bearing of such articles on resolute readings, see the controversy between Peter Hacker, especially his "Naming, Thinking, and Meaning in the Tractatus," Philosophical Investigations 22 (1999): 119-135, reprinted in Wittgenstein: Connections and Controversies (Oxford: Oxford University Press, 2001), 170-183; and his "Postscript" (also in the same volume), 184-190, and Cora Diamond, see especially her "Peter Winch on the Tractatus and the Unity of Wittgenstein's Philosophy," in Wittgenstein: The Philosopher and his Works, ed. Pichler and Säätelä, 133-143.

76. And, indeed, one often comes across a commentator who can strike one as, in this sense, lost-adrift, as it were, in the text of the Tractatus. The three most telling symptoms of such disorientation on the part of a reader are: (1) that his reading seems to be guided, above all, by a desire to find certain doctrines (such as naïve mentalism) somewhere in the book, (2) that this leads him to cast about for hooks onto which to hang such doctrines, regardless of how little weight the candidates for hooks can bear, and (3) that this impetus to suppose that the doctrines in question are in the text seems to flow (not from an encounter with the text itself, but rather) from firmly entrenched antecedent assumptions about what must be there.

77. Considerations of space regrettably preclude more than intermittent brief discussion of this topic in the pages that follow.

78. For more on this topic, see my "The Method of the Tractatus," 411-418.

79. Indeed, early Wittgenstein went to some trouble (1) to redesign his logical notation so that it could best serve the exclusive ends of philosophical elucidation (as opposed to, say, those of formalizing mathematical proof, eliminating a reliance upon intuition, etc.), and (2) to drain it of the sort of potential doctrinal philosophical significance with which Frege and Russell wished to invest a Begriffsschrift in the context of (their respective understandings of) a logicist demonstration of the true metaphysical character of the truths of mathematics.

80. The assumption that these questions can effect such a division informs much of the relevant body of critical tertiary literature on resolute readings.

81. Some further questions that may do the trick are the following: How important is that question (i.e., the question about how to read the Tractatus that divides them) to an understanding of later Wittgenstein? How important is it to arrive at an accurate account of Wittgenstein's original self-understanding as author of his early work, in order to achieve an accurate appreciation of what he later thought was confused and self-deluded in his earlier self-understanding of what he had achieved in philosophy? And how important is an appreciation of that to an understanding of much else in his later philosophy?

82. What Wittgenstein perhaps did not anticipate is the extent to which this might become an extraordinarily difficult thing for a later generation of students of his work to undertake to doin part because of the extraordinary success that his later work would come to enjoy. 
83. I do not mean in the least to suggest here that reading the Tractatus through the lens of the Investigations is simply irrelevant to the task of viewing the old and new ways of thinking together, but only that what will thus come into view for us when we read in that direction will inevitably suffer some distortion if we are not equally adept at the complementary task of reading in the opposite direction-if we are not able to see clearly what stands out as genuinely new and what does not in the new way of thinking when it is contrasted with the old way of thinking. But to see this we need some independent appreciation of how tremendously radical (even if, by his later lights, very insufficiently radical) his old way of thinking already was.

84. The validity of the point made here is not restricted to an appreciation of the momentous yet unwitting character of the specific commitments of the author of the Tractatus. Throughout his later work, Wittgenstein seeks to instill in us an appreciation of how we can become philosophically ensnared without being aware of it. The specific form of sensitivity that he wishes to impart here (which a properly attentive critical reading of the Tractatus calls for) acquires its primary significance in relation to these more general aims of the Philosophical Investigations. For what is required of us in such a mode of reading the Tractatus is meant to offer a particularly vivid illustration of a sort of sensitivity that later Wittgenstein wants us to learn to exercise more generally-in our relation, not only to the philosophical utterances of others, but especially in relation to those moments in our own philosophizing with respect to which we ourselves feel on most secure ground. This means that we will have understood the object-lesson here (i.e., the example that his later interrogation of his own earlier philosophy is meant to provide) only when we have learnt to direct the same exquisite degree of sensitivity to discovering just how philosophically momentous and altogether noninnocuous many of the forms of expression that presently strike us as obvious and innocent actually are.

85. Again, I take the difficulties at issue here not to be ones that are mere artifacts of a resolute account of this relation, but rather to be ones that themselves belong to Wittgenstein's conception of the task of philosophical criticism and, in particular, to his later conception of the difficulty of that task.

\section{Philosophical Investigations, $\$ 91$.}

87. It was, above all, in connection with this presupposition that Piero Sraffa's Neapolitan gesture of disdain (along with his query "What is the logical form of this?") was able to do its fixationshattering work.

88. This commitment involves a great many subsidiary commitments about the character of the process of analysis, about such a process presupposing a point at which the analysis terminates, about when such a point is reached, about what is thereby disclosed, etc. A great many items could be added to the list in this connection.

89. There are a great many subsidiary commitments that come into play here through the commitment to the idea of an absolutely perspicuous notation. That any entailment can be set out as a truth-table tautology is perhaps the most famous such commitment. Additional commitments come into play through his attachment to the Sheffer-stroke notation and the topic of the nature of logical constants, through the operator $\mathrm{N}$ and the topic of the general form of the proposition, and through the Klammerausdruck notation and the topic of the nature of 
quantification. It would go well beyond the scope of this essay to show why Wittgenstein did not, at the time of writing the book, take his attachments to any of these to reflect a substantial doctrine and why he later changed his view about each. The point that matters for our present purpose is simply that a great many additional items, tied to more determinate commitments regarding the logic of our language, could be added to the list in this connection.

90. I have attempted to arrange the items on the actual list above so as to give some sense of how one of these commitments quickly begins to bleed into another and so on.

91. A standard reader might be happy to include all of the items on the second list on his (standard reader's) list. This might suggest the following conclusion: standard and resolute readers are at least in full agreement about the status of the set of sentences that belong to the intersection of the standard reader's list and the second list. One can think this only if one overlooks many of the points established previously, including the differences between standard and resolute readers with respect to the following topics: (1) the role of the doctrinal schema, (2) the role of the paradox, (3) how to understand the prefatory remark, and, above all, (4) the second sort of indiscriminateness.

92. See part 4 of "On Reading the Tractatus Resolutely" for discussion of this point, in which Conant and Diamond reply to Peter Sullivan's article "What Is the Tractatus About?"; the latter is also in Wittgenstein's Lasting Significance, ed. Kölbel and Weiss, 32-45.

93. Such sentences themselves could not even apparently be expressed in anything that would count, by the author of the Tractatus's lights, as a proper logical grammar-i.e., a perspicuous logical notation with the sorts of properties that these sentences aspire to claim such a notation must have.

94. This latter option requires an understanding of the early procedure of elucidation in which it can be brought to a kind of completion in which its commitments to its own canons of analysis (which underwrite its employment of logical notation) are themselves dissolved. The threat of reinstating a variant of the paradox looms here. Later Wittgenstein has a ground to stand on here (in espousing such a nondogmatic ideal of clarification) that early Wittgenstein lacks: the ground of the ordinary. The availability of such a ground requires taking seriously the thought that in ordinary language nothing is hidden. Each of the commitments on the second list is tied to early Wittgenstein's picture that what is of real interest-the logical structure of the propositionis hidden, disguised by its surface appearance in language, and must be brought to light.

95. To show that a zealous interpreter must invite Incredulity does not, of course, suffice to show that he is wrong. It is open to the zealous to maintain that, at the end of the day, standard readers and mild mono-Wittgensteinians alike ought to learn to embrace that which presently excites their incredulity.

96. There seem to be a number of these. Burton Dreben is sometimes rumored to be the founder of this denomination of resolute readers. Rupert Read and Rob Deans are clearly zealous. (Rupert Read claims in print that Warren Goldfarb is, but I don't see the evidence for this claim.) Some things Matthew Ostrow says suggest an inclination to lean this way (see his Wittgenstein's 
Tractatus: A Dialectical Interpretation [Cambridge: Cambridge University Press, 2002]), but he also says "it is unquestionable that the notion of a canonical Begriffsschrift plays an important (if extremely unclear) role in the Tractatus" (p. 9). There seems to be a variety of ways to flesh out a zealous approach. Warner Goldfarb, Rupert Read, and others have found the most provocative elaboration of this variant of mono-Wittgensteinianism in several of Juliet Floyd's recent articles. She has seemed to such readers to be concerned to advance (what Goldfarb, in his unpublished article Das Überwinden, without endorsing the reading in question, calls) a Jacobin reading-a reading that denies that the Tractatus is committed to any canons of analysis, and $a$ fortiori to the metaphysical commitments that figure on the actual second list above. (In "On Reading the Tractatus Resolutely," Diamond and I also read Floyd in this way.) See, for example, Floyd's "Number and Ascriptions of Number in Wittgenstein's Tractatus," in From Frege to Wittgenstein, ed. Reck, 308-352). She appears to claim there that "the best answer that can be given to those critics of Diamond (and other anti-metaphysical readers of the Tractatus)" is to allow that early Wittgenstein "does not think any notation can depict the grammar of language...the logical order" (p. 340). It is perhaps helpful to note in this connection that Floyd's phrase "antimetaphysical readers of the Tractatus" is ambiguous. On one understanding of it (i.e., as denoting those who read the Tractatus as aiming to avoid metaphysics), it is well suited to sort comparatively resolute readers from others; on another understanding of it (i.e., as denoting those who read the Tractatus as having largely avoided metaphysics), it is better suited to sort the (much narrower class of) comparatively zealous resolute interpreters from all others. On the second understanding of the phrase, what Floyd appears to say here (about what such readers should hold) is arguably correct, but then Diamond is not, in fact, such a reader. On the first understanding of the phrase, Diamond is such a reader, but what is here said (about what such readers should hold) is arguably no longer correct. Perhaps the intention of the remark is to claim that those who wish to join Diamond in being "anti-metaphysical readers" in the first sense will be able best to answer her critics if they join Floyd in taking the further step here mentioned in the direction of becoming "anti-metaphysical readers" in the second sense. This seems to be the invitation that Rupert Read and his coauthors find in Floyd's work and enthusiastically take up. (I fear, however, that rather than answering the critics of resolute readings, this plays directly into their hands.) I am told that Floyd takes such readings of her work to be misreadings and that she seeks to redress them in her contribution to the present volume.

97. This means that mild and zealous mono-Wittgensteinians alike will insist, though with rather different motives, that it is no less important to a proper understanding of the items on the second actual list (than it was to those on the first) that they be taken to be associated with sentences, not thoughts.

98. And this means that the dispute is not likely to be resolved, at least by appeal only to "internal" textual evidence, any time soon.

99. Some of what Rupert Read has written in a number of his recent writings suggests that he takes something of this sort to be true. He seems to take resolution to define a certain direction one can go in one's reading of the Tractatus, but then sees Conant and Diamond as wanting to jump off the train while it is still en route, whereas he (along with other zealous mono- 
Wittgensteinians) "resolutely" remains on board until the last stop. (See, for example, his "A NoTheory? Against Hutto on Wittgenstein," Philosophical Investigations 29, no. 1 [January 2006], where on p. 81 it is suggested that Conant and Diamond are enacting "something of a retreat" from the program of reading that they once shared with him.) Conant and Diamond take resolute readers to be committed to trying to make as much sense of the Tractatus as is possible in the light of a certain approach to understanding Wittgenstein's aim in that book. Resolution thus understood is an interpretative strategy for making sense of a book not a self-standing measure of the book's philosophical success. To read the Tractatus resolutely is to try to make out what the author of that book took himself to be up to in the light of this particular understanding of his aim. Someone who tries to read the book in this way need not claim that the author was completely successful in realizing that aim. It might be that the only way to make full sense of the book requires sensitivity to where it falls short of its aspirations. To claim that early Wittgenstein had a resolute conception of his project in the Tractatus, on this understanding of what it is to be "resolute," does not commit one to claiming that the project, conceived in its original terms, was free of misconception, any more than claiming that Kant was a transcendental idealist commits one to the claim that transcendental idealism is true. If one saddles oneself qua interpreter with an additional commitment to the effect that Kant (not only never intended to be, but actually) never was wrong about anything, then it may be very hard to make sense of everything he says. Similarly, if resolution is a strategy for making sense of a text, one ought not to saddle oneself with any further commitment of this sort up front. One ought to have an understanding of what Wittgenstein was trying to do that is able to tolerate the possibility that he may not have succeeded in doing it. It seems desirable therefore to employ the term "resolution" (as a label for a program of reading the text) in such a way as to leave room for debate about the further question of the success of the project thus understood. This is not to deny that early Wittgenstein's aspiration in the book was to think the problems through in such a way that one cleanses oneself of all apparently weighty philosophical commitments, rids oneself of all confusion, and makes the problems completely disappear. One can easily slide, for this reason, into using the term "resolute" as a term for a measure of a philosopher's success in living up to these aspirations. Using the term in this second way, one can now say that Wittgenstein turns out to have been more resolute on Read's assessment of his early project than he turns out to have been on the ConantDiamond reading. It seems to me that Read falls into using the term "resolute" in this second way on occasion and that doing so runs the risk of begging important interpretative questions both about the early work and about its relation to the later work. This possible slide in the usage of the term "resolute" contains two dangers: (1) it can lead one into thinking that one needs to claim that early Wittgenstein is fully "resolute" in the second sense in order to be entitled to claim that one's reading of him is fully "resolute" in the first sense, (2) it can thereby lead one (in a zealousness to be resolute in the second sense) to lose track of the original interpretative task: namely, to make the best possible sense of the text as it stands on the page.

100. Unless, as indicated in the previous note, one wants to build the following extra premise into the very idea of resolute reading: “. . . and, moreover, the author of the Tractatus was in no way mistaken about anything." First, for reasons indicated in the previous note, this must be an additional premise. It cannot be a consequence of a mere commitment to resolution (understood 
as a program for reading the book). A pithy (and slightly misleading) way of putting the point is to say: the latter is a de dicto ascription of certain philosophical aims to the early Wittgenstein; whereas the former is a de re claim about the successful prosecution of those aims. Second, it is hard to see how the de re claim in question, without further backing, can constitute anything more than a dogmatic assertion. Third, the premise, if added, would entirely rob a resolute reading of its greatest feature of interest to its original progenitors-the feature of it that will preoccupy us, beginning with the next paragraph, for the remainder of this essay.

101. Rupert Read and Rob Deans, in their article "Nothing Is Shown," Philosophical Investigations 26 no. 3 (2003): 239-268, distinguish between (what they call) "weak resolutism" and "strong resolutism" in ways that worry me partly for the reason raised here. In fact, their distinction between two purported kinds of resolute reader tries to tie so many (potentially independent) issues together that only some of what they say about it is evidently pertinent to the topic of mono-Wittgensteinianism per se. But at least some of the criteria (see, e.g., pp. 251-252) they wish to employ to effect their division seem to be intended to sort readers into those who are, by my lights, mildly and those who are zealously mono-Wittgensteinian. Their classification does not appear to admit of degrees of severity, however, partly because of extraneous considerations that are introduced. At points, Read and Deans, for example, try to distinguish the "strong" from the "weak" (versions of "resolutism") by further stipulating that members of the strong camp hold that the Tractatus (further?) seeks to show that no language or logical system is able to express perfectly general truths about which "possible configurations of signs" as such can or cannot make sense (while members of the weak camp are said not to hold this). But any configuration of signs can be given a sense, according to the Tractatus. If this is changed to a claim about permissible configurations of symbols, it still cannot serve as a principle for classifying such readers. Any (unconfused) resolute reader is obliged to hold that such sentences about what can and cannot be expressed are no better off than sentences about the (supposed) inexpressibility of "There are objects" (see, e.g., Tractatus, §4.1272)—which is not to say that there is a determinately intelligible something in view here in either case that it turns out that one cannot express. (Read and Deans further muddy the water here by sometimes suggesting that this disagreement has something to do with a claim about no system being "powerful enough" to "express" such "truths" - a claim that the strong camp is said to affirm and the weak to deny; see, e.g., p. 250.) If members of the strong camp take there to be something in this vicinity for the Tractatus to "establish" (and over which they and the members of the weak camp can then disagree as to whether the book is further seeking to establish that), then it is hard to see why they are not chickening out. If they do not, it is hard to see how at least this one of their criteria for classifying resolute readers is supposed to do any work. This example is representative of the manner in which Read and Deans tend to conflate issues on which all resolute readers as such ought to be able to agree (at least if the issues come to be expressed more carefully) with ones that may genuinely divide them (such as whether early Wittgenstein's conception of the activity of elucidating such sentences-i.e., ones that purport to express such "truths" as, e.g., that "no language [or logical system] can express truths about what can be expressed in any language [or logical system]"-itself implicitly rests on certain philosophical preconceptions regarding what language [or logic] is). In a later article, Phil Hutchinson and Rupert Read appear to wish to draw a far less 
complicated but related distinction between what they call (borrowing the terminology of Floyd and Goldfarb) "Girondin" and "Jacobin" versions of a resolute reading. See their "Whose Wittgenstein?" Philosophy 80 (2005), see p. 444n. These articles certainly testify to how resolute readers can find themselves in disagreement with one another!

102. A central interest of mine from the beginning in developing such a reading of the Tractatus has been to try to understand why later Wittgenstein singles out for criticism only (what are, from a standard reader's point of view, very) particular aspects of the Tractatus. It is clear from Cora Diamond's writings-and, in particular, from the way she draws the contrast between the metaphysical spirit and the realistic spirit-that this has also been true of her. (See her The Realistic Spirit, especially pp. 20-22.)

103. It is open to a zealous interpreter to claim either (1) that such (mildly monoWittgensteinian) readings of the relevant passages in the later work involve a complete misconstrual of their critical intention, or (2) that later Wittgenstein misrepresented (perhaps because he came no longer to understand) his own early work. Neither option strikes me as overly promising. An attempt to assess the merits of either is well beyond the scope of this essay. A brief remark about how each option might go is, however, perhaps in order. One way a zealous interpreter could go about trying to pursue option (2) is to point out that there does seem to be a certain bias in later Wittgenstein's discussions of the Tractatus. I think there is something to this point. (See note 110.) One way a zealous interpreter could go about trying to pursue option (1) is to urge that most of the criticisms of "earlier work" in later writings are criticisms of some other Wittgenstein than the author of the Tractatus. Though I do not see how to make this strategy work for a great many passages, this is not because I think criticism of "earlier work" is, for the most part, exclusively focused on the Tractatus. Many of the passages I discuss below drawn from later writings (that I contend contain criticisms of the Tractatus's unwitting commitments) equally involve, for example, criticisms of Middle Wittgenstein. I will return to this issue briefly in the penultimate note.

104. Though, as a mere matter of nomenclature, the author of the Investigations might have been slightly inclined to prefer the term "grammatical" (over "logical") in his formulation of each of the resulting remarks.

105. In my subsequent remarks in this section, I occasionally borrow and elaborate points made in the final pages of Conant and Diamond, "On Reading the Tractatus Resolutely."

106. "The only way namely for us to avoid prejudice-or vacuity in our claims, is to posit the ideals as what it is, namely as an object of comparison-a measuring rod as it were-within our way of looking at things, \& not as a preconception to which everything must conform. This namely is the dogmatism into which philosophy can so easily degenerate" (Wittgenstein, Culture and Value, 2nd ed., ed. G. H. von Wright, trans. Peter Winch [Oxford: Blackwell, 1998], p. 30). See also Philosophical Investigations, §131: "For we can avoid ineptness or emptiness in our assertions only by presenting the model as what it is, as an object of comparison-as, so to speak, a measuring-rod; not as a preconceived idea to which reality must correspond. (The dogmatism into which we fall so easily in doing philosophy.)" The differences that come out through 
Winch's and Anscombe's respective translations of (these two slightly different versions of) this passage are helpfully suggestive and pertinent to our present topic. I take it that there is a connection between the topic of this passage and that of the following famous passage that is more focally concerned with the preconceptions of the author of the Tractatus:

We see that what we call "sentence" and "language" has not the formal unity that I imagined, but is a family of structures more or less related to one another... The preconceived idea of crystalline purity can only be removed by turning our whole examination round. (One might say: the axis of reference of our examination must be rotated, but about the fixed point of our real need.) (Philosophical Investigations, §108 [I have modified the translation.])

The first of these passages connects the topic of dogmatism (of a sort into which we easily fall in doing philosophy) with that of an object of comparison (and what its proper role in philosophy should be). Later Wittgenstein sees his earlier self as employing helpful objects of comparison (comparing a proposition with a picture, a natural language mode of expression with its translation into a particular logical notation, etc.) for the purpose of overcoming certain philosophical confusions, but in the process in each case mistaking the role that the object of comparison plays in the demonstration, taking it to be something more than a mere object of comparison, and thereby subliming that which he takes the comparison to reveal. The second of these passages touches on some of the notions that thus come to be sublimed in his early thought—-"sentence," "language," "unity," "structure." This suggests that, by Wittgenstein's later lights, a way to eliminate the italicized expressions (and the corresponding moments of insistence) from some of the items on the second list would be to attain clarity regarding the role that objects of comparison (e.g., forms of notation) ought to play in the activity of philosophical elucidation. This dimension of his later engagement with aspects of his early philosophy is a central theme in Oskari Kuusela's work. See his "From Metaphysics and Philosophical Theses to Grammar: Wittgenstein's Turn," Philosophical Investigations 28, no. 2 (April 2005), as well as his forthcoming book Wittgenstein and the Concept of Philosophy.

107. Tractatus, $\$ 3.324$.

108. That is, early Wittgenstein fails to realize that the very idea of "an absolutely clear way of expressing thoughts" itself represents a substantial metaphysical commitment. For an illuminating discussion of this idea, see Martin Gustafsson, "Travis, the Tractatus, and TruthConditions," in A Philosophical Smorgasbord, ed. Krister Segerberg and Rysiek Sliwinski, Uppsala Philosophical Studies 52 (Uppsala: Uppsala University, 2003), pp. 169-182.

109. The later Wittgenstein differs from the early even here, however, inasmuch as there is no longer room on his later conception for anything that could be correctly described as the method or the aim of his philosophy. Not only the realization of "the aim" and the application of "the method" must unfold piecemeal over time (as was already the case in his early philosophy), but now a new dimension of pluralism is introduced into the heart of his very conception of each. The aims and methods of the later philosophy no longer have the unity of the aspects of a single great problem, but rather that of a family, deriving their unity from the interrelated family of problems of which they treat-a form of unity that admits of the possibility that hitherto unanticipated members of the family may constantly continue to burst onto the scene, newly 
demanding a degree of genuine innovation in both aim and method. This difference in the early and later philosophies is, in turn, tied to a profound difference in their respective conceptions of essence-e.g., of language-and the forms of novelty, surveyability, and surprise that these can tolerate.

110. The difficulty of attaining a clear view of this is compounded by the fact that in his later writings Wittgenstein is primarily concerned to highlight what is wrong in his earlier way of thinking; he is not primarily concerned to highlight continuities in his philosophy. His overt aim, generally, when later reflecting on one or another aspect of his earlier way of thinking, is to try to pinpoint its philosophical Achilles heel. One therefore needs to handle such retrospective comments in his later writings with some care if one wishes to tease out of them a portrayal of what his earlier way of thinking might have been, such that it would have had the power to captivate a philosopher with his high standards of rigor and clarity, with his determination to think things through to the bloody end, and with his desire not only to avoid but to put an end to metaphysics.

111. Do the "must" and the "any" in this sentence reintroduce moments of dogmatism into Wittgenstein's later philosophy? This question takes us beyond the scope of this essay. But it is the right sort of question to ask, if one wants to begin to locate the fundamental differences between the early and the later work.

112. Philosophical Investigations, $§ 308$.

113. One way of summing up this immense difference between early and later Wittgenstein would be to say that the following question assumes a pivotal importance in later Wittgenstein's investigations that it never (could have) had in early Wittgenstein's procedures: How does philosophy begin? On this, see Stanley Cavell's "Notes and Afterthoughts on the Opening of Wittgenstein's Investigations," in The Cambridge Companion to Wittgenstein, ed. Sluga and Stern, 261-295.

114. "[M]y thoughts were soon crippled if I tried to force them on in any single direction against their natural inclination-And this was, of course, connected with the very nature of the investigation. For this compels us to travel over a wide field of thought crisscross in every direction" (Philosophical Investigations, p. ix).

115. This parenthetical remark involves some overstatement in part for the following reason: any condidate for a first step on the ladder must be one whose character is equivocal as to whether it represents an unobjectionable aspect of the elucidatory process or part of the beginning of an ascent up the ladder. This therefore allows a different sort of consideration to acquire importance in reflection upon the shape of the first list-one that puts a new pressure on the question: how should the list begin? The first item on the actual first list above, if shorn of its insinuation of an explanatory order, might be turned into a formulation about which it would no longer be clear as to which list it belonged on. As long as the so-called "picture theory" of the Tractatus is formulated so that its theoretical pretensions are unmistakable (which requires slanting "the theory" so as to privilege a direction of explanatory order), the resulting formulation corresponds to a rung on the ladder. As long as formulations of observations about picturing take on the 
aspect of (what for the author of the Tractatus might be) remarks internally related to those on the second list, it must become less clear as to how we should answer questions as to which list these particular formulations themselves belong on. (These are questions for us. There are no such questions for the author of the Tractatus - there is no second list made up of items of this sort for him.) Resolute readers are committed to the idea that any version of something properly called "the picture theory" is, at the end of the day, to be thrown away. But this does not entail that the idea that comparing a proposition with a picture might be helpful (for dispelling certain philosophical confusions) needs to be thrown away. (Incidentally, and for internally related reasons, a similar point holds about the notion of showing that the Tractatus opposes to saying - as long as a formulation of that notion turns it into a form of "quasi-saying," resolute readers are obliged to see it as comprising a rung of the ladder; as long as it does not, they are not obliged thus to regard it. [See Conant and Diamond, "On Reading the Tractatus Resolutely," for further discussion of this point, especially pp. 65-67; and Michael Kremer's "The Cardinal Problem of Philosophy," in the present volume].) So a mere commitment to resolution cannot suffice to decide the question as to whether any given remark about picturing in the Tractatus is best regarded as a candidate for inclusion on the first or on the second list. For it depends on the point at which one thinks the second list begins to bleed into the first. (Again, it must be an interpretative error to suppose that this point could have itself been a clearly marked one for the author of the Tractatus.) These are matters about which resolute readers can disagree and whose adjudication can be settled only through closer attention to the details of the text.

116. It is interesting in this connection to note how many of the doctrines of the sort that standard readers ascribe to the Tractatus and that resolute readers are committed to rejecting-such as the commitment to the existence of ineffable truths, various optional subsidiary doctrines (such as realism, mentalism, solipsism, etc.) and optional subsidiary commitments (such as the distinction between understanding propositions and "understanding" nonsense, between saying and "conveying" truths, etc.) — never figure in any of the passages in Wittgenstein's later writing where he is explicitly concerned to criticize something he identifies as a questionable philosophical commitment actually held by the author of the Tractatus. What figure in such passages instead are the sorts of metaphysical commitments that belong on the second list.

117. Zettel, trans. G. E. M. Anscombe (Oxford: Blackwell, 1967), §444.

118. The questions that exercised us in section IV regarding how to specify the shape and rungs of the ladder no longer have straightforward application to the crisscross. What counts as a step along such a philosophical path? Or if you prefer: What counts as a philosophical step along such a path? And what counts as a step forward in the direction of progress and clarity in one's thinking? These become questions that acquire in Wittgenstein's later philosophy new degrees of difficulty.

119. This difference in early and later Wittgenstein's respective conceptions of philosophical procedure is tied to a further difference in their conceptions of what it is to exhibit forms of orderor systematicity-in language. As we have seen above, a resolute reader may hold, for example, that Wittgenstein's having taken himself to have dissolved the "Big Question" of the nature of language (and thus to have solved the problems of philosophy "in essentials" by having 
demonstrated a method through which all confusions could be clarified) itself reflected a kind of philosophical confusion that colored also his ideas about philosophical method. Such a reader may take a remark in the later writing such as the following to be concerned to mark a further aspect of this difference between the early and later philosophies: "We want to establish an order in our knowledge of the use of language: an order with a particular end in view; one out of many possible orders; not the order" (Philosophical Investigations, §132).

120. It is partly this quest to identify the moment at which philosophy begins that makes what Wittgenstein later engages in (properly termed) Untersuchungen. There are no Untersuchungen, in this sense, in the Tractatus, only Erläuterungen.

121. What I here present as a contrast between the procedure of the Tractatus and that of the Investigations might be more happily reformulated as a contrast between sorts of procedure both of which are present in the Investigations. That would allow us to see the Investigations as inheriting and reshaping a feature of the early procedure while supplementing it with procedures that were originally foreign to it. I briefly attempt such an alignment in my "Varieties of Skepticism," in Wittgenstein and Skepticism, ed. Denis McManus (London: Routledge, 2004), see especially pp. 124-128.

122. The following remark of Stanley Cavell's is to the point here: "[T]he shortest way I might describe such a book as the Philosophical Investigations is to say that it attempts to undo the psychologizing of psychology" (Must We Mean What We Say? p. 91). Part of what is so nice about this remark is how it simultaneously marks a moment of significant continuity in Wittgenstein's philosophy (the quest to preserve the gains of his early attempts to undo the psychologizing of logic) while drawing attention to an equally significant discontinuity (the quest to recover the logical/grammatical aspects of so much that had been tossed into the early garbage can of the "merely psychological"). Many of the specific investigations undertaken in the later workinto the grammar of pain-talk, the intentionality of sensation, the epistemic standing of avowals, first-person authority, the first-person pronoun, our apparent immunity to errors of selfidentification, our picture of the inner, the expressive dimension of language, etc.- are contributions to this task (of undoing the psychologizing of psychology).

123. "A picture held us captive. And we could not get outside it, for it lay in our language and language seemed to repeat it to us inexorably" (Philosophical Investigations, §115). I take this passage, among other things, to be an autobiographical statement by the author of the Investigations looking back on the author of the Tractatus.

124. Philosophical Investigations, $§ 103$.

125. It is not the pictures themselves that are to be criticized, but the forms of fixation and insistence to which they give rise if we are, in our philosophizing, held captive by them. One way we can go wrong, in seeking to liberate ourselves from such captivity, is to place the blame on the pictures themselves rather than on ourselves and our miscontruals of their application. For discussion of this point, see my "Introduction" to Hilary Putnam's Words and Life (Cambridge, Mass.: Harvard University Press, 1994), pp. xlvi-lviii. See also John McDowell, "Intentionality and Interiority in Wittgenstein," collected in Mind, Value, and Reality (Cambridge, Mass.: Harvard University Press, 1998), 297-324. 
126. Such as, e.g., the following excerpt:

If one says "Moses did not exist," this may mean various things. It may mean: The Israelites did not have a single leader when they withdrew from Egypt-or: their leader was not called Moses—or: there cannot have been anyone who accomplished all that the Bible relates of Moses—or: etc., etc.-We may say, following Russell: the name "Moses" can be defined by means of various descriptions. For example, as "the man who led the Israelites through the wilderness," "the man who lived at that time and place and was then called 'Moses'," "the man who as a child was taken out of the Nile by Pharaoh's daughter" and so on. And according as we assume one definition or another the proposition "Moses did exist" acquires a different sense, and so does every other proposition about Moses.-And if we are told "N did not exist," we do ask: "What do you mean? Do you want to say, ..... or .... etc.?

But when I make a statement about Moses, - am I always ready to substitute some one of these descriptions for "Moses"? I shall perhaps say: By "Moses" I understand the man who did what the Bible relates of Moses, or at any rate a good deal of it. But how much? Have I decided how much must be proved false for me to give up my proposition as false? Has the name "Moses" got a fixed and unequivocal use for me in all possible cases?-Is it not the case that I have, so to speak, a whole series of props in readiness, and am ready to lean on one if another should be taken from under me, and vice versa? (Investigations, §79)

127. See Tractatus, $\$ 3.326$.

128. This passage and those that follow it in the Investigations seek to bring out not just how "Moses did not exist" might mean various things, but how, on some of the nontrivially different understandings of what it would thus mean, the resulting differences in meaning would not be a function of differences of a sort that could be reflected through symbolically distinct Begriffsschrift expressions corresponding to each. Thus they would not be the sorts of difference in meaning that could be made perspicuous by the Tractatus's method of clarification. The attempt to understand each of the possible differences in meaning here as possible ways of conferring alternative Tractarian methods of symbolizing on one and the same propositional sign leads to a representation of the differences we are concerned with here in which the difference between any two such cases comes out being either too small (for, qua propositions, they end up occupying the same position in logical space) or too large (for, qua propositions, they end up being utterly distinct—having nothing more than their mere signs in common-each expressed in a proper logical notation by a distinct propositional symbol).

129. This can be seen, for example, simply by noting the degree of continuity in conception to be found between many passages in the Tractatus and a passage such as $\$ 664$ of the Investigations:

In the use of words one might distinguish "surface grammar" from "depth grammar." What immediately impresses itself upon us about the use of a word is the way it is used in the construction of the sentence, the part of its use-one might say-that can be taken in by the ear--And now compare the depth grammar, say of the word "to mean," with what its surface would lead us to suspect. No wonder we find it difficult to know our way about.

A modified version of a central Tractarian idea-that one cannot immediately gather from the language of everyday life what sort of logical (or grammatical) role a sign is playing merely from those outward features of it such as how it appears to the eye or is taken in by the ear-is still very much alive here; along with a continuing commitment to the complementary thought: "Thus there easily arise the most fundamental confusions (of which the whole of philosophy is full)" (Tractatus, §3.324). An important difference here, however, is that in the later thought this 
idea (that we can be misled by superficial similarities between sentences) is no longer taken to underwrite a conception of there being something hidden-the structure of the proposition. The virtue of a good notation, for later Wittgenstein, is simply that it helps us overcome confusion. It no longer is taken to supply a logical X-ray of hidden structure.

130. Consider, e.g., $\$ 90$ of Philosophical Investigations. Although the passage occurs in the midst of a series of remarks critical of the Tractatus, it also seeks to make clear that there is still an important place in the later conception for the following three ideas-all of which play a central role in the early conception: (1) that some misunderstandings concerning the use of words are caused by analogies between the forms of expression in different regions of language, (2) that these can be removed by substituting one form of expression for another, and (3) that this process may be called "analysis" because it is like taking a thing apart. All of this shows that in the later conception there is still plenty of room for the idea that a misunderstanding may be removed by substituting a logically regimented form of expression for its natural language counterpart. I have, however, here used italics to mark the way in which the modal force that attaches to each of these ideas has been weakened. Each of the italicized expressions in (1)-(3) above now corresponds to a nondogmatic moment (of noninsistence, as it were). This is typical of the manner in which even those of the earlier ideas that are most fully preserved in the later writings still undergo significant reformulation.

131. More focally at issue in $\$ 79$, in particular, is the role that Russell's theory of descriptions played for the author of the Tractatus as a paradigm of analysis-as an exemplary demonstration of how depth structure in a proposition can be shown to differ from surface structure. (See, e.g., §4.0031.) The three ideas mentioned in the previous note (all of which figure in $\$ 90$ of Philosophical Investigations) fit very nicely together with the sort of use to which the author of the Tractatus wished to put the theory of descriptions. The "misunderstandings" here at issue lead to the idea that something must exist (in some way or to some degree) in order to be spoken about. This means, I take it, that (if we can keep ourselves from being seduced into certain misconceptions by various features of the tool that we are employing) the theory of descriptions, even by his later lights, can serve as a helpful tool in philosophical clarification in bringing out how some misunderstandings concerning the use of words are caused (by analogies between the forms of expression in different regions of language), that these can be removed by substituting the Russellian form of expression for its natural language counterpart, and that this process may be called "analysis". So while $\$ \$ 79 \mathrm{ff}$. in part seek to show that the author of the Tractatus was seduced into certain misconceptions by the Russellian tools that he employs for elucidatory purposes, at the same time, $\$ 90$ in part seeks to recover and modify aspects of this very moment in the early philosophy that is subjected to such severe criticism in $§ \S 79 \mathrm{ff}$.

132. The italics in items 3 and 21 on this list are Wittgenstein's.

133. The commentary is, above all, on $\$ 5.5563$ of the Tractatus. It brings out how the achievement of a proper alignment of the old and new ways of thinking requires sensitivity to yet a further moment of discontinuity folded with an overarching continuity in Wittgenstein's thought. The text that is the immediate object of this commentary runs as follows: 
All propositions of our everyday language are actually, just as they are, logically completely in order. That simple thing which we ought to give here is not a model of the truth but the complete truth itself.

(Our problems are not abstract but perhaps the most concrete that there are.)

The Tractatus is here concerned to effect a break with Frege's and especially Russell's disparagement of ordinary language. What for Frege can only be the structure of an ideal language is for early Wittgenstein the structure of all language. This thought itself contains a moment that is inherited and one that is repudiated by later Wittgenstein. The overly neglected moment of continuity here constitutes another instance of how some of what is standardly put forward by commentators as a criticism that later Wittgenstein directs against his earlier work is in fact already partially developed in the Tractatus as a criticism of Frege and Russell. In his remarks clarifying his emendations of Ogden's initial attempt to translate $§ 5.5563$, Wittgenstein says:

By this [i.e., §5.5563] I meant to say that the propositions of our ordinary language are not in any way logically less correct or less exact or more confused than propositions written down, say, in Russell's symbolism or any other Begriffsschrift. (Only it is easier for us to gather their logical form when they are expressed in an appropriate symbolism.) (Letters to C. K. Ogden, p. 50 [emphases in the original])

On the one hand, we see here that, already in the Tractatus, Wittgenstein's interest in a logical symbolism is not that of someone who seeks to overcome an imprecision in ordinary thought through recourse to a more precise medium for the expression of thought. On the other, this early rescue of ordinary language from false philosophical conceptions of it is, in turn, shaped by the Tractarian conception (toward which we have just seen, in the previous section of this essay, later Wittgenstein directs critical attention) regarding how the logic of our language can be gathered from a transposition of sentences into a suitably constructed symbolism, modeled on Frege's Begriffsschrift (though designed now solely to further the clarificatory ends of the Tractatus, without ostensible further constructive or theoretical aspirations constraining or deforming its design). So what we have here is a moment in the early thought which is a defense of ordinary language on the part of the author of the Tractatus (against what he takes to be Frege's and Russell's failures to appreciate its perfection within concreteness) and yet also a central example for the Investigations of his earlier impulse to sublime ordinary language (mistaking its concreteness for a kind of crystalline purity)_again, a moment of subliming in his thinking to which he himself was, at the time of writing the Tractatus, oblivious. It is to the final parenthetical sentence of $§ 5.5563$ that the following remark is directed: "[T]his crystal does not appear as an abstraction; but as something concrete, indeed, as the most concrete, as it were the hardest thing there is" (Philosophical Investigations, §97).

134. This is a feature of the text that was already well understood and emphasized by Elizabeth Anscombe in a number of writings, including her book An Introduction to Wittgenstein's "Tractatus" (London: Hutchinson, 1959). Thus, for example, in connection with the topic of the previous note, she is quite sensitive to how the moments of continuity and discontinuity intertwine here. She goes to a slightly earlier moment in the text (than I do in the previous note) to illustrate the complexity of the relation, connecting the discussion of ordinary language being "all right" in Investigations, §95 with Tractatus, §5.5563: "It is a mistake to suppose that the dictum 'Ordinary language is all right' is an expression only of Wittgenstein's later views" (p. 91). She explores this connection to show how Wittgenstein is "dialectically expounding, not opposing" 
(pp. 91-92) his earlier view. (I would prefer to say: "not merely opposing." I am sure Anscombe would agree.) Her discussion of ordinary language being all right comes after her discussion of an equally central Tractarian point-one that, at first blush, constitutes another such moment of significant continuity: "What does not get expressed in the signs, comes out in their application: What the signs fail to express their application declares" (Tractatus, §3.262). Anscombe takes the continuity here to be obvious, but she also rightly worries that it might lead one to overestimate the extent of the continuity. So she seeks to bring out (albeit very briefly) the moment of discontinuity here as well, by focusing on what can be meant by "application" in the philosophies of early and later Wittgenstein respectively. This discussion of Anscombe's shows, on the one hand, how you do not need to be a resolute reader in order to be sensitive to the complexity of the relation between the philosophies of early and later Wittgenstein, and, on the other hand, how such a sensitivity does require a willingness to forgo conceiving that relation in the terms dictated by the doctrinal schema. The impressive depth of Anscombe's sensitivity to the intricacy of the relation raises an interesting question about how far one can go here (in recognizing the complexity of continuities that enfold discontinuities) within the constraints of a nonresolute reading. This question lies outside the brief of this essay (which is merely to show that a resolute reading can go quite far here). As mentioned in note 7, alongside Anscombe, Rhees and Winch are the two other commentators who are particularly sensitive to this dimension of complexity in Wittgenstein's development. An exploration of this question (concerning how far one can go here within the constraints of a nonresolute reading) would need to take account of the work of at least these three commentators.

135. Of particular interest in this connection is the entire stretch in Philosophical Investigations that runs from $\S 89$ to $§ 133$. In almost every remark, we have some effort on Wittgenstein's part to bring his later methods of philosophy into relief by contrasting them with his earlier conception of the method (cf. §133) of philosophy, and yet numerous local moments of continuity surface within this overarching contrast. This contrast-between the (early) method and the (later) methods - draws many of the other points of difference between the early and later philosophies together and, in particular, the difference between the Tractatus's point of view on the problems of philosophy (according to which they have in essentials been solved) and the refusal of such a point of view in the Investigations (in which the essentials can no longer be separated in such a manner from the details). The confidence expressed in the claim (in the preface to the Tractatus) that the problems of philosophy have in essentials been solved is tied to a confidence that, at least in its essentials, the basic outline of the method for dissolving all such problems has been put in place. (This, in turn, is tied to a confidence that there is something which is the logic of our language - the structure of which can be displayed in a perspicuous notation-and hence to the items on the second list.) The Tractatus is to furnish this basic outline and demonstrate its worth. Once it has successfully done so, it is now to become clear, in retrospect, that the prior absence of a serviceable method had been the big problem for the early philosophyfor the solution to all other problems had depended on the solution to this one-and now that it has been resolved, they, are in principle (if not yet in practice) also resolved. This central (apparent) achievement of the early philosophy, in turn, becomes a central target of the later philosophy. The entire stretch in Philosophical Investigations that runs from $\S 89$ to $\$ 133$ can be read as 
seeking to expose the latent preconceptions that allowed early Wittgenstein to imagine that he had done this-that he had been able to survey the structure of the problems as such and attain a perspective on them from which there could appear to be one big problem that could admit of an overarching form of solution (at least in its essentials). Yet, at the same time, there is much of local value in his early conception of clarification that is to be recovered within this fundamental break with the early conception. Hence, even in the course of this markedly critical sequence of reflections on the relation between the early and later conceptions of philosophical method, a crisscrossing method of investigation is required-one that denies nothing of value and recoups each of the gains of the early philosophy, while laboring to identify each of the moments in which it oversteps or overreaches.

136. The question of "the extent of the continuity and the discontinuity in Wittgenstein's philosophy" here at issue has to do with the relation between the author of the Tractatus and the author of the Investigations. This, however, is by no means the only question worth addressing regarding the extent of continuity and/or discontinuity in Wittgenstein's philosophy. The narrow focus here is a function of the aim of this essay (i.e., to show that a resolute reader can make sense of the relation between the Tractatus and the Investigations). This limitation, however, can introduce its own sort of distortion into a narrative of the development of Wittgenstein's philosophy. And this is especially the case in connection with the last sentence of $\$ 133$. The contrast emphasized in my remarks in the previous note is between the Tractarian methodological conception (the conception of the method) and that of $\$ 133$ (the conception that there is not one philosophical method, though there are indeed methods). But there is also criticism by Later Wittgenstein of Middle Wittgenstein here. For this idea of "the method" did not immediately die with Wittgenstein's return to full-time philosophizing in 1929. §133 is arguably equally concerned to draw a contrast between the later methodological conception and the very emphatic views of Middle Wittgenstein. Despite the far-reaching differences in their respective methodological conceptions, there remains the following important similarity between Early and Middle Wittgenstein: each believes he has hit upon the method. One of Middle Wittgenstein's favorite ways of putting this, in the context of discussing his "new" method, is to emphasize how philosophy can now become a matter of skillful practice. There can be skillful philosophers as there are skillful chemists because "a new method" had been discovered, as happened when chemistry was developed out of alchemy: "The nimbus of philosophy has been lost. For we now have a method of doing philosophy ... Compare the difference between alchemy and chemistry; chemistry has a method" (Wittgenstein's Lectures: Cambridge, 1930-1932, ed. Desmond Lee [Ottawa, N. J.: Rowman and Littlefield, 1980], p. 21). What matters now is not the truth or falsity of any specific philosophical results but rather this all-important fact: "a method had been found" (ibid.). (Joachim Schulte explores this topic of the relation between middle and later Wittgenstein on method in his article "Wittgenstein's 'Method'," in Wittgenstein and the Future of Philosophy, ed. Rudolf Haller and Klaus Puhl [Vienna: ÖBV \& HPT, 2002], 399-410, emphasizing the contrast between there being $a$ philosophical method [according to Middle] and there being philosophical methods [according to Later].) This suggests that it would be no less a mistake (than any of the ones this essay seeks to correct) to insist that $\$ 133$ (in its denial that there is " $a$ philosophical method") must be concerned to draw a contrast solely with the "early" view (where 
early $=$ Tractatus $)$. It is worth noting in this connection that the predecessor version of $\S 133$ in The Big Typescript (p. 316) is missing the last sentence (about there not being a philosophical method, but rather different methods). Yet most of $\$ 133$ is in The Big Typescript, and is clearly concerned with drawing contrasts between the author (i.e., Middle Wittgenstein) and Early Wittgenstein. This nicely brings out one aspect of the way in which the break with the Tractatus was a graduated one. Here we see two crucial steps coming one after the other. Middle Wittgenstein (who still thought there was one method) thought that Early Wittgenstein had been confused (in thinking that it was possible to solve all the problems at once by solving them in essentials). Yet Later Wittgenstein (who thinks there can only be methods) thinks Middle Wittgenstein is still confused in his criticisms of Early (i.e., he has unwittingly preserved an essential feature of the metaphysics of the Tractatus). This shows how, as a matter of historical fact, the process of purging himself of the unwitting commitments is one that unfolded for Wittgenstein, over the course of his own philosophical development, piecemeal. A proper treatment of this topic would require another essay at least as long as this one.

137. This essay is indebted to several decades of lengthy and lively long-distance telephone conversations with Cora Diamond (including some very helpful recent ones), to several years of less lengthy but equally lively short-distance conversations with Michael Kremer, and to several of Peter Sullivan's recent writings and several short but stimulating conversations with him about them. It is indebted to Martin Gustafsson and to Martin Stone for comments on a previous draft, to Alois Pichler for several corrections, to Judy Feldmann at MIT Press, and to Alice Crary for enormous forbearance and assistance in her capacity as editor. Finally, it would not exist but for the encouragement and patience of my wife, Lisa Van Alstyne, who had to live in uncomfortably close proximity to the conditions of its gestation and birth. 